\title{
CIVILIAN \\ NUCLEAR \\ POWER
}

\section{AN EVALUATION \\ OF}

\section{ALTERNATE COOLANT}

FAST BREEDER REACTORS

April 1969

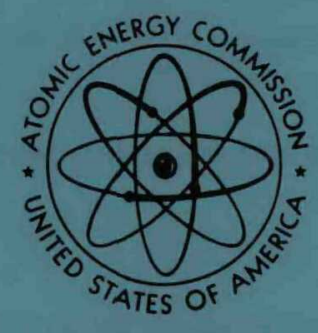

Prepared for

DIVISION OF REACTOR DEVELOPMENT \& TECHNOLOGY 


\section{DISCLAIMER}

This report was prepared as an account of work sponsored by an agency of the United States Government. Neither the United States Government nor any agency Thereof, nor any of their employees, makes any warranty, express or implied, or assumes any legal liability or responsibility for the accuracy, completeness, or usefulness of any information, apparatus, product, or process disclosed, or represents that its use would not infringe privately owned rights. Reference herein to any specific commercial product, process, or service by trade name, trademark, manufacturer, or otherwise does not necessarily constitute or imply its endorsement, recommendation, or favoring by the United States Government or any agency thereof. The views and opinions of authors expressed herein do not necessarily state or reflect those of the United States Government or any agency thereof. 


\section{DISCLAIMER}

Portions of this document may be illegible in electronic image products. Images are produced from the best available original document. 


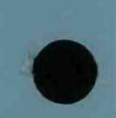

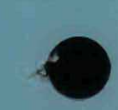


WASH-1090

UC - 80

AN EVALUATION OF ALTERNATE COOIANT FAST BREEDER REACTORS

\author{
Prepared by \\ ALTERNATE COOLANT TASK FORCE \\ Under the Direction of \\ Division of Reactor Development and Technology
}

Apri1 1969

With the Assistance of

Oak Ridge National Laboratory

General Electric

Westinghouse

Babcock \& Wilcox

Gulf General Atomic

Argonne National Laboratory

Los Alamos Scientific Laboratory

Pacific Northwest Laboratory

\title{
LEGAL NOTICE
}

This report was prepared as an account of Government sponsored work. Nelther the A. Makes any warranty or representation, exp on behalf of the Commission

racy, completeness, or usefulness of the informationsed or implied, with respect to the accuof any information, apparatus, method, or proction contained in this report, or that the use privately owned rights; or B Assumes any labiliti

use of any information, apparatus, method, or procese of, or for damages resulting from the As used in the above. "person acting on behaif disclosed in this report.

ployee or contractor of the Commisaton, or employee the Commission" includes any emsuch employee or contractor of the Commission, or of such contractor, to the extent that disseminates, or provides access to, any inform, or employee of such contractor prepares, with the Commission, or his employment with such contractor. 


\section{LEGAL NOTICE}

This book was prepared under the sponsorship of the U. S. Atomic Energy Commission. Neither the United States, nor the Commission, nor any person acting on behalf of the Cómmission:

A. Makes any warranty or representation, expressed or implied, with respect to the accuracy, completeness, or usefulness of the information contained in this publication or that the use of any information, apparatus, method, or process disclosed in this book may not infringe privately owned rights; or

B. Assumes any liabilities with respect to the use of, or for damages resulting from the use of any information, appa ratus, method, or process disclosed in this publication.

As used in the above, "person acting on behalf of the Commission" includes any employee or contractor of the Commission, or employee of such contractor, to the extent that such employee or contractor of the Commission, or employee of such contractor prepares, disseminates, or provides access to, any information pursuant to his employment or contract with the Commission, or his employment with such contractor. 
FOREWORD

In implementing the civilian nuclear power research and development program, specific fast breeder reactor concepts using alternate coolants (other than sodium) have been assessed in detail. This report, "An Evaluation of Alternate Coolant Fast Breeder Reactors," was prepared by the Alternate Coolant Task Force under the direction of the Division of Reactor Development and Technology, U.S. Atomic Energy Commission, and is part of an overall assessment of the Civilian Nuclear Power Program being made in response to a request in 1966 by the Joint Committee on Atomic Energy. As outlined in the 1967 Supplement to the 1962 Report to the President on Civilian Nuclear Power, changes since 1962 in the technical, economic, and resources picture have necessitated further study of the AEC program. This report evaluates two types of reactors and provides a basis for their consideration in the assessment of the overall program of the USAEC.

The overall assessment will include consideration of the technical status and economic potential of advanced converters and breeders, the role of thorium, various reactor fuel cycles, and a system analysis of the future nuclear-electric power complex. Although all phases of the assessment effort are based on one set of ground rules to achieve a common basis for comparison, it is inevitable that when the reports are published, many changes now taking place will not be reflected. The differences will be due to efforts to consolidate and strengthen the reactor development programs and to the rapid expansion of the nuclear power industry. These matters are discussed in more detail in the 1967 Supplement to the 1962 Report to the President on Civilian Nuclear Power.

This evaluation was conducted by the Alternate Coolant Task Force, whose members include representatives of Babcock \& Wilcox, Gulf General Atomic, General Electric, Westinghouse, Oak Ridge National Laboratory, Argonne National Laboratory, Pacific Northwest Laboratory, Los Alamos Scientific Laboratory, and the Division of Reactor Development and Technology of the U.S. Atomic Energy Commission. 
The advantages and disadvantages of using sodium, steam, and helium, as reviewed early in 1966, are as follows:

\section{Advantages}

Sodium

Inherent emergency and postaccident cooling of fuel

Low pressure, 100 psi

Potentially high breeding ratio

Extensive sodium reactor experience (15 years)

Low pumping power

Lowest fuel cladding temperature

Potential vented fuel

Highest heat transport properties

Steam

Direct cycle

Visible refueling maintenance

Minimum chemical reactions

Industrial capability available for components

Fluidity at room temperature

Helium

No intermediate loop

Potential high breeding ratio

Visible refueling maintenance

Minimal void coefficient

Most compatible with materials

Potential vented fuel

Utilization of thermal GCR technology

Fluidity at room temperature

Disadvantages

Sodium

Void coefficient

Secondary loop required

Chemical reactions with air and water

Nonvisible refueling

Maintenance difficult and time consuming on primary system because

of induced radioactivity

Extensive component development required 
High pressure (1200 to 3700 psi)

Lack of fast breeder reactor technology

High pumping power

Emergency and postaccident cooling provisions not established

Low breeding ratio

Unproven high power density

Radiolytic decomposition

Stress corrosion

Fission product carryover to turbine

Unfavorable coolant reactivity coefficient

Helium

High pressure (1250 to 1750 psi)

Lack of fast breeder reactor technology

High pumping power

Emergency and postaccident cooling provisions not established

Unproven high power density

Gas leakage difficult to control

High cladding temperature

Extensive component development required

Both alternate coolant concepts have been evaluated. Specifically, four reactor designs were considered: three cooled by steam at 1250, 2650 , and 3700 psi, and the fourth cooled by helium. These reactors, it is believed, adequately represent the class of alternate coolant fast breeders for the purpose of system analysis studies. The main objective of this evaluation was to weigh the relative value of the various alternate coolant fast breeders, one against the other, from the standpoint of technical feasibility, economic potential, and fuel utilization performance in the overall U.S. power economy.

The conclusions arrived at in this report were based on detailed technical and economic evaluations made by the Oak Ridge National Laboratory working group, and on designs and information generously provided by the Karlsruhe Nuclear Research Center, Babcock \& Wilcox, and Gulf General Atomic. The detailed evaluations of these designs are described in two reports: WASH 1088, "An Evaluation of Steam-Cooled Fast Breeder Reactors" and WASH 1089, "An Evaluation of Gas-Cooled Fast Breeder Reactors."

The procedure in the preparation of the material contained in this report was the following: 
1. review of the two reports (WASH 1088 and WASH 1089) by the task force members and the Division of Reactor Development Staff;

2. review of results from analyses of specific alternate coolant reactor combinations completed by the Systems Analysis Task Force covering the relative economic and fuel utilization performance;

3. preparation of a draft report by the ORNL working group, followed by an extensive review by the task force;

4. preparation of conclusions by the task force and final approval of the report;

5. review of the final report by the Commission.

Finally, before publishing, the report was reviewed by selected representatives of reactor industry, national laboratories, and the U.S. Atomic Energy Commission. There has been general acceptance of the content, and all comments received have been considered in the final version of the report.

As discussed in the 1967 Supplement to the 1962 Report to the President on Civilian Nuclear Power, a large effort has been required to develop the light water reactors - starting with naval reactors, followed by the early civilian power experiments and demonstrations - which culminated in major engineering efforts to construct large central station plants. The widespread acceptance of the light water reactor is an established fact. The large industrial commitments and improvements in technology should result in further improvements in performance. These factors will make difficult the introduction in the United States of any new system, even though a potential economic gain is indicated. Further, the continued improvement in the industrial posture of the light water reactors, plus the urgent need to introduce breeder reactors at the earliest date possible, will make the successful introduction of alternate coolant fast breeders more difficult. The possible future role of such reactors in the U.S. nuclear power economy is, therefore, not yet clear.

If the overall assessment of the civilian nuclear power research and development program should indicate that a specific alternate coolant fast breeder reactor concept appears to have an attractive economic potential, such a conclusion could provide a basis for further development. 
The basis for development, however, would depend upon additional factors such as the interest of U.S. utilities in alternate coolant fast breeder reactors, the availability of funds over and above those necessary to meet the present heavy commitment to develop the LMFBR as soon as possible, and the ability of the U.S. government, industry, and utilities to support parallel reactor development efforts.

The alternate coolant fast breeder designs evaluated in this report are based on information provided by the proponents of the systems and, therefore, generally reflect their viewpoint. It is recognized that the inclusion of membership on the task force from industrial organizations engaged in the design of alternate coolant fast breeders has resulted in a report that reflects their enthusiasm. This report presents an evaluation of alternate coolant fast reactor technology that the proponents of these systems believe can be achieved.

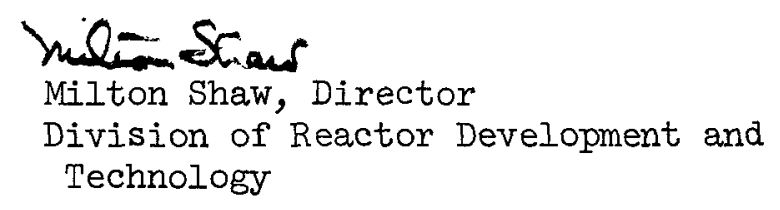


0

○ 
1. INTRODUCTION $\ldots \ldots \ldots \ldots \ldots \ldots \ldots \ldots \ldots \ldots \ldots \ldots \ldots \ldots \ldots \ldots \ldots \ldots \ldots$

1.1 Background Information $\ldots \ldots \ldots \ldots \ldots \ldots \ldots \ldots \ldots \ldots, 1$

1.1.I Steam-Cooled Breeder Reactors .............. I

1.1 .2 Gas-Cooled Fast Reactors $\ldots \ldots \ldots \ldots \ldots \ldots \ldots \ldots .63$

1.2 Objectives and Scope of This Study $\ldots \ldots \ldots \ldots \ldots \ldots \ldots . \ldots$

1.3 Reactor Systems Considered .................... 5

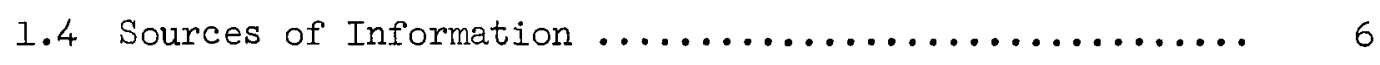

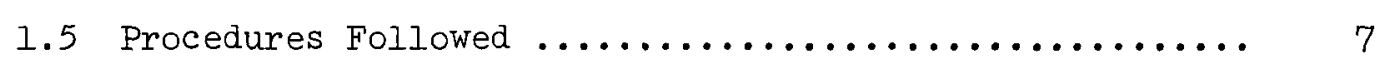

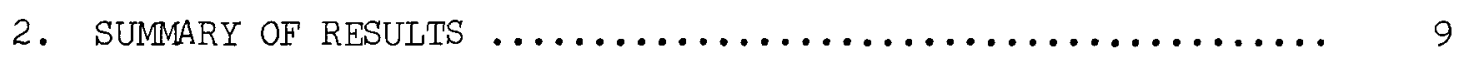

2.1 Evaluation of Performance Characteristics ........... 9

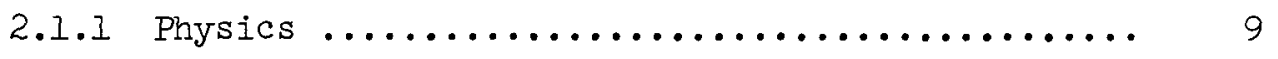

2.1.2 Thermal-Hydraulic Performance ............. 12

2.1 .3 Materials $\ldots \ldots \ldots \ldots \ldots \ldots \ldots \ldots \ldots \ldots \ldots \ldots \ldots .13$

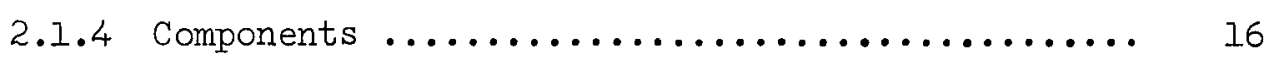

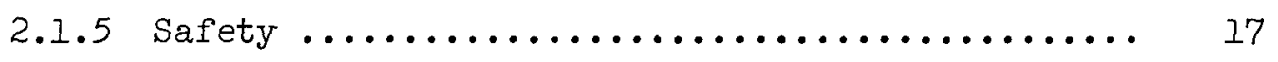

2.2 Economic Evaluation $\ldots \ldots \ldots \ldots \ldots \ldots \ldots \ldots \ldots \ldots \ldots .20$

2.2.1 Capital Costs ....................... 20

2.2.2 Fuel Cycle Costs $\ldots \ldots \ldots \ldots \ldots \ldots \ldots \ldots \ldots \ldots .21$

2.2 .3 Operating and Maintenance Costs $\ldots \ldots \ldots \ldots \ldots \ldots .22$

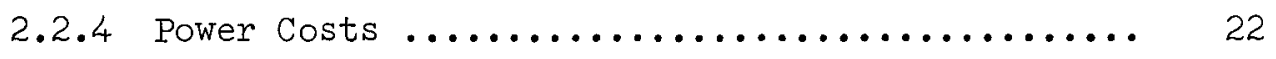

2.3 Research and Development Programs ............... 23

2.3.1 Steam-Cooled Fast Reactors ............... 24

2.3.2 Gas-Cooled Fast Reactors ................ 25

2.3.3 General Comments on Development Programs ...... 26

2.4 Important Milestones and Dates of Introduction of
Alternate Coolant Fast Breeder Reactors ............ 27

2.4.I Basic Assumptions .................... 27

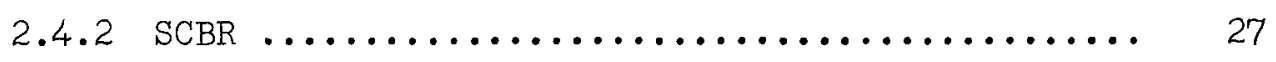

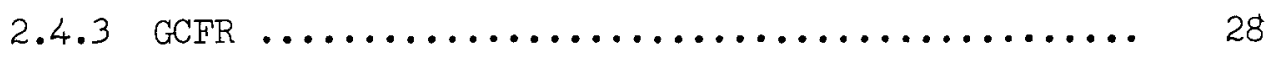


3. GROUND RULES AND COST BASES ......................... 29

3.1 General Considerations ....................... 29

3.1.1 Definition of Criteria for Evaluating

Technical Feasibility ................... 29

3.1.2 Timing (Date of Introduction) ............ 30

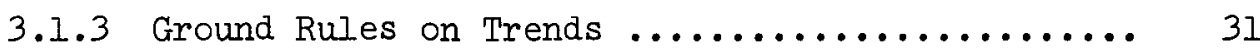

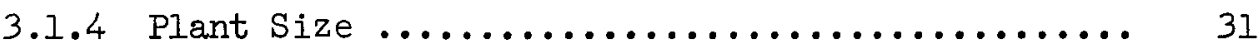

3.2 Financing Conventions ...................... 31

3.3 Capital Cost Bases ........................ 32

3.4 Value of Materials ....................... 32

3.5 Fuel Cycle Cost Bases ....................... 33

3.6 Operation and Maintenance Cost Bases .............. 34

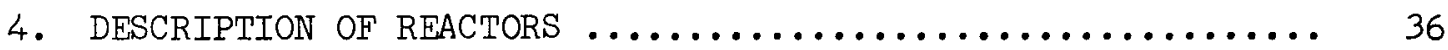

4.1 Steam-Cooled Fast Breeder Reactors ................ 36

4.1 .1 Fuel ............................. 36

4.1.2 Core Composition and Construction ........... 36

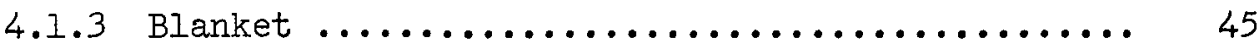

4.1.4 Coolant Flow Diagrams ................... 45

4.1 .5 Reactor Vessels ....................... 47

4.1 .6 Steam Generators ..................... 51

4.1 .7 Circulators ........................ 52

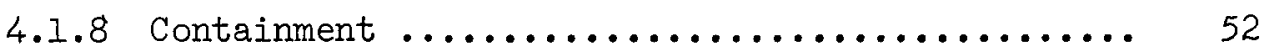

4.1.9 Shutdown and Emergency Cooling Systems ....... 53

4.2 Gas-Cooled Fast Reactors (GCFR) ................. 55

4.2.1 Oxide Fueled GCFR-4 .................... 55

4.2.2 Reference Carbide Fueled Design (GCFR-C) ...... 62

5. TECHNICAL EVALUATION .......................... 67

5.1 Steam-Cooled Breeder Reactors ................... 67

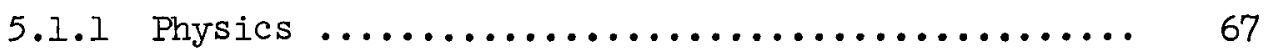

5.1.2 Thermal-Hydraulic Analysis ............... 71

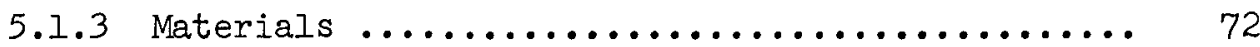

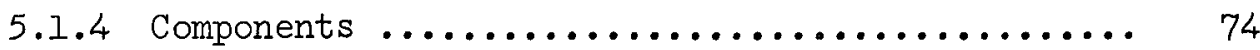

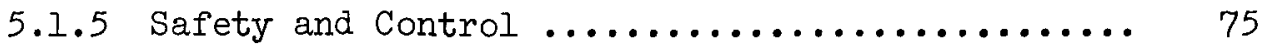


5.2 Gas-Cooled Fast Breeder Reactors ................. 79

5.2.1 Physics ........................... 79

5.2.2 Pressure Equalized Manifolded Fuel Element ..... 83

5.2.3 Thermal-Hydraulic Analysis ............... 89

5.2 .4 Materials ........................... 93

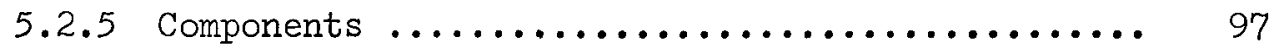

5.2.6 Safety and Control .................... 100

6. ECONOMIC COMPARISON OF CONCEPTS $\ldots \ldots \ldots \ldots \ldots \ldots \ldots \ldots \ldots . \ldots 10 . \ldots \ldots$

6.1 Capital Costs ............................. 105

6.1.1 Sargent \& Lundy Participation ............. 106

6.1.2 Estimated Capital Costs .................. 107

6.1.3 Comparison of Unit Costs ............... 111

6.1 .4 Discussion of Unit Costs ............... 111

6.1.5 Influence of Capital Costs on Energy Costs .... 122

6.2 Fuel Cycle Costs .......................... 123

6.2.1 Fuel Preparation Costs ................. 123

6.2.2 Fabrication Costs ..................... 124

6.2 .3 Shipping Costs ..................... 129

6.2.4 Reprocessing Costs ..................... 130

6.2.5 Summary of Fuel Cycle Costs .............. 131

6.3 Operating and Maintenance Costs ................ 133

6.4 Power Costs .............................. 133

7. RESEARCH AND DEVELOPMENT PROGRAMS $\ldots \ldots \ldots \ldots \ldots \ldots \ldots \ldots \ldots \ldots$

7.1 Steam-Cooled Breeder Reactors .................. 136

7.1.1 Annual and Total Costs .................. 136

7.1 .2 Summary of Important Milestones ............ 138

7.1.3 Dates of Commercial Availability ............ 139

7.2 Gas-Cooled Fast Breeder Reactors ................ 139

7.2.1 Performance Characteristics of Preferred and Alternative Designs .................. 140

7.2.2 Problems Associated with Each GCFR Design

7.2 .3 Costs of Program ..................... 142

7.2 .4 Important Milestones .................... 144

7.2.5 Applicability of Other Research and

Development Work to the GCFR Program ......... 144 


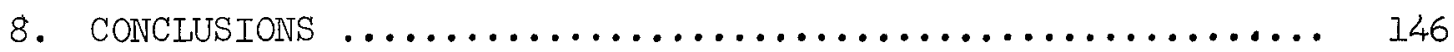

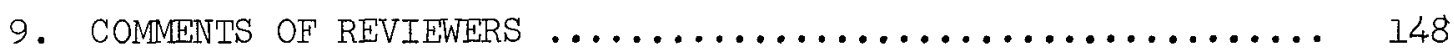

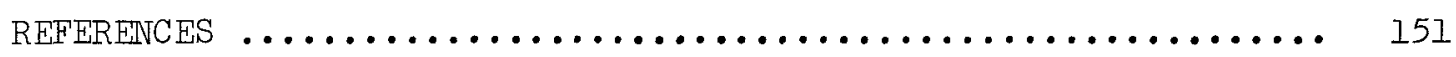




\section{INTRODUCTION}

\subsection{Background Information}

Most of the development work of fast breeder reactors has been based on the use of liquid metal cooling, but in the early 1960's some interest was expressed in the use of other coolants as a means of alleviating some of the problems associated with liquid metals. ${ }^{1}$ Numerous coolants were considered; however, most were eliminated either by chemical or metallurgical evaluations (air, hydrogen, carbon monoxide) or heat transfer considerations (neon, argon). In addition to relatively poor heat transfer, argon also has problems of neutron activation, and neon is very expensive. Nitrogen has a high neutron-absorption cross section and might cause nitriding at high temperatures. Supercritical $\mathrm{SO}_{2}$ cooling has been studied at the Oak Ridge National Laboratory ${ }^{2}$ and appears to be feasible; however, experience with this system at the required operating conditions is very limited. Thus, the list of alternate coolants of interest for fast breeder reactors was reduced to carbon dioxide, helium, and steam. Although from purely thermal and cost standpoints there appears to be little choice between $\mathrm{CO}_{2}$ and helium, $\mathrm{CO}_{2}$ cooling leads to higher core pressure drops, higher fuel ratings, and greater potential for flow-induced vibrations. Thus, present designs of alternate-coolant fast breeder reactors are based on the use of helium or steam cooling.

\subsubsection{Steam-Cooled Breeder Reactors}

There is interest in the development of steam-cooled fast breeder reactors because of the possibility that breeding ratios comparable with those of liquid-metal-cooled fast breeder reactors (LMFBR) can be obtained with a system utilizing the large background of light water reactor technology and utility experience with steam systems. The steam cooling technology is simpler than that for sodium; and, since steam cooled reactors operate on a direct cycle, primary heat exchangers are not required, and a simpler steam supply system results. Additional incentives include the elimination of chemical reactions with the coolant, the possibility of flooding the reactor with a transparent medium (water) during refueling or 
maintenance operations, and the possibility of using water spray systems for emergency cooling.

Disadvantages of the steam cooled fast breeder reactors include the high operating pressure and high velocity flow of the coolant, the reduction in breeding ratio due to the relatively soft neutron spectrum, and safety problems arising from the possibility of loss-of-coolant (depressurization) accidents.

Steam-cooled fast breeder reactors have been studied in varying degrees of depth since 1961. At least four groups in the United States have studied the concept, and studies have also been made in Germany by the Karlsruhe Nuclear Research Center, Institute of Reactor Development; in Sweden by A. B. Atomenergi; and by the Euratom-Belgium Fast Reactor Association.

The study reported in 1965 by the Babcock \& Wilcox Company jointly with American Electric Power Service Corporation ${ }^{3}$ was based on use of supercritical steam as a coolantand, although the concept appeared to be economically competitive, the breeding ratio was only about 1.03. It was concluded that the concept was not consistent with the objectives of the AEC breeder reactor program but that it did fulfill the requirements for an advanced converter. The low breeding ratios found in this study, and the conviction that the core could be cooled with low-pressure steam, led the Babcock \& Wilcox Company to propose in a paper ${ }^{4}$ presented at the Argonne National Laboratory in October 1965 that a lower steam pressure would result in a higher breeding ratio. Their paper indicated that, with a steam pressure of $1200 \mathrm{psi}$, it would be possible to attain an overall breeding ratio of about 1.40. They had not developed a complete design based on the parameters of the lower pressure steam-cooled reactor, so in 1966 and 1967, under contract to the Oak Ridge National Laboratory, Babcock \& Wilcox Company and Sargent \& Lundy Engineers developed a more complete design study of the low pressure concept for use by the Alternate Coolant Task Force in the evaluation of steam-cooled breeder reactors. 5, 6 A rather complete study by the Karlsruhe group ${ }^{7}$ was published in August 1966 based on the use of steam at a pressure of approximately 2650 psia. The German study showed a breeding ratio of about 1.15 and a doubling time of about 37 years. Thus, considerations of the range of 
steam pressures from 1250 to 3700 psia was available to the task force in three design studies. The Oak Ridge National Laboratory attempted to normalize design parameters of these three studies sufficiently to evaluate the potential of steam cooling for fast breeder reactors, and to obtain some understanding of the economics, physics, safety, unsolved problems, and the effect of steam pressure on the concept. As a supplement to this evaluation, the Pacific Northwest Laboratory was asked to perform a parametric study of reactor design over the range of steam conditions of current interest. The results of this study are reported in Ref. 8 .

The use of heavy water steam in the steam-cooled fast reactor has not been evaluated in this study because no design concepts are available. Some work has been done in Sweden and other places in the study of the physics of fast reactor cores cooled by heavy water steam, and it is possible that the lower absorption cross section and the slightly improved neutron spectrum could give that concept some advantage over the light water-cooled system. The advantages would tend to be offset by increased capital costs brought about by the investment in heavy water and the higher cost of equipment for handling it.

\subsubsection{Gas-Cooled Fast Reactors}

Incentives for developing the helium-cooled fast reactor (GCFR) include the attainment of a high breeding ratio in a system utilizing gas cooling technology. The breeding ratios obtained in the GCFR can be equal to or better than those of the LMFBR. Principal components, including the helium circulators, steam generators, prestressed concrete pressure vessel, and helium piping, would draw heavily on technology for existing thermal gas-cooled reactors, on the EGCR development work, and on current HTGR development programs. Fuel element design would utilize the current and planned AEC development programs for sodium-cooled fast reactors. The high internal breeding ratio of the GCFR, along with the provision for on-load variation of flow orificing, would permit a fuel cycle in which the entire core was reloaded at one time; this would minimize the frequency of outages for refueling. Because of the high internal breeding ratio, the reactivity swing over the cycle would be only 
about $\$ 1.00$ and, thus, the neutron losses to control poison would be low. The low coolant void reactivity effect (considerably less than $\$ 1.00$ for complete coolant loss) would allow the core to be optimized without regard to this factor, and might alleviate the necessity for compromising the design to increase the Doppler coefficient.

Disadvantages of the gas-cooled fast breeder reactors include the high operating pressure of the coolant and the safety problems arising from the possibility of loss-of-coolant (depressurization) accidents.

Conceptual design studies of the GCFR were started in 1961 by the General Atomic Division* of General Dynamics Corporation. These studies were continued and expanded in additional work by GGA under an AEC contract starting in 1963. The AEC-sponsored work has been discussed in various reports. 9 , 10 A conceptual design study to establish the practicality of a 1000-Mw(e) GCFR power plant was undertaken in August 1965 as a joint effort by GGA and the East Central Nuclear Group (ECNG). The results to date of the ECIGG study were made available to the AEC and the Alternate Coolant Task Force. ${ }^{11}$ This study was updated and reoptimized for the current assessment of civilian power reactors under contract to ORNL, and the results were published in a report by GGA. ${ }^{12}$

The advantages of gas cooling for fast breeder reactors were also considered by the Karlsruhe group. 13,14

\subsection{Objectives and Scope of This Study}

The objectives of this study were:

1. to evaluate the feasibility of developing and constructing alternate: coolant (steam or gas) fast breeder reactors,

2. to assess the economic potential of each breeder reactor,

3. to evaluate the research and development program required for each breeder reactor to achieve commercial use, and

4. to provide data to the Systems Analyses Task Force (SATF).

The assessment of the alternate coolant fast breeder reactors was initiated by the USAEC in the fall of 1966. To guide this assessment,

*Now Gulf General Atomic and referred to hereafter as GGA. 
an Alternate Coolant Task Force was established that consisted of representatives of industry (General Electric Company, Westinghouse Electric Corporation, Babcock \& Wilcox, and Gulf General Atomic), the USAEC Iaboratories (Oak Ridge National Laboratory, Argonne National Laboratory, Brookhaven National Laboratory, Los Alamos Scientific Laboratory, and Pacific Northwest Laboratory), and the USAEC Division of Reactor Development and Technology. The industrial sponsors of each concept were requested to generate or up date designs of $1000-\mathrm{Mw}(e)$ plants to provide a basis for comparison. A working group was established at the Oak Ridge National Laboratory to develop independently the technical and economic performance characteristics of these concepts. The results were then compared with those claimed by the sponsors and the differences were resolved. Finally, each alternate coolant fast breeder reactor was examined from the standpoint of possible contribution to the overall nuclear power system of the U.S. This was done through the assistance of the Systems Analyses Task Force.

\subsection{Reactor Systems Considered}

Three steam-cooled fast breeder reactors (SCBR) were considered in the evaluation. The first is a high pressure concept cooled by steam which enters the reactor at 3700 psia and $750^{\circ} \mathrm{F}$. Steam enters the turbine at 3300 psia and $994^{\circ} \mathrm{F}$, with reheat to $950^{\circ} \mathrm{F}$. This high pressure SCBR concept was developed jointly by the Babcock \& Wilcox Company and American Electric Power Service Corporation.

An intermediate pressure SCBR concept developed by the Karlsruhe group is the second concept considered. In this system the steam enters the reactor vessel at $2680 \mathrm{psia}$ and $710^{\circ} \mathrm{F}$ and enters the turbine at 2350 psia and a temperature of $1000^{\circ} \mathrm{F}$. The steam is reheated in a surfacetype heat exchanger to $950^{\circ} \mathrm{F}$.

The third SCBR considered was developed by Babcock \& Wilcox Company and Sargent \& Iundy Engineers and is referred to as the low-pressure SCBR design. In this concept steam enters the core at 1250 psia and $575^{\circ} \mathrm{F}$, and the turbine throttle conditions are $1050 \mathrm{psia}$ and $925^{\circ} \mathrm{F}$. There is no reheat of the steam in this power cycle. 
In all three SCBR concepts, the steam used for cooling the reactor core is generated in a Loeffler-type cycle that uses steam from the reactor exit as a heat source. Steam generated by mixing the high-temperature exit steam with feedwater is circulated through the reactor by a steam circulator. In the low pressure design, the boiler and circulator are integral with the reactor vessel so that piping between the Loeffler boiler, the steam ciculator, and the reactor is eliminated. In the other two concepts, the steam generators and circulators are located separately from the reactor vessel and are connected by piping.

Three helium-cooled designs were also considered; namely, a derated oxide fueled design (GCFR-4D) with a limit on the cladding temperature set $50^{\circ} \mathrm{C}$ below that specified in the reference design, a reference oxide fueled design (GCFR-4) with relatively high values for maximum pin heat rating and cladding temperature, and a carbide fueled design operating at higher pin rating, gas pressure, power density, and specific power.

In a typical GCFR, the reactor and steam generators are contained in a prestressed concrete pressure vessel which also serves as the biological shielding. Electricity is generated from a high pressure steam cycle with a net thermodynamic efficiency of almost 40\%. The steam generators are supplied with 1250- to 1750-psi high-temperature helium. The coolant flow is downward through the core, with the fuel elements cantilevered from a deep top-mounted grid plate. Each fuel element is comprised of metal clad mixed uranium-plutonium oxide or carbide fuel rods. Overall conversion ratios of 1.45 to 1.60 are obtained, and the internal conversion ratios are about 1.0 .

\subsection{Sources of Information}

Complete design reports, including cost estimates and performance calculations for all concepts (Refs. 3, 7, 12, 15-19), were generated by the sponsors. In all cases in which additional information was required in order to complete the evaluation, the sponsors were consulted directly. Also, when ORNL results differed appreciably from those obtained by the sponsors, the results were discussed with the sponsors and efforts were made to reconcile the differences. Inevitably, because of the wide 
disparity in interest and enthusiasm of the members of the Task Force for the various reactor systems under consideration, it was not possible in all cases to obtain complete agreement with respect to the reactor performance projected by the system proponents or calculated by the ORNI working group.

\subsection{Procedures Followed}

Starting with the reference design (or designs) provided by the sponsor of each concept, the ORNL working group first carried out detailed thermal-hydraulic and nuclear physics analyses to verify that the proposed design and operating conditions were technically feasible. In this regard, it was assumed that research and development programs associated with each concept would be successfully completed. The performance requirements for individual components of the heat removal and powergeneration systems were checked in detail. Fuel performance calculations (exposure levels, mass balances, power peaking factors), as well as reactivity coefficients, were also determined. Possible problems relative to reactor performance, fuel element integrity, safety, and control were identified in each case. Finally, the research and development programs required to solve these problems were analyzed with respect to costs and timing.

Once the technical feasibility of a concept was established and a specific set of design and operating parameters identified, the capital costs of the plant were estimated by ORNL and compared with the proponents' estimated costs. Adjustments were made where necessary to put the capital costs of all reactor concepts being considered on a consistent basis. ORNL had the responsibility for this cost normalization for all concepts treated in the system analysis studies. Unit costs in dollars per kilogram of plutonium and uranium for fuel fabrication, conversion, shipping, and processing were determined for each type of fuel, and these costs, combined with core performance data to determine present worth (levelized) fuel cycle costs over the 30-year life of any given type of reactor. Capital costs, fuel costs, and operating and maintenance costs were then combined to provide an overall comparison of power costs. 
Operating and maintenance costs were also normalized by ORNL by following a consistent set of labor, materials, and other costs. Finally, the research and development programs proposed by the sponsors were evaluated as to scope, schedules, and costs. 


\section{SUMMARY OF RESULTS}

\subsection{Evaluation of Performance Characteristics}

\subsubsection{Physics}

The primary areas of concern in the physics analysis are (1) fuel inventories, lifetime fuel requirements, and breeding ratios for determination of fuel aycle costs, (2) power peaking factors for use in the thermal-hydraulic evaluation, and (3) reactivity coefficients for the safety and control analysis. These physics characteristics (calculated by ORNL) are summarized in Table 2.1. Lifetime mass balances for use in system analysis studies were also computed for each concept. Details of these are given in Refs. 20 and 21.

The physics evaluations of the various concepts are summarized in the following paragraphs.

2.1.1.1 SCBR. Steam-cooled fast reactors, as represented by the designs studied in this evaluation, have equilibrium breeding ratios of 1.11 for the supercritical steam-cooled design, 1.14 for the intermediate pressure design, and 1.38 for the low pressure design. These breeding ratios correspond to a range of median fission energy from $30 \mathrm{kev}$ for the high pressure design to $160 \mathrm{kev}$ for the low pressure design, with a value of $120 \mathrm{kev}$ for the intermediate pressure design. When combined with the system average fissile plutonium inventory, these breeding ratios result in exponential doubling times of 12, 38, and 41 years, respectively, for the low, intermediate and high pressure systems. The reactivity change resulting from either loss of coolant or flooding is positive for all three systems, with the exception of the high pressure SCBR at end of life. Loss of coolant at beginning of life results in increases in effective multiplication factors of 0.009, 0.021, and 0.005 for the low, interme diate and high pressure systems. Flooding at end of life results in an increase of 0.012 for the intermediate pressure system and 0.04 for the high pressure system. The maximum effect of flooding occurs at beginning of life in the low pressure system where the change in effective multiplication factor is 0.168 . The principal unsolved physics problems or areas requiring additional information in the steam cooled concepts are kinetics 
Table 2.1. Equilibrium Physics Characteristics of Alternate-Coolant Fast Breeder Reactors

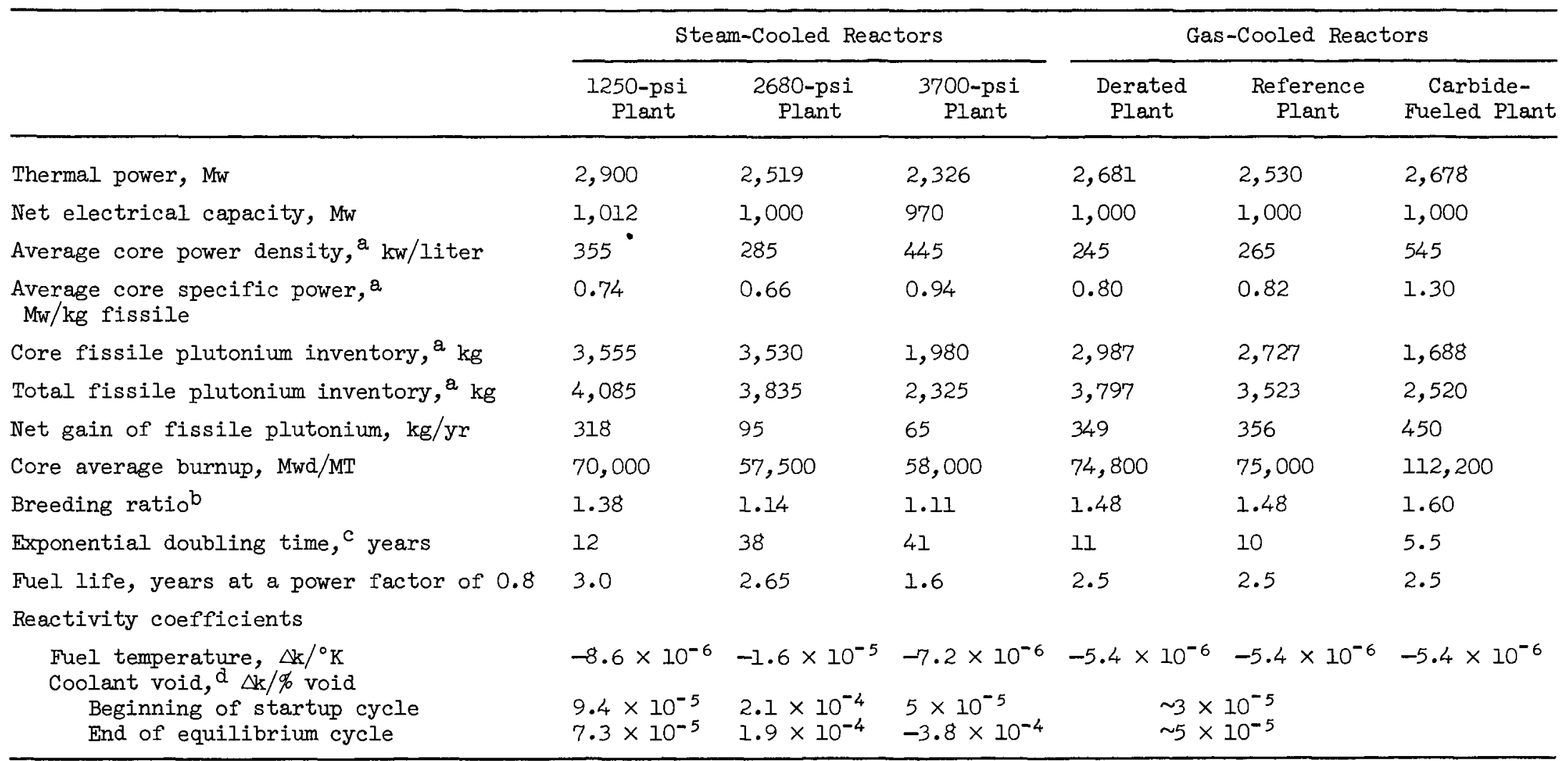

\footnotetext{
${ }^{a}$ Calculated as linear averages over equilibrium cycle.
}

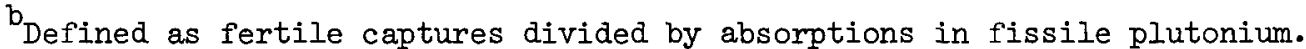

${ }^{c}$ Based on one-year out-of-core holdup of fissile plutonium.

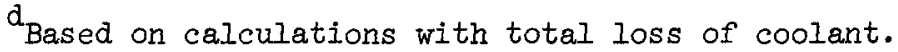


analyses of the various cores, lack of the critical experiments needed to confirm calculations, and lack of understanding of the density effect on reactivity.

From the physics standpoint, the larger inventory and low breeding ratio present the greatest handicap for the high pressure steam-cooled fast reactor. The breeding ratio and doubling time obtained for the low pressure design are comparable with those of other fast breeder reactors, but the economics suffer from the larger inventory requirement. It is recognized that the core design and fuel cycle program for the low pressure concept were not optimized by the designer and, therefore, some improvement in these results may be possible when further study is given to these problems with the support of adequate critical experiment data.

2.1 .1 .2 GCFR. The calculated equilibrium breeding ratio of the GCFR-4 design is about 1.48 and corresponds to an exponential doubling time of 10 years. The reference carbide fueled design, on the other hand, is estimated to have a breeding ratio of 1.6 and a doubling time of 5.5 years.

The overall core peak-to-average power distribution for the oxide fueled reference design was found to be 1.47 at beginning of life and 1.40 at end of life.

2.1.1.3 ${ }^{239} \mathrm{Pu}$ Cross-Section Uncertainties. Recent measurements, which became available after completion of these evaluation calculations, indicate that the capture-to-fission ratio of ${ }^{239} \mathrm{Pu}$ may be somewhat higher than previously estimated in the energy range between 0.2 and $25.0 \mathrm{kev}$. Some preliminary calculations show that this change would result in a reduction in the predicted breeding performance of fast breeder reactors. Technical, as well as economic penalties, would result, including lengthen. ing the doubling times. Should the recent measurements be confirmed, the various breeder reactor designs undoubtedly would be reoptimized in an attempt to minimize the effect.

Since further consideration of the uncertainties in the physics data is needed, it is impossible to determine their impact on the breeder reactor development program prior to the publication of this report. 


\subsubsection{Thermal-Hydraulic Performance}

2.1.2.1 SCBR. All three SCBR designs were analyzed to determine the flows, pressure drops, and temperature distributions throughout the cores and blankets. The calculated maximum cladding surface temperature in the low pressure SCBR is below $1350^{\circ} \mathrm{F}$, the specified value for the design maximum. In the intermediate pressure design, the maximum surface temperature is below $1200^{\circ} \mathrm{F}$, which is to be compared with the $1390^{\circ} \mathrm{F}$ design maximum. The high pressure design was found to have a maximum surface temperature of about $1350^{\circ} \mathrm{F}$, which is the specified design maximum.

If the melting point of the irradiated mixed uranium and plutonium oxide is assumed to be about $4900^{\circ} \mathrm{F}$, only the intermediate pressure design meets the criterion of no center melting. It is estimated that center melting would occur in the other two designs, for which the linear heat ratings reach maximum values of 15 to $16 \mathrm{kw} / \mathrm{ft}$. Melting could be avoided by altering the core design, without suffering large cost penalties. Use of more smaller diameter pins would reduce the linear heat rating at the expense of a small increase in fuel fabrication cost. It was estimated that for a center-Iine temperature of $4900^{\circ} \mathrm{F}$, the heat that could be removed from the vibration-packed fuel per unit length of fuel rod would be about $13 \mathrm{kw} / \mathrm{ft}$. The use of pelletized fuel would permit a higher linear rating without center-line melting for the given fuel surface temperature (about $1530^{\circ} \mathrm{F}$ ), and both fuel forms would permit higher fuel ratings if the surface temperature was reduced. Since both the low and intermediate pressure SCBR designs utilize pins whose diameters are not constant along the length, core redesign would be required if pellets were used.

2.1.2.2 GCFR. The core power distributions calculated for the reference core GCFR-4 were also applied to the derated design because core zoning and compositions were similar. The maximum cladding surface temperature for the reference design was calculated to be $1315^{\circ} \mathrm{F}$ under nominal full power conditions and to be $1435^{\circ} \mathrm{F}$ at the hot spot. Such temperatures are higher than those of most other fast reactor designs, and they would introduce significant technical problems. These values may be compared with design values of 1293 and $1472^{\circ} \mathrm{F}$, respectively, specified by 
GGA. For the derated design, the full power nominal and hot-spot maximums were 1205 and $1315^{\circ} \mathrm{F}$, respectively, compared with design values of 1200 and $1380^{\circ} \mathrm{F}$, respectively, specified by GGA. The maximum hot-spot temperatures calculated at $110 \%$ rated power were $1515^{\circ} \mathrm{F}$ for the reference design and $1385^{\circ} \mathrm{F}$ for the derated design. These temperatures would be experienced on a short-term basis only.

Maximum reference design fuel temperatures were calculated to exceed the melting point of unirradiated ( $\mathrm{U}, \mathrm{Pu}) \mathrm{O}_{2}$ fuel $\left(4950^{\circ} \mathrm{F}\right.$ ) under all conditions except nominal 100\% power with no engineering hot-spot factors included. Maximum fuel temperatures calculated for the derated design were also above the oxide melting point when hot-spot factors were included. It is thought that fuel melting cannot be permitted because the cored pellets would provide a passage for flow of the molten fuel to a lower position in the pin where the coolant would be even hotter.

Interior fuel melting can be avoided at slight cost penalty by one of several design alternatives. A slight reduction in pin heat rating below that of the derated design would avoid melting at a very small cost penalty. Also, the use of higher density oxide (95 instead of 90\%, for example) with a larger central hole would provide a considerable reduction in the interior fuel temperature, although increasing the fuel density would conceivably enhance fuel swelling problems.

\subsubsection{Materials}

2.1.3.1 SCBR. It appears that compatibility between fuel and steam will be satisfactory if no excess oxygen is present; however, the ability to assure this condition in an intense radiation field is not known. The type 19-9DL stainless steel cladding may suffer stress-corrosion cracking and, also, be much less resistant to oxidation. Coolant-cladding compatibility may be satisfactory for Inconel 625 and/or Incoloy 800 ; however, radiation effects on all cladding materials are recognized as a problem in that reduced ductility will shorten stress-rupture life at the low strain rates involved. On this basis, the fuel element life was limited to that at which the increasing cladding stress from fission gas pressure would develop 1\% cladding strain. The high and intermediate pressure concepts would require additional void-plenum volume to achieve 
100,000-Mwd/MT maximum burnups. The low pressure concept was designed for 100,000-Mwd/MT average burnup, and it appears satisfactory from the aspect of fission gas pressures.

All the steam-cooled reactor designs use prepressurization of the fuel rods to prevent cladding collapse under initial operating conditions. Calculations indicate that in the high and low pressure designs the internal pressures for this prepressurization should be increased.

For purposes of economic comparisons, all three designs were assumed to operate to a point-maximum fuel burnup of 100,000 Mwd/MT. It appears possible to achieve a suitable combination of fission product gas plenum volume and initial prepressurization to accommodate the fission product gases while holding cladding stresses to an acceptable level. In regard to fuel pin prepressurization, however, it should be pointed out that problems of quality control and inspection to insure acceptable pins could be substantial.

The development of cladding strain from fuel swelling and other factors is dependent on the creep strength of the cooler outer layer of fuel, which may be a function of stress, rate of stress application, character and amount of pore volume, fission rate, and external restraint. This problem is common to all proposed fast reactor designs, and experimental tests will be required to evaluate effects of such fuel cladding mechanical interactions on burnup limits as a function of the operating environment.

2.1.3.2 GCFR. It appears from the results of short term out-ofpile tests that no problems of compatibility exist between stainless steel and $\mathrm{UO}_{2}$ fuels. The advanced gas-cooled reactor (AGR) uses $\mathrm{UO}_{2}$ in contact with $20 \% \mathrm{Cr}-25 \% \mathrm{Ni}-1 \% \mathrm{Nb}$ cladding at temperatures up to $750^{\circ} \mathrm{C}\left(1380^{\circ} \mathrm{F}\right)$. Fuel cladding compatibility has been established in furnace tests with $\mathrm{UO}_{2}-20 \% \mathrm{PuO}_{2}$ in contact with various stainless steels (including type 316 stainless steel) for $1000 \mathrm{hr}$ at $1400^{\circ} \mathrm{F}$. No bonding or diffusion across the interface developed, although hyperstoichiometric oxide developed a l-mil-thick oxide film on the inner surface of the steel, and slight metallurgical effects (to a depth of $0.1 \mathrm{mil}$ ) were noted in adjacent metal. However, successful performance of mixed oxides under the 
higher temperature conditions of commercial GCFR's remains to be demonstrated.

With the use of the pressure equalizing technique to avoid differential pressure loads on the cladding, fuel volumetric changes will be a major source of cladding stress. The volume increase from solid fission product formation is about $1 \%$ or less per 10,000-Mwd/MT burnup if a major fraction of the fission gas escapes. Gas release is a function of temperature and burnup and ranges from about 50 to $95 \%$ at high heat ratings and burnups of 50,000 to 125,000 Mwd/MT.

The pressure generated at the fuel cladding intertace as a result of swelling is relieved by plastic and elastic deformations of the fuel and cladding. The criterion limiting fuel element life will probably be the development of about $1 \%$ cladding creep strain. Cladding strength must, therefore, be sufficient to insure that most of the volume increase is accommodated by the flow of the fuel to the internal pores and the void space at the interior of the cored fuel pellets.

At the high temperatures proposed for the GCFR-4, the reference oxide fueled design, the cladding will offer little restraint against fuel swelling. However, the parameters controlling creep strength of fast reactor fuels have not been established.

It is apparent that the cladding used in the gas-cooled reactor designs studied here offers less restraint against fuel swelling than cladding used in other proposed fast reactor designs due to the higher operating temperature. Other factors being equal, it might be expected that comparable swelling rates would be achieved at comparable restraining pressures. However, fuel temperatures in the GCFR-4 are somewhat higher, and it is possible that this effect in causing greater fuel plasticity and fission gas release may indeed require less restraint. Because of the unknown interaction of many processes, it is concluded that the effects of cladding temperature and cladding thickness on burnup limitations of the fuel element cannot now be established.

It is concluded that the fuel element proposed for the GCFR-4 represents a considerable extrapolation of current technology, and that considerable experimental testing will be required to define effects of various 
parameters on the burnup attainable. A major limitation results from reduced cladding ductility, which is recognized as a major problem for development of any fast reactor design. The maximum cladding temperature for GCFR-4 of $1435^{\circ} \mathrm{F}$ is at least $100^{\circ} \mathrm{F}$ higher than for other fast reactors. Higher cladding temperatures will adversely affect compatibility and cause development of metallurgical changes that may reduce cladding strength. It is concluded that maximum allowable cladding temperatures cannot now be determined.

\section{1 .4 Components}

2.1.4.1 SCBR. The proposed reactor vessels are considered feasible to build in present-day manufacturing facilities, except that the two layer vessel for the 3700- and 2680-psi designs may require some development. The acceptability of using a welded head vessel, with its limited capability for inspection and maintenance, is questionable.

The feasibility of using a direct cycle with an uncontained turbine is an uncertainty. The potantial for higher fuel failure and the lack of a phase separation to reduce fission product or corrosion product carryover makes the situation very different from BWR experience. Also, the concept of having a major portion of the primary system outside the containment vessel is questionable.

The principal components of these systems that differ from those in other water-cooled reactors are the steam generators and the steam circulators. The steam generators are a mixing type in which superheated steam from the reactor is mixed with the feedwater to generate stear to cool the core. Some experimental work may be required on spray distribution and droplet size, etc., in order to demonstrate performance of each steam-generator concept. The circulator designs all represent an extension of present technology to larger sizes. The most significant problem areas in these components are the shaft seals and bearings.

With the high core pressure drops characteristic of the designs studied here, vibration of the core and core support structure is a potential problem. Flow tests will be required as part of the development program to demonstrate that the design is adequate in this area. 
2.1.4.2 GCFR. The proposed prestressed concrete reactor vessel represents a considerable extrapolation of current operating experience with such vessels; therefore, a substantial verification of the design will be needed, including model tests. Vibration of the core structure due to physical loads imposed by the flow of the coolant could be a problem that might require extensive flow studies for its solution. The helium circulators, on the other hand, appear to be reasonable extrapolations of current technology.

Steam generator designs prepared by three different manufacturers have total heat transfer areas ranging from about 46,000 to 62,000 $\mathrm{ft}^{2}$, with the ORNL estimate being $73,000 \mathrm{ft}^{2}$. The range of values is presumably due in large part to uncertainties in helium heat transfer correlations. This uncertainty should be substantially reduced as part of the HTGR program.

\subsubsection{Safety}

It was recognized that safety considerations are a most important aspect of fast reactor design and evaluation. Within the limitations of the design information and effort available, the evaluation identified those aspects of the designs with safety implications.

The safety problems of all fast reactors differ from those of thermal reactors in that ( 1 ) the fast reactors operate at higher power density, (2) a larger quantity of fissile material is present in the core of each fast reactor and provides a potential of several critical assemblies in a thermal neutron environment, (3) the fast reactors have a weaker negative reactivity response to change in temperature and power, and (4) there is a positive reactivity effect of coolant voids in the core, either locally or totally. The steam- and gas-cooled fast reactors have all these problems, except local voiding, and because of the low density coolants, they also have low heat capacity and resultant very rapid temperature changes when loss of coolant or reactivity insertions occur.

It appears that the only inherent power limiting characteristic of the steam- and gas-cooled cores is the Doppler coefficient associated 
with the fuel, so an applied reactivity shutdown will be required to cancel a reactivity transient. Possible causes of reactivity transients in these reactors were reviewed, and based on the review, it appears that for realistic reactivity insertion rates a well designed fast safety system and shutdown mechanism would be able to terminate an accident before the fuel was damaged.

Since the GCFR and SCBR operate with gaseous coolants, they do not have the problem of reactivity increase from local coolant voiding due to a phase change. Flooding of the core with unpoisoned water would add substantial reactivity in both the GCFR and SCBR; however, accidental flooding appears least likely in the GCFR.

The problem of meltdown of core materials has been encountered in sodium-cooled prototype reactors, and it seems reasonable to assume that the steam- and gas-cooled breeder reactors will also encounter this problem. Some preliminary analyses were made of the energy release by a postulated destructive nuclear burst resulting from fuel consolidation into a critical configuration. Analyses indicate that the proposed SCBR vessel may be adequate to contain the burst, but no study was made of the capabilities of the prestressed concrete vessel used in the GCFR design. The designs do not include provisions for removal of heat from the resulting debris inside the vessel.

Further study is required to determine the credibility of a destructive burst and the upper limit for the energy release and to develop reliable means of containing the fuel after a core meltdown and removing the heat from it to prevent reactor vessel melt-through. The potential meltthrough problem is common to all large reactor types, but it is more severe in fast reactors (with higher power density) than in thermal reactors.

These potential problems have not been treated for the various types of steam- and gas-cooled reactors covered in this study.

2.1.5.1 SCBR. The most difficult safety problem of the SCBR seems to be that of insuring continued core cooling. Fmergency cooling of the core would be required within 1 to $5 \mathrm{sec}$ after a major failure in the primary cooling system of a steam-cooled fast reactor. Demonstrations of the ability of core sprays or steam jets or any other device proposed 
for such emergency cooling would be required. It would have to be shown that the emergency coolant would be distributed within a short time in the quantities needed throughout the core and that the core would remain subcritical under these conditions of emergency cooling.

The high pressure and low pressure SCBR's include the feature of a closely fitting high pressure containment vessel around the reactor vessel. If the main reactor vessel or nozzles should break, this secondary vessel should hold the reactor pressure up and, consequently, minimize the reduction in cooling ability and the reactivity increase associated with a loss of coolant. This vessel also increases the capability of containing a destructive nuclear burst.

Further study of the kinetics of steam-cooled fast reactor cores is also necessary to provide adequate information on which to base a complete safety analysis.

2.1.5.2 GCFR. The GCFR has several inherent safety advantages as well as disadvantages. For example, the reactivity increase associated with loss of coolant is considerably smaller than that associated with loss of coolant in steam-cooled designs. Also the use of a prestressed concrete reactor vessel may make very high blowdown rates unlikely for the GCFR concept.

The most crucial safety consideration for the GCFR is that of maintaining forced circulation of coolant under normal as well as emergency conditions. The main and auxiliary blowers and drives must have a higher level of reliability than is required for rotating equipment in current light water reactors, and further study is needed to demonstrate that an adequate level of reliability can be achieved. A depressurization accident would further increase the requirements on the circulators because of loss of coolant mass flow. If depressurization were accompanied by blower failure, damaging conditions could result. Use of a pressuresustaining containment building around the prestressed concrete reactor vessel would help maintain coolant pressure and, thereby, improve the mass flow capability of the operative circulators.

Based on the safety review, costs of a pressure-sustaining secondary containment building were included in the GCFR capital cost estimates. 


\subsection{Economic Evaluation}

\subsubsection{Capital Costs}

The capital cost estimates of alternate coolant fast breeder reactors are based on information submitted by sponsors for reference plant designs. It must be kept in mind when attempting to compare these systems with others that are considerably more advanced, that the conceptual details considered herein have been carried to limited levels of detail, and that the corresponding research and development programs are at best uncertain. Design and operating conditions were varied somewhat to place concepts on an equivalent basis for comparison. For example, because of safety considerations, a secondary containment vessel was recommended for the GCFR, and its cost was included in the GCFR capital costs. These changes were generally quite small and equivalent to less than \pm 0.1 mill/kwhr in power costs. However, changes made to the high pressure SCBR to make it more equivalent to the low pressure design added about $0.15 \mathrm{mill} / \mathrm{kwhr}$ to its cost. The procedure used in determining adjusted and normalized capital costs consisted of the following steps:

1. Costs reported by sponsors were tabulated in accordance with the USAEC classification of accounts outlined in Ref. 22.

2. Costs of systems and components common to more than one plant were normalized to a reference set of costs. These were derived from suppliers list prices, materials costs, and labor costs as of June 1 , 1967, by using methods developed at ORNL.

3. Costs of components unique to a particular concept were checked against applicable cost experience and modified when apparent discrepancies were found.

4. Constant percentages were applied sequentially to the direct costs of all concepts to determine the total indirect costs. These were general and administration, 6\%; miscellaneous construction, $1 \%$; architect-engineer services, 5\%; nuclear engineering, 2\%; startup, $35 \%$ of operating and maintenance costs; contingency, 10\%; interest during construction of investor-owned plant, $10.8 \%$. In combination, these indirect charges amounted to about $41 \%$ of the direct construction costs. 
Table 2.2 summarizes the capital costs of the reactors being considered. Since the cost normalization methods used were sensitive to the accuracy of the reference design costs and were for a fixed set of site conditions, the values reported should be regarded as relative rather than absolute investment costs. They are not intended to reflect possible future prices of plants, particularly where the state of technology is somewhat new. Furthermore, even after development programs are scoped and detailed designs are available for commercial application, costs will be influenced by changes in "market place" conditions.

Table 2.2. Normalized Capital Costs of Investor-Owned Fast Breeder Reactors

\begin{tabular}{lcc}
\hline Concept & $\begin{array}{c}\text { Total Unit } \\
\text { Costs } \\
{[\$ / \mathrm{kw}(\mathrm{e})]}\end{array}$ & $\begin{array}{c}\text { Corresponding } \\
\text { Energy Costs } \\
\text { (mills/kwh })\end{array}$ \\
\hline SCBR & & \\
1250-psi system & 129.1 & 2.53 \\
2680-psi system & 131.4 & 2.57 \\
3700-psi system & 121.7 & 2.38 \\
GCFR & & \\
Derated plant & 129.3 & 2.53 \\
Reference plant & 130.0 & 2.54 \\
Carbide-fueled plant & 130.0 & 2.54 \\
\hline
\end{tabular}

\subsubsection{Fuel Cyocle Costs}

The fuel cycle costs were resolved into the following components: (1) burnup costs, (2) fuel preparation costs, (3) fabrication costs, (4) processing cost, including ultimate waste disposal costs, (5) shipping costs, (6) fixed charges on fissile and fertile inventories, and (7) interest charges on operating capital invested in fabrication, processing, and shipping facilities and in inventories of special materials. The fixed charges and interest were computed by the "present wor $t h$ " formula. A value was assigned to fuel discharged from the reactor at the 
end of plant life ( 30 years) that included linearly prorated credits for fabrication and debits for processing of partially irradiated fuel. In computing the present worth of the power produced, the price of power and the plant factor were assumed to be constant with time. Resulting fuel cycle costs are summarized in Table 2.3 .

Table 2.3. Fuel Cycle Costs for AlternateCoolant Breeder Reactors (Relative)

\begin{tabular}{lccc}
\hline & \multicolumn{3}{c}{ Fuel Cycle Costs $(\mathrm{mills} / \mathrm{kwhr})$} \\
\cline { 2 - 4 } & Fuel Handling & $\begin{array}{c}\text { Inventory and } \\
\text { Interest Charges }\end{array}$ & Total \\
\hline SCBR & & & \\
1250-psi system & 0.32 & 1.04 & 1.36 \\
2680-psi system & 0.49 & 1.03 & 1.52 \\
3700-psi system & 0.54 & 0.72 & 1.26 \\
GCFR & & & \\
Derated plant & 0.16 & 0.89 & 1.05 \\
Reference plant & 0.13 & 0.79 & 0.96 \\
Carbide fueled plant & -0.07 & 0.62 & 0.55 \\
\hline
\end{tabular}

\subsubsection{Operating and Maintenance Costs}

Operating and maintenance costs were derived from estimates of salaries, consumable supplies and equipment, outside support services, administrative and general costs, coolant and makeup costs, and nuclear liability insurance premiums. The resulting total annual costs and associated power costs are summarized in Table 2.4 .

\section{2 .4 Power Costs}

Power costs of investor owned alternate coolant fast breeder reactors are summarized in Table 2.5. These costs are based on capital charges at $13.7 \%$ and a 0.8 plant factor, 30-year levelized fuel cycle costs, and the other ecoromic ground rules given in Chapter 3. 
Table 2.4. Normalized Operating, Maintenance, and Nuclear Liability Insurance Costs

\begin{tabular}{ccc}
\hline & Total Annual & \\
Operating and & Associated \\
Concept & Maintenance & Power Costs \\
& Costs (millions & (mill/kwhr) \\
& of dollars) & \\
\hline
\end{tabular}

SCBR

$\begin{array}{lll}1250 \text {-psi system } & 1.99 & 0.28 \\ 2650 \text {-psi system } & 1.98 & 0.28 \\ 3700 \text {-psi system } & 1.97 & 0.28\end{array}$

GCFR

Derated plant

2.09

0.30

Reference plant

2.09

0.30

Carbide fueled plant

2.09

0.30

Table 2.5. Power Costs in Alternate Coolant Fast Breeder Reactors

\begin{tabular}{lcccc}
\hline & \multicolumn{3}{c}{ Power Costs (mills/kwhr) } \\
\cline { 2 - 5 } Concept & Capital & $\begin{array}{c}\text { Fuel } \\
\text { Cycle }\end{array}$ & $\begin{array}{c}\text { Operation } \\
\text { and } \\
\text { Maintenance }\end{array}$ & Total \\
& & & & \\
SCBR & & & 0.28 & 4.16 \\
1250-psi system & 2.52 & 1.36 & 0.28 & 4.37 \\
2680-psi system & 2.57 & 1.52 & 0.28 & 3.92 \\
3700-psi system & 2.38 & 1.26 & & \\
GCFR & & & 0.30 & 3.88 \\
Derated plant & 2.53 & 1.05 & 0.30 & 3.80 \\
Reference plant & 2.54 & 0.96 & 0.30 & 3.39 \\
Carbide fueled plant & 2.54 & 0.55 & & \\
\hline
\end{tabular}

Development programs for alternate coolant fast breeder reactors have been given preliminary treatment. A significant assumption of these 
programs is that fuel materials will be developed as part of the LMFBR program, and these programs would rely on the LMFBR program to develop fuel performance data. Thus the timing of each alternate coolant effort would depend to a large extent on that of the LMFBR program. Additional work would be required to establish a reliable cladding material from the standpoint of temperature and compatibility. Over and above these considerations would be the need for special development and proof-test facilities, only a limited number of which have been provided, and the cost assistance for the industry to establish the required industrial base to provide for such things as reliable components. Based on experience with other reactor development undertakings, the AEC feels that the cost estimates proposed for the alternate coolant research and development are low. A successful development program for a reliable unit meeting utility requirements would be considerably greater than the levels proposed by concept sponsors. These programs must, therefore, be considered as incremental efforts to be accomplished in addition to much of the basic effort planned for the IMFBR program.

\subsubsection{Steam-Cooled Fast Reactors}

The incremental research and development program outlined by B\&W for the low-pressure SCBR includes the design and construction of a 50-Mw(e) reactor experiment costing about $\$ 25.9$ million. The annual operating cost for this experiment is assumed to be $\$ 3$ million, including fuel charges. This would be followed by a 500-Mw(e) prototype plant, which is estimated to require financial assistance of about $\$ 42$ million. The development program includes a 1000-Mw(e) demonstration plant, which requires an estimated $\$ 19$ million in first-of-a-kind cost assistance. This leads to a total cost of $\$ 86.9$ million for assistance in constructing experimental, prototype, and demonstration reactors, plus an annual cost of $\$ 3$ million for operating the 50-Mw(e) experimental reactor. Costs of other proposed research and development programs contribute a total of $\$ 42.5$ million. The total cost of the proposed research and development plan is, therefore, $\$ 140.9$ million, including four years of operating costs for the 50-Mw(e) experimental reactor. 
Incremental costs for the low pressure SCBR development program are summarized in Table 2.6.

Table 2.6. Incremental Low Pressure SCBR Research and Development Program Costs

\begin{tabular}{lc}
\hline & $\begin{array}{c}\text { Costs } \\
\text { (thousands of } \\
\text { dollars) }\end{array}$ \\
\hline 50-Mw(e) experiment & \\
$\begin{array}{l}\text { Construction } \\
\text { Four years of operation }\end{array}$ & 25,850 \\
500-Mw(e) prototype plant cost assistance & 12,000 \\
Engineering and construction assistance for & 41,540 \\
first-of-a-kind loo0-Mw(e) demonstration & 19,000 \\
plant & 42,538 \\
\hline
\end{tabular}

\subsubsection{Gas-Cooled Fast Reactors}

The incremental research and development program outlined by GGA for helium-cooled fast reactors includes the design and construction of a 100$M W(t h)$ (with no electrical generation) gas-cooled reactor experiment (GCFRE) costing \$33.6 million. The annual operating cost for this experiment is estimated to be $\$ 3$ million, including charges on the fuel. An extensive fuel irradiation program is included that uses FFTF and other facilities at a cost of $\$ 77.7$ million. Other aspects of the program, which include program planning and design studies, core materials development, core mechanical and thermal tests, and components development, add another $\$ 52.2$ million, bringing the total cost of the GGA development plan for GCFR to $\$ 187.5$ million through 1980 (including eight years of operating cost for GCFRE). 
These cost figures do not include costs for developing carbide fuels or any other research and development costs in the IMFBR and HTGR programs, which contribute an estimated $\$ 200$ million worth of applicable research and development to the GCFR program in addition to the use of test facilities. Also, not included in the above figures is the cost assistance required for an intermediate-size prototype plant and the first 1000-Mw(e) demonstration plant. It is probable that a prototype plant with a power level of about 300 to $500 \mathrm{Mw}(\mathrm{e})$ should be included in the development program. This intermediate power prototype would require considerable financial assistance.

The total of the above development costs is $\$ 247.5$ million, and the timing leads to operation of the first 1000-Mw(e) GCFR in 1980. The costs for the GCFR development program are summarized in Table 2.7.

\subsubsection{General Comments on Development Programs}

The costs presented in the above sections lead to a total research and development cost for the GCFR that is higher than for the low-pressure

Table 2.7. Incremental GCFR Research and Development Program Costs

\begin{tabular}{|c|c|}
\hline & $\begin{array}{l}\text { Costs (thousands } \\
\text { of dollars) }\end{array}$ \\
\hline \multicolumn{2}{|l|}{ 100-Mw (th) experiment (GCFRE) } \\
\hline $\begin{array}{l}\text { Construction } \\
\text { Eight years of operation }\end{array}$ & $\begin{array}{l}33,600 \\
24,000\end{array}$ \\
\hline $\begin{array}{l}\text { Prototype plant, } 300 \text { to } 500 \mathrm{Mw}(\mathrm{e}) \text {, } \\
\text { cost assistance }\end{array}$ & 40,000 \\
\hline $\begin{array}{l}\text { Fngineering and construction assistance } \\
\text { for first-of-a-kind 1000-Mw (e) demonstra- } \\
\text { tion plant }\end{array}$ & 20,000 \\
\hline \multicolumn{2}{|l|}{ Research and development programs } \\
\hline $\begin{array}{l}\text { Fuel irradiation tests } \\
\text { General programs }\end{array}$ & $\begin{array}{l}77,700 \\
52,200\end{array}$ \\
\hline Total & 247,500 \\
\hline
\end{tabular}


CBRR. This is due mainly to differences in approach and emphasis in the development programs, rather than to any inherently greater research and development requirements for the GCFR. For example, the GCFR program includes eight years of operation of the GCFRE, whereas the SCBR program includes only four years of operation of the 50-Mw (e) reactor experiment. The GCFR program includes costs for fuel-irradiation tests, while the SCBR development plan relies on LMFBR programs for fuel development.

There is also a significant difference in the cost estimates for the small reactor experiments, with the construction cost for the 100-Mw(th) GCFRE being 30\% higher than that for the 50-Mw(e), perhaps 150-Mw(th), SCBR experiment. In summary the GCFR program includes about $\$ 90$ million for items not included in the SCBR program.

\subsection{Important Milestones and Dates of Introduction of Alternate Coolant Fast Breeder Reactors}

\subsubsection{Basic Assumptions}

1. All reactor development programs require at least one prototype plant, followed by one "essentially full scale" demonstration plant by each reactor manufacturer pursuing the concept.

2. The earliest date of introduction of the first four full scale "commercial" plants $[1000 \mathrm{Mw}(e)]$ is two years after the first full scale demonstration plant has been operated at full power.

3. Design and construction schedules are based on the assumption that there will be no undue delays as a result of licensing, work stoppages, or procurement problems. Thus the given schedules are minimum.

With these assumptions as a basis, the schedules of important milestones leading to possible dates of introduction of alternate coolant fast breeder reactors are outlined in the following sections.

It was assumed for scheduling that the development program would be the same regardless of which steam pressure was chosen for the preferred concept. The schedules for the SCBR and GCFR were: 


\subsubsection{SCBR}

1. Start design of 50-Mw(e) experimental unit by July 1968. Unit to be in operation by December 1973.

2. Make commitments for 300- to 500-Mw(e) prototype plant by December 1971. Unit to be in operation by December 1977.

3. Make commitments for first 1000-Mw(e) demonstration plant by December 1975. Plant to be in operation by December 1980.

4. Make commitments for four 1000-Mw(e) commercial plants by December 1978, with date of introduction to be 1982 .

\section{$2.4 .3 \quad \mathrm{GCFR}$}

1. Start design of 100-Mw(th) GCFRE in July 1968. Experiment to be in operation by December 1973.

2. Start design of 300- to 500-Mw(e) prototype plant by December 1971. Plant to be in operation by December 1977.

3. Make commitments for first 1000-Mw(e) demonstration plant (GCFR4D) by December 1975. Plant to be in operation by December 1980.

4. Make commitments for four 1000-Mw(e) commercial plants (GCFR-4D) by December 1978, with date of introduction to be 1982 .

The reference oxide fueled GCFR-4 could be introduced two years later. The reference carbide fueled GCFR depends on the LMFBR carbide fuel development program, with the date of introduction being 1986 . 


\section{GROUND RULES AND COST BASES}

\subsection{General Considerations}

\subsection{Definition of Criteria for Evaluating Technical Feasibility}

The technical evaluation of the alternate-coolant fast breeder reactors covers five general areas: (1) physics, (2) heat transfer, materials, (4) systems and components, and (5) safety. Calculations were made by ORNL personnel in these areas for verifying the designers' results and also for providing an evaluation of all concepts on a comparable basis.

The heat transfer calculations consisted of a check of the surface and interior maximum temperatures and the total heat removal based on the core configuration provided by the designer and on the power distributions determined by the ORNL physics analysis. These temperatures were then used by the materials engineers in evaluating the ability of the materials to serve at the indicated temperatures. The pressure drops and pumping power required were also calculated, as were the emergency cooling capability and the general heat balance of each system.

The physics evaluation included calculation of neutron balance, breeding ratio, and plutonium yield, all based on core composition as given by the designer and initial loading with plutonium from PWR discharge fuel. Power distributions were calculated on the basis of the specified fuel management program provided by the designer. Coefficients of reactivity due to fuel Doppler effect, coolant void, flooding, and overall coolant density effects were calculated. Based on initial core and blanket compositions and the proposed core and blanket management programs, complete histories of the mass balances throughout the life of the reactor were calculated. The analysis also included a determination of a fuel cycle cost, including fuel fabrication, shipping, and reprocessing costs.

The design characteristics of some of the principal components of the reactor primary system were calculated, and their requirements were compared with current technology of corresponding equipment for which some experience is available. Particular attention was paid to equipment when new requirements were involved, such as those for the steam or gas circulators. The reactor vessels and their internals were analyzed and 
compared with code requirements for the specified design and operating conditions. Refuleing and fuel-handling equipment were reviewed for adequacy and for consistency with the requirements of the other reactor systems with which comparisons were made.

The safety evaluation consisted of a review of several types of accidents that might occur, their effects on the integrity of the reactor, and the resulting potential hazards that might develop. The accidents considered included (1) reactivity accidents, (2) thermal accidents, (3) plant startup and control accidents, and (4) destructive nuclear bursts, and there was some discussion of containment of core meltdown. For al1 these conditions, safety features were examined to determine whether they could successfully cope with the postulated accidents.

There were no firm ground rules established for the design of the safety features, and AEC General Design Criteria changed during the course of this study. Also, concept sponsors used considerably different approaches to the design of safety features and emergency equipment. ORNL attempted to normalize the emergency equipment to a reasonable degree of reliability, but it was not normalized to give the various types of reactor "equivalent" degrees of safety for a similar siting situation. Such a normalization would be reflected in the capital costs of the different reactors; however, this would be difficult to do on a consistent basis because of the conceptual nature of these designs and the lack of safety feature analyses and licensing experience with these advanced designs.

\subsubsection{Timing (Date of Introduction)}

The time period under consideration in the studies was from 1970 to 2020. For each reactor design an estimate was made as to the year in which a prototype reactor would be in operation and the first 1000-Mw(e) demonstration reactor would be started up. This would be followed by the introduction of four such reactors two years later, which would set the date of introduction of "commercially available" plants. The schedule for these reactors was based on the assumption of successful completion of the proposed development programs. This criterion implies that although engineering development may be required to make the design practicable, a technological breakthrough is not needed. 
1. 3 Ground Rules on Trends

Capital costs were estimated for each reactor plant as a part of the economic evaluation based on costs as of June 1967 with no allowance for escalation.

\title{
3.1.4 Plant Size
}

The electrical capacity of each reactor plant was nominally sized at $1000 \mathrm{Mw}(\mathrm{e})$ (net); however, the fuel fabrication and processing plants were sized to handle fuel from about 15 reactors of each type.

\subsection{Financing Conventions}

The financing conventions used to estimate total power costs are summarized in Table 3.1.

\author{
Table 3.1. Financing Conventions for Alternate Coolant \\ Breeder Reactor Evaluation \\ Type of ownership: private investor \\ Plant capacity factor: 0.80 \\ Salvage value of plant: zero
}

\begin{tabular}{|c|c|c|c|}
\hline & \multicolumn{3}{|c|}{ Fixed Charge Rates ( $\%$ per year) } \\
\hline & $\begin{array}{l}\text { Depreciating } \\
\text { Investment }\end{array}$ & $\begin{array}{c}\text { Land and } \\
0 \text { \& } \mathrm{M} \text { Working } \\
\text { Capital }\end{array}$ & $\begin{array}{l}\text { Fuel Cycle } \\
\text { Working } \\
\text { Capital }\end{array}$ \\
\hline Return on investment ${ }^{a}$ & 7.20 & 7.20 & 7.20 \\
\hline $\begin{array}{l}\text { Depreciation (30-year } \\
\text { sinking fund) }\end{array}$ & 1.02 & & \\
\hline Interim replacements & 0.35 & & \\
\hline Federal income taxes ${ }^{b}$ & 2.04 & 4.80 & 4.80 \\
\hline State and local taxes & 2.84 & 0.80 & 0.80 \\
\hline Property insurance & 0.25 & & 0.40 \\
\hline Total & 13.7 & 12.8 & 13.2 \\
\hline
\end{tabular}

Based on $52 \%$ bonds at $4.615 \%$ per year and $48 \%$ equity at 10\% per year.

$\mathrm{b}_{50 \%}$ of gross taxable income. 


\subsection{Capital Cost Bases}

The bases for the capital cost estimates are listed below:

1. The equipment and systems of each plant were assumed to have been completely developed and each plant was one of a number of the same type to be built. No discount credit for quantity orders of equipment was assumed.

2. Indirect costs were based on the breakdown used in Ref. 22 and amounted to about $41 \%$ of direct costs.

3. The plants were located at the AEC hypothetical Middletown site described in Ref. 22, and river-water cooling was assumed. No thermal pollution problem was considered.

4. A four-year construction schedule with a 40-hr work week and no overtime was assumed.

5. Direct costs were based on June 1967 U.S. list prices, with no allowance for escalation.

6. Turbine-generator costs were based on U.S. manufacturers' June 1967 list prices, with a 7\% discount factor applied.

7. Reported capital costs do not include costs of transformer and switchyard and do not allow for a state sales tax.

8. Land costs were assumed to be $\$ 360,000$ for all concepts.

9. Interest during construction was based on a $6 \%$ annual cost of money.

10. Differences in net electrical ratings of various concepts (970 to $1000 \mathrm{MW}$ ) were taken into account by dividing the estimated total construction cost by the quantity $10^{6}$ (rating/1000) 0.75 .

\subsection{Value of Materials}

The unit costs of the materials specifjed are summarized below:

Item

1. Natural uranium as $\mathrm{U}_{3} \mathrm{O}_{8}$

2. Unirradiated thorium as $\mathrm{ThO}_{2}$

3. Separative work cost
Unit Cost

$\$ 8.00 / 1 b$

$\$ 5.00 / 1 b$

$\$ 26 / k g$ 
Unit Cost

4. Diffusion-plant tails concentration

5. Fully enriched ${ }^{235 \mathrm{U}}$

0.002 weight fraction

6. Depleted uranium

7. Fissile plutonium

$\$ 11.18 / \mathrm{g}$

$\$ 3 / \mathrm{kg}$

Five-sixths of value of fully enriched ${ }^{235} \mathrm{U}$; i.e., $\$ 9.32 / \mathrm{g}$

\subsection{Fuel Cycle Cost Bases}

The bases for the fuel cycle cost estimates are given below:

1. The reactors were assumed to be loaded initially with plutonium or enriched uranium and refueled with discharged plutonium until equilibrium was reached. Excess plutonium was assumed to be sold.

2. "Levelized" fuel cycle costs were based on the present worth of all expenditures and receipts during a reactor lifetime of 30 years, with a discount factor of $6 \%$. The effective average lifetime load factor was assumed to be 0.8 and constant over plant life. Unit fuel costs were also assumed to be constant based on a 15,000-Mw (e) industry.

3. Private ownership of fissile and fertile materials during fabrication and processing, as well as on-site at the reactor plant, was assumed to be vested in the reactor plant owner.

4. Annual charges on fissile and fertile inventories and on fabrication costs of fuel elements were computed at $13.2 \%$.

5. The reprocessing plant and fabrication plants were assumed to be located at the same site and to be 1000 miles from the reactor plant. These plants were assumed to be designed to process a single type of fuel element and to be capable of serving an electrical industry of 15,000or 30,000-Mw(e) capacity of the concept being considered. A reference value of $22 \%$ per year was used as the fixed charge rate on these plants.

6. Losses during fabrication were assumed to be $0.2 \%$ per pass, and losses during processing were assumed to be $1 \%$ per pass.

7. Based on the spent fuel being shipped to a plant located at a distance of 1000 miles from the reactor site, it was assumed that: (a) the maximum allowable cask weight was 120 tons fully loaded; (b) shipments 
of spent fuel would be made by rail, and all sites would have railroad sidings and facilities for handling l20-ton casks; (c) rail freight rates would be $\$ 0.0204 / 1$ b for a full cask and $\$ 0.0187 / 1 b$ for an empty cask; (d) round-trip time would be 20 days; (e) casks would be purchased at a cost of $\$ 1.25$ per pound of cask weight, and fixed charges on casks would be $15 \%$ per year, including recovery of investment, return on investment, taxes, and maintenance; (f) shipments would be designed to comply with the Code of Federal Regulations, Title 10, Part 71, and with Interstate Commerce Commission Order 70; and the cask would have the exclusive use of the vehicle; $(g)$ casks could be shared among reactors of the same type, and when casks were shared, a maximum limit of 0.8 was placed on the cask utilization factor (time in use divided by total time); (h) the cost of property insurance against damage to or loss of cask and contents would be 0.0005 times the value of the shipment; (i) it would not be necessary for a courier to accompany the shipment; (j) individual. fuel assemblies would be canned before shipping; and $(\mathrm{k})$ fuel assemblies would not be disassembled before shipping.

8. Holdup times were established separately for each concept, depending on the characteristics of the fuel concerned.

\subsection{Operation and Maintenance Cost Bases}

Estimates of operation and maintenance costs were based on methods described in the NUS economic evaluation guide (Ref. 22, revised). Items in the operation and maintenance category were plant staffing, consumable supplies and equipment, outside support services, administrative and general expenses, coolant makeup, and nuclear liability insurance. Plant staffing costs consisted of the direct payroll plus $10 \%$ fringe benefits. A reference staff of $78^{\circ}$ people was assumed for a 1000-MW(e) BWR or PWR single-unit station and was based on five-shift operation. Five more people were assumed for the GCFR designs because of coolant-handling requirements: Consumable supplies and equipment costs were based on the estimates for BWR and PWR plants, with adjustments made for evaluated 
differences in requirements for other concepts. The annual cost of outside support services was assumed to be $\$ 130,000$ for all concepts. Administrative and general support functions were supplied through the utility's central office, and the cost of these functions was estimated at $14 \%$ of the sum of the costs for plant staffing, consumables, and outside support services. The initial charges for coolant inventory were included in capital cost charges; the operation and maintenance component of this cost covered the cost of makeup quantities of these fluids. Nuclear liability insurance cost included commercial coverage at an estimated cost of $\$ 240,000$ per year for a $1000-\mathrm{Mw}(\mathrm{e})$ station and government coverage to a total of $\$ 560$ mililion at an annual premium of $\$ 30$ per thermal megawatt of reactor rating. 


\section{DESCRIPTION OF REACTORS}

\section{I Steam-Cooled Fast Breeder Reactors}

This chapter contains brief descriptive data for the low, intermediate, and high pressure designs as presented by the sponsors. The principal design parameters for these three systems are given in Table 4.1, with some values revised by ORNL calculations. The data are for the beginning of operational lifetime.

The concepts are described here by first discussing the fuel and working outward through the core construction and composition; the blanket; the coolant flow diagrams; and the major components of the systems, the reactor vessels, steam generators, circulators, containment structure, and the shutdown and emergency cooling systems.

\subsubsection{Fuel}

The fuel material proposed for all the designs is a mixture of plutonium and uranium oxides, and the cladding materials include Inconel 625, Incoloy 800, and stainless steels. Fuel elements for the three steamcooled concepts are illustrated in Figs. 4.1, 4.2, and 4.3. The fuel rods will be pressurized internally to counteract the collapsing load on the cladding. The proposed maximum heat ratings vary from a low of about $11 \mathrm{kw} / \mathrm{ft}$ in the German design to $18 \mathrm{kw} / \mathrm{ft}$ in the design for using low pressure steam.

\subsubsection{Core Composition and Construction}

The arrangements of the cores of the three SCBR's are illustrated in Figs. 4.4, 4.5, and 4.6. The incentive to maintain low water content in the steam-cooled systems is reflected in the low coolant fraction in these three designs. The core power densities range from 286 to 447 $\mathrm{kw} /$ liter, and the values of average specific power range from a low of around $660 \mathrm{kw} / \mathrm{kg}$ for the German design to a high of $940 \mathrm{kw} / \mathrm{kg}$ for the high pressure steam-cooled reactor, with the low pressure system in between at $740 \mathrm{kw} / \mathrm{kg}$. The data shown do not include power generated by the blanket, and are averaged over equilibrium cycles. 
Table 4.1. Generai Data for Steam-Cooled Fast Reactors

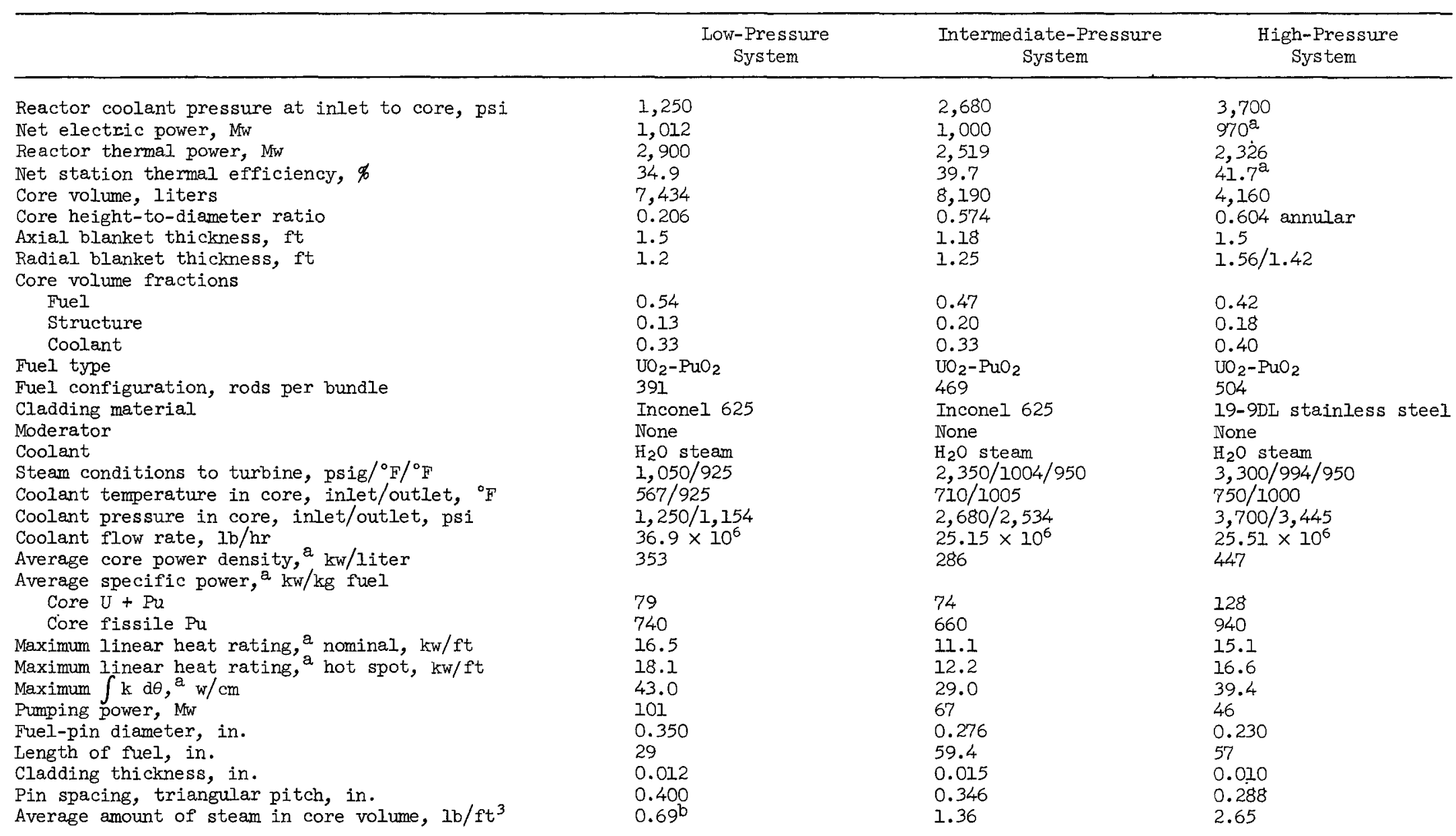

avalues determined by ORIL.

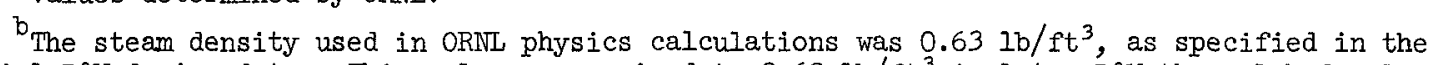
initial B\&W design data. This value was revised to $0.69 \mathrm{lb} / \mathrm{ft}^{3}$ in later B\&W thermal hydraulics studies. 
Table 4.1 (continued)

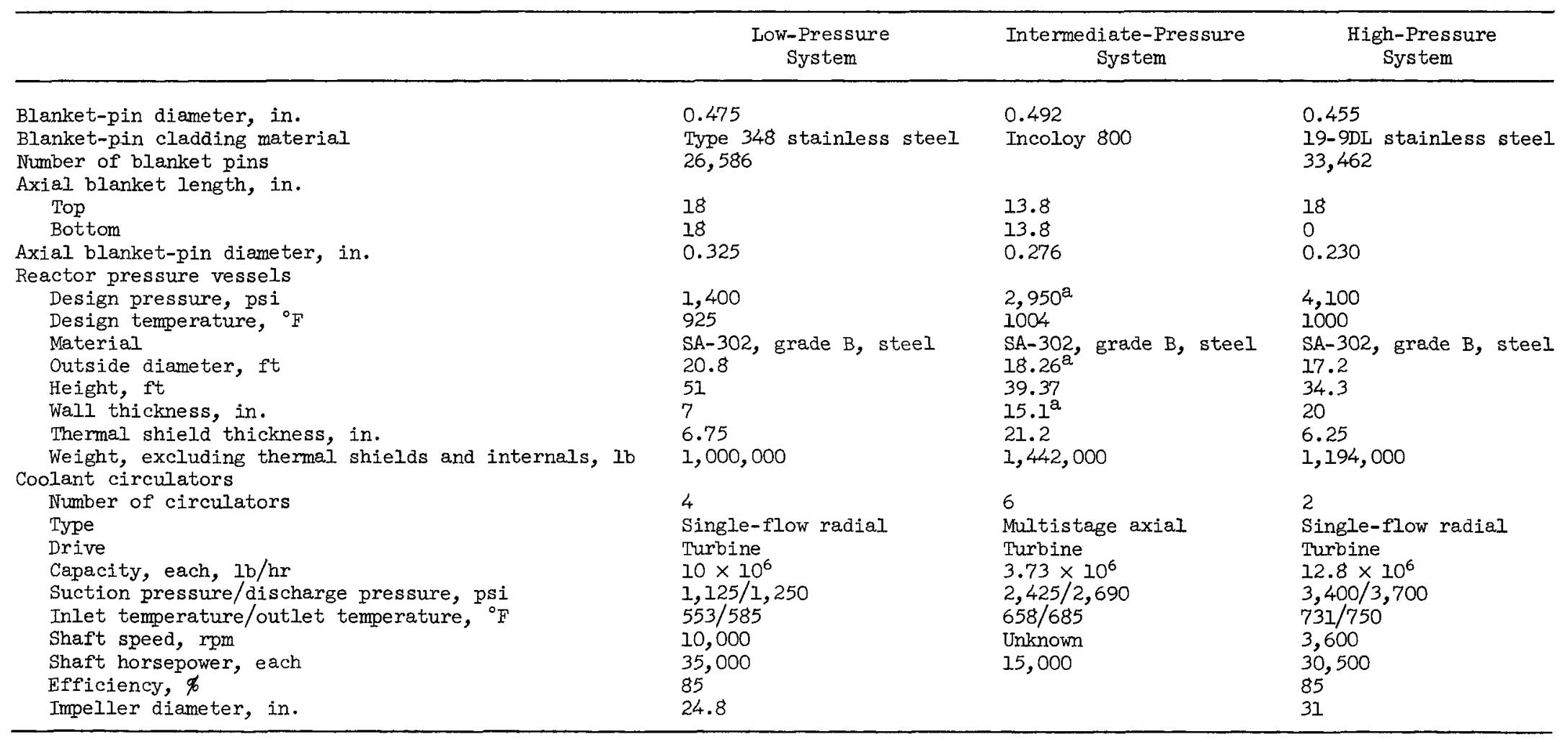


$=-2 n 0 / 4236$
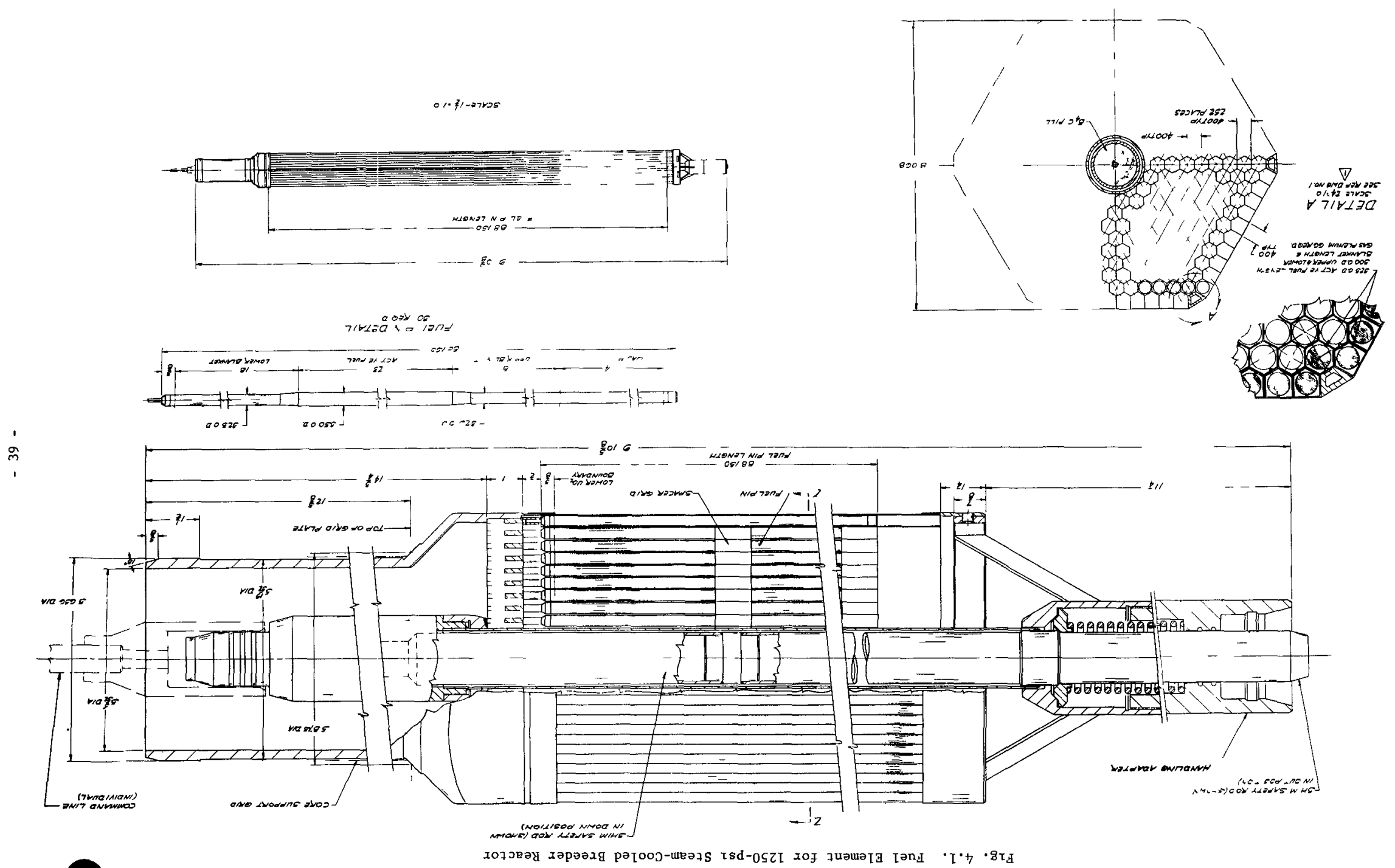

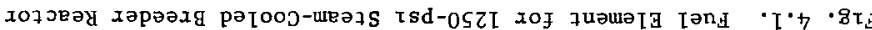




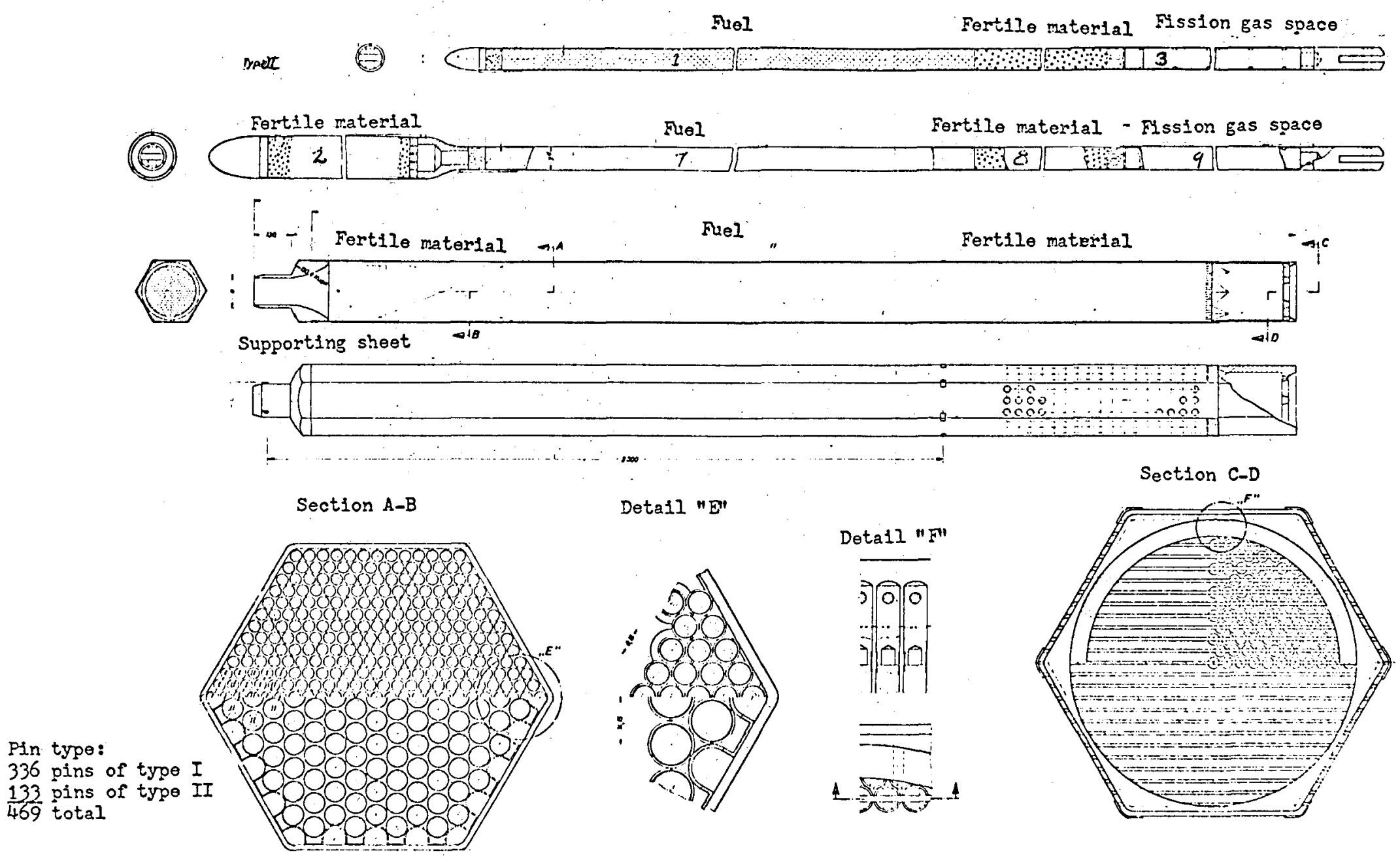

Fig. 4.2. Intermediate-Pressure (2680-psi) Steam-Cooled Reactor Fuel-Element Assembly. 

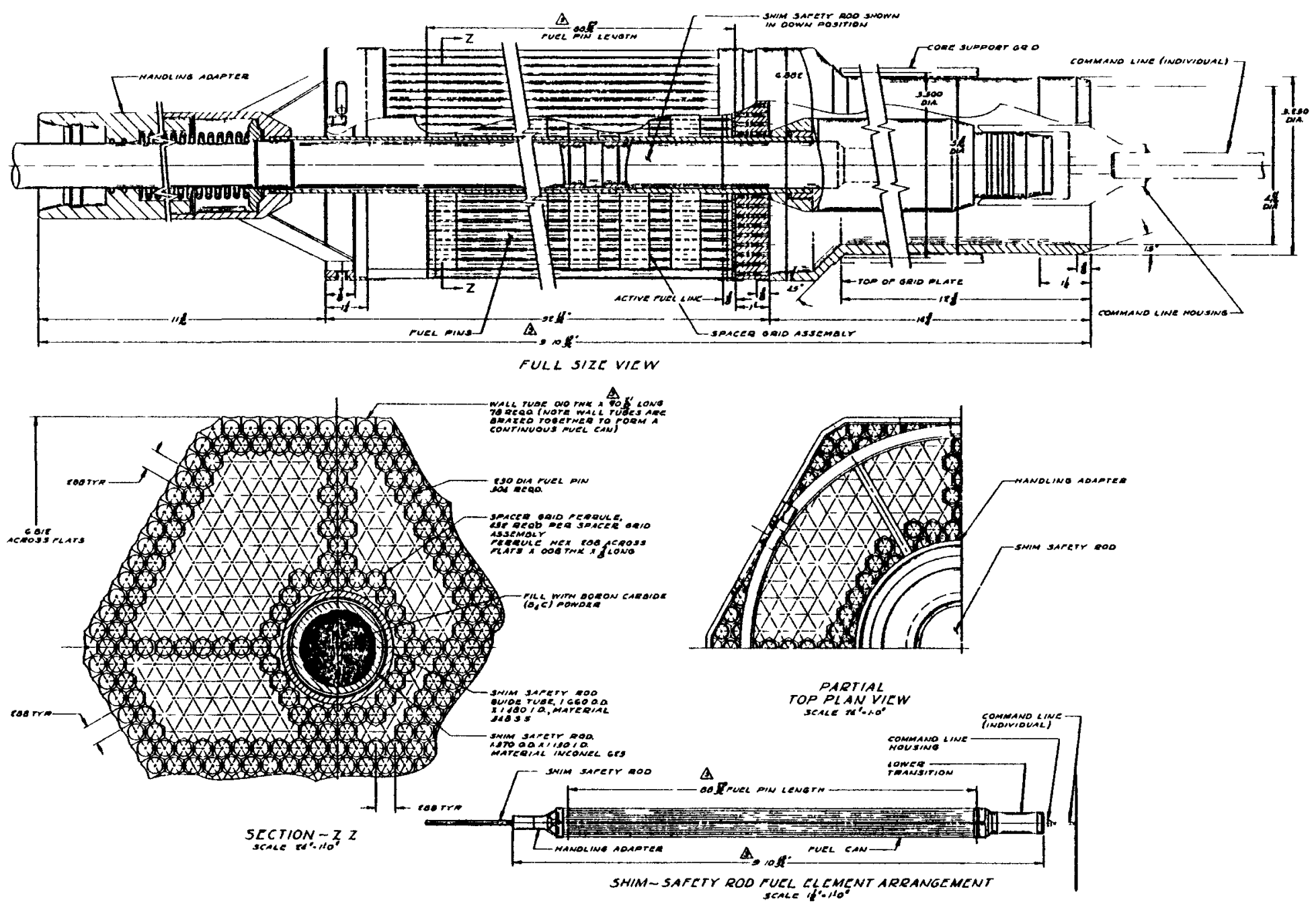

Fig. 4.3. Fuel Assembly for Mgh-Pressure (3700-psi) SCBR. 


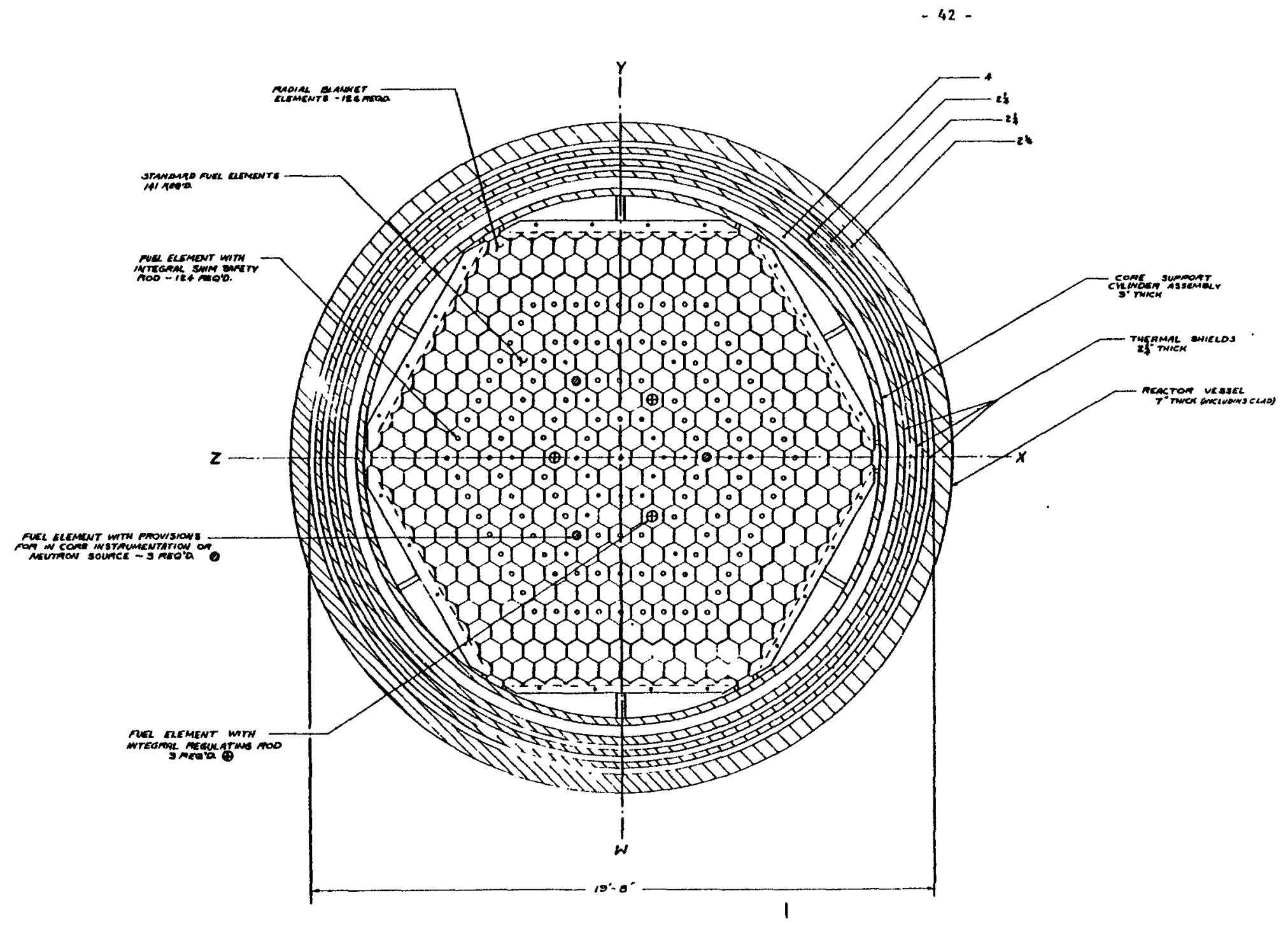

F1g. 4.4 Core Arrangement for Low-Pressure 1000-MW(e) SCBR. 


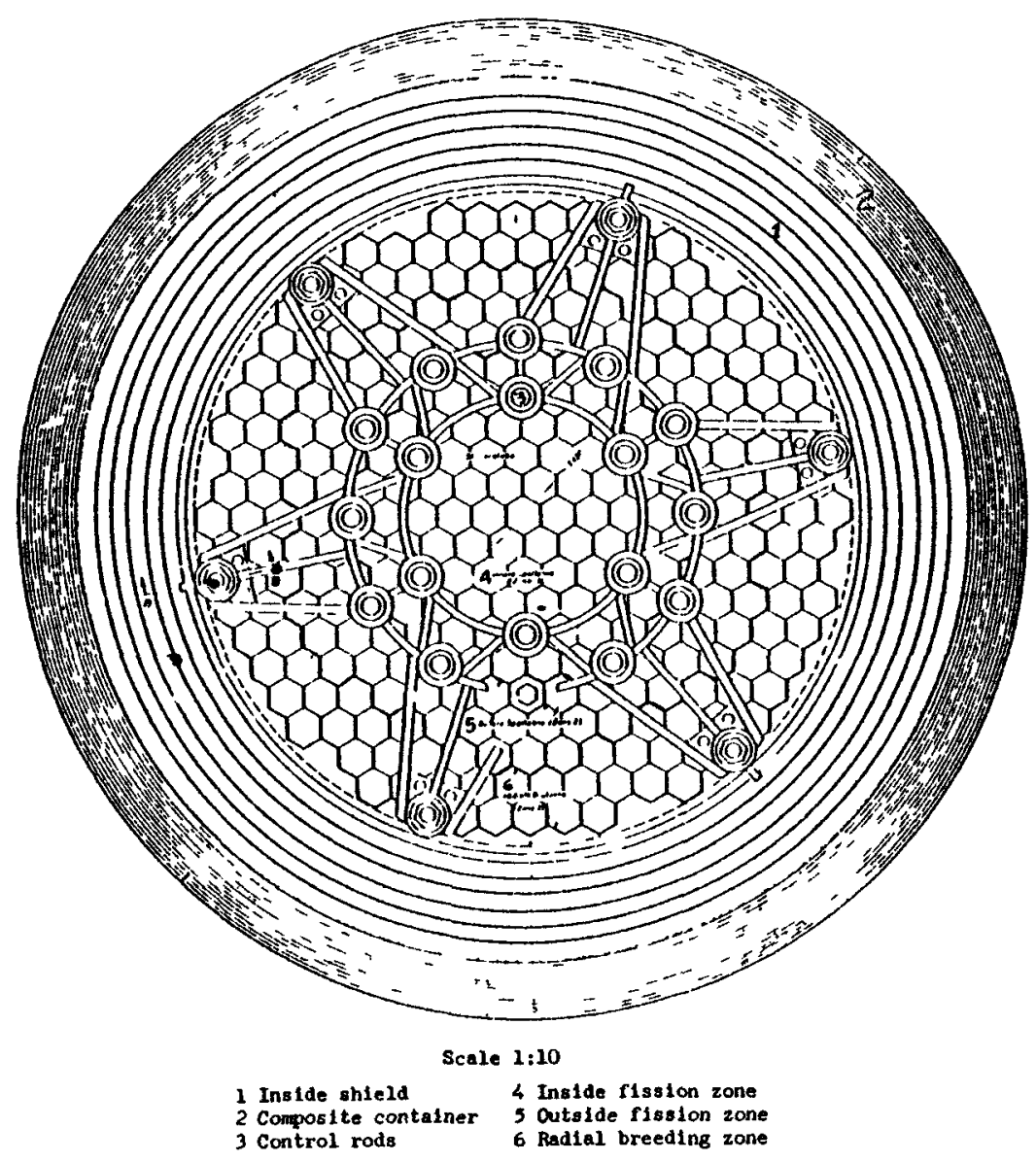

Fig. 4.5. Core Arrangement for Intermediate-Pressure 1000-Mw(e) SCBR. 


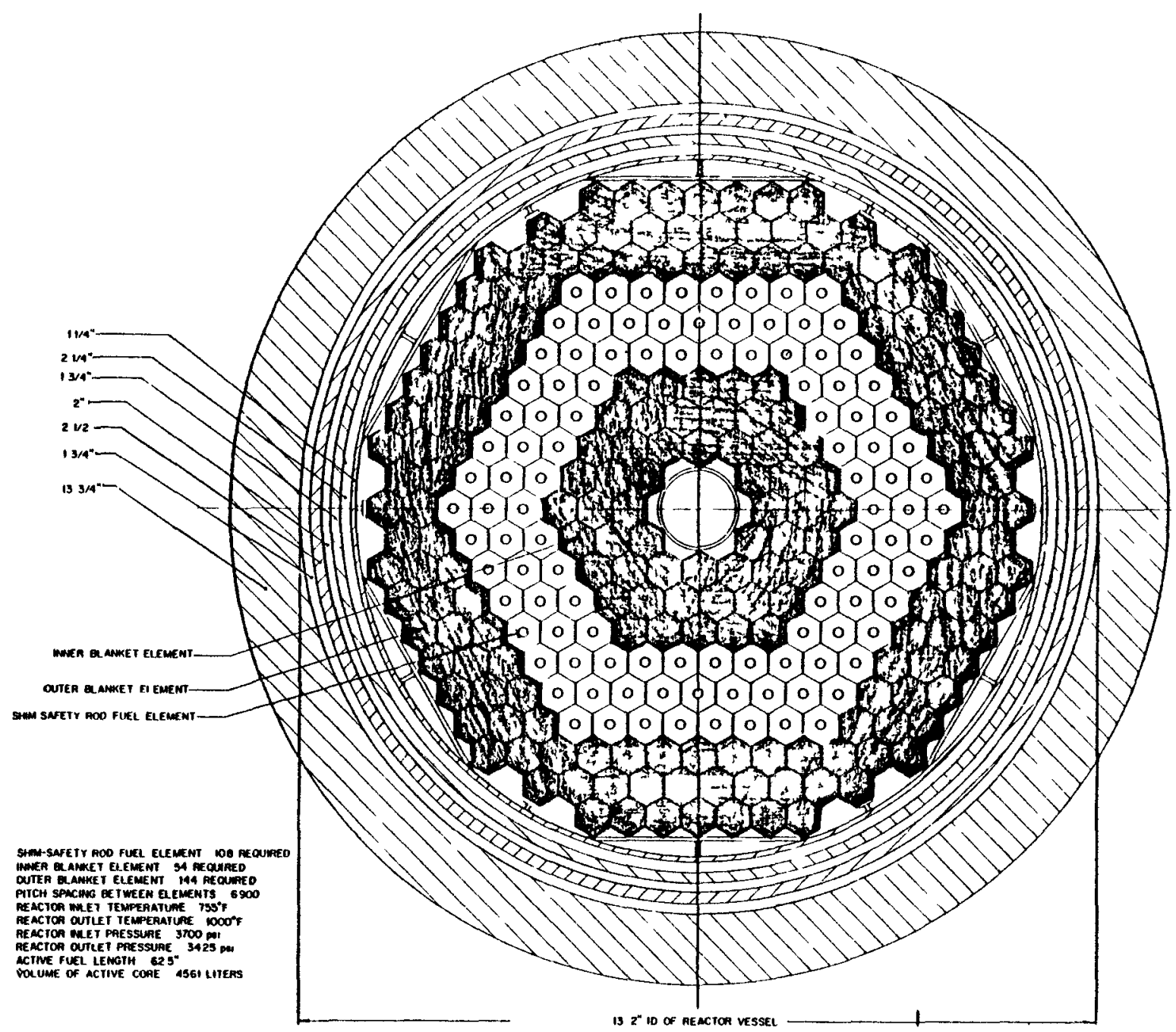

Fig 4.6. Core Arrangement for High-Pressure 1000-Mw(e) SCBR. 
4.1.3 Blanket

In each of the three concepts, the radial blankets are approximately 15 to $18 \mathrm{in.} \mathrm{thick,} \mathrm{and} \mathrm{the} \mathrm{axial} \mathrm{blankets} \mathrm{consist} \mathrm{of} \mathrm{extensions} \mathrm{of} \mathrm{the}$ fuel rod approximately $18 \mathrm{in}$. above the fuel section in all concepts and below it in all except the supercritical design. The annular core in the design for the supercritical steam-cooled system is sandwiched between inner and outer radial blankets.

\subsubsection{Coolant Flow Diagrams}

The schematic flow diagram for the low pressure steam-cooled breeder reactor (SCBR) shown in Fig. 4.7 illustrates a so-called "integral" design in which all recirculated steam remains inside the primary reactor vessel. The steam is generated by a direct contact boiler at the bottom of the vessel where feedwater is sprayed into direct contact with the superheated steam leaving the bottom of the core. In the other designs this boiler and the circulators are located external to the reactor vessel, as shown in Figs. 4.8 and 4.9. In the design illustrated in Fig. 4.7 , the only steam leaving the primary vessel is that required to operate the turbines that drive the electric generator and the circulators.

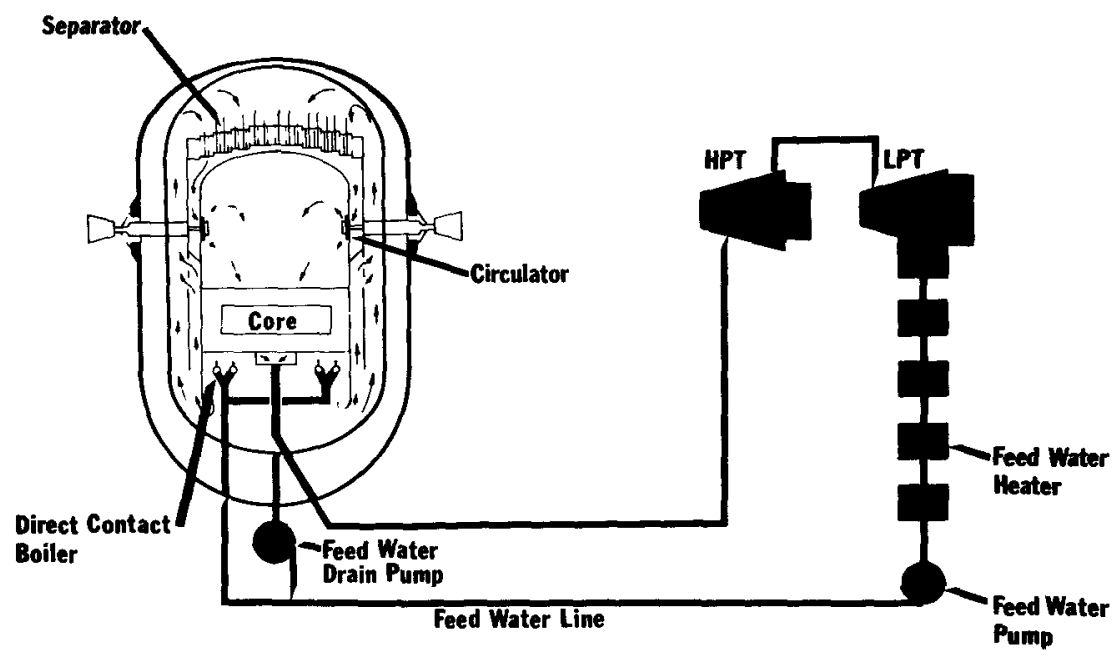

Fig. 4.7. Simplified Flow Diagram for a 1200-psi Steam-Cooled Breeder Reactor. 


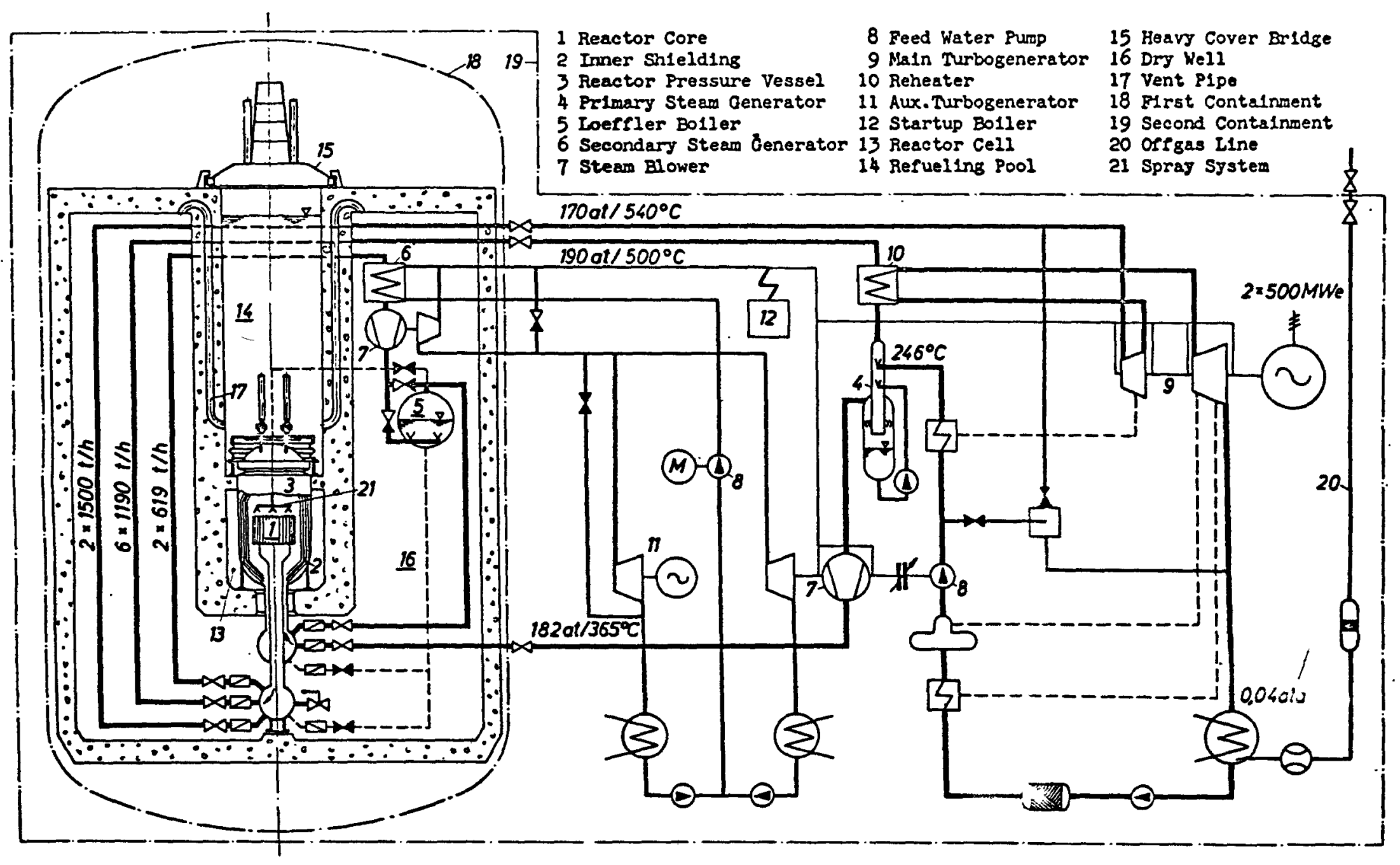

Fig. 4.8. Simplified Flow Diagram and Containment System for a $2680-$ psi Steam-Cooled Breeder Reactor. 


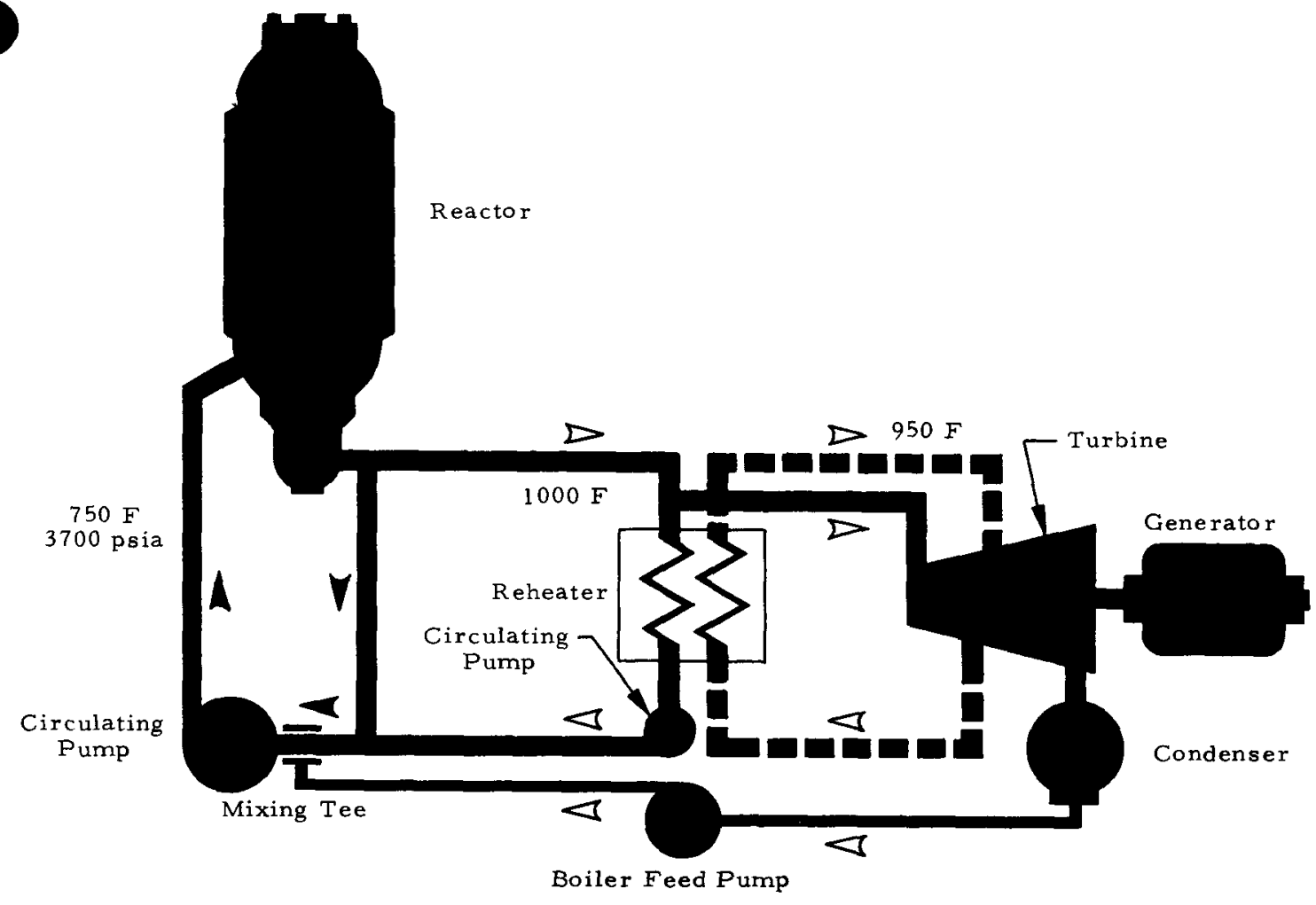

Fig. 4.9. Simplified Flow Diagram for the 3700-psi Steam-Cooled Fast Breeder Reactor.

The steam-cooled breeder reactor resembles the boiling water reactor in that it employs a direct cycle, with the steam from the reactor being used to drive the turbines. When reheat is necessary, steam-tosteam surface heat exchangers are used, as shown in Figs. 4.8 and 4.9.

\subsubsection{Reactor Vessels}

The steel vessels used for these concepts are fabricated of materials equivalent to $\mathrm{SA} 302$, grade $\mathrm{B}$, steel. A vertical cross-sectional view of the vessel for the low pressure steam-cooled breeder reactor is illustrated in Fig. 4.10, and the vessels used for the intermediate and high pressure steam-cooled reactors are shown in Figs. 4.11 and 4.12. The design for the low pressure steam-cooled system requires a somewhat larger vessel than is required for the systems with higher pressures. This is caused partially by the pancake shape of the core and partially 


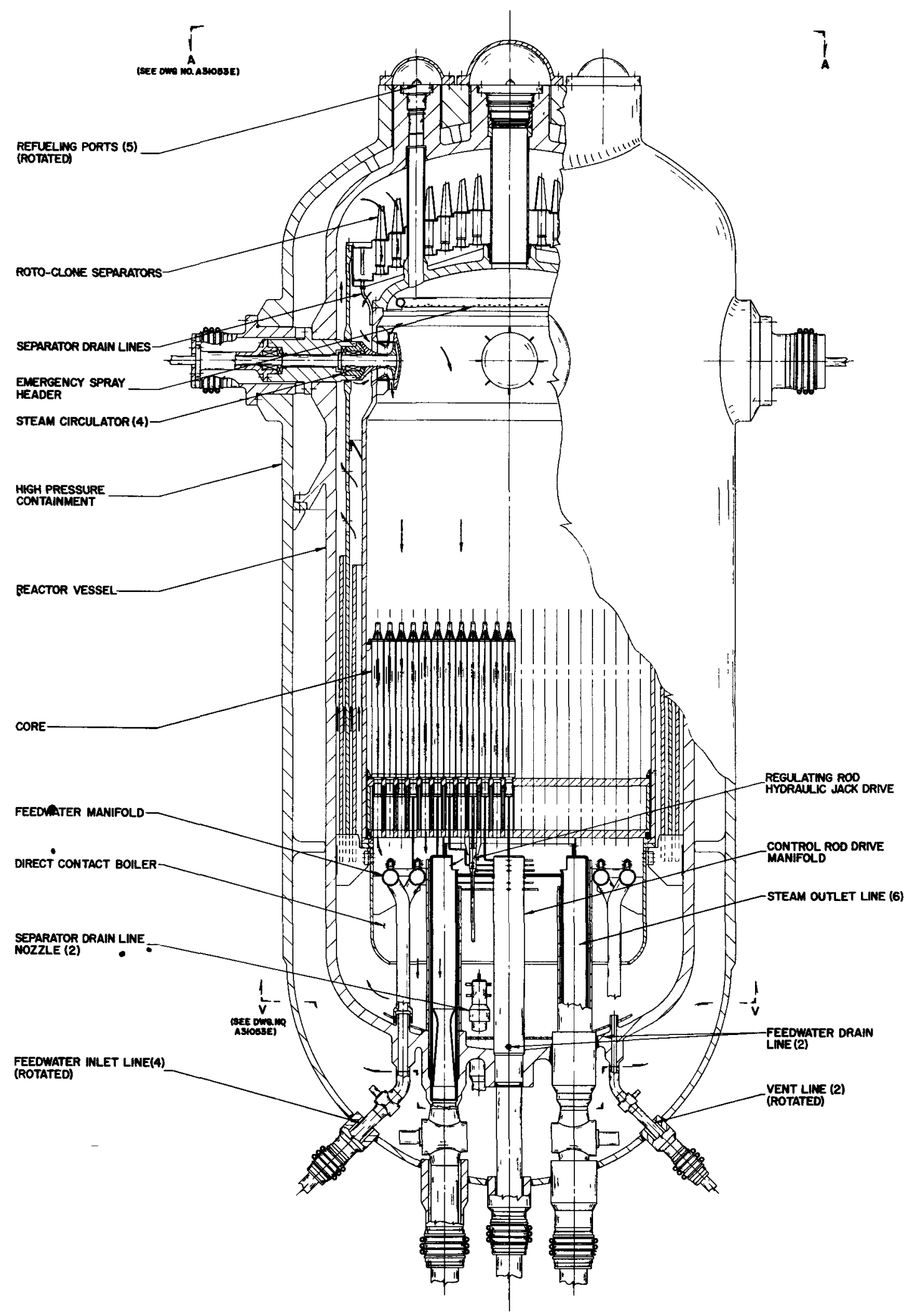

Fig. 4.10. Vertical Cross-Sectional View of the Vessel for the low Pressure Steam-Cooled Breeder Reactor. 
49

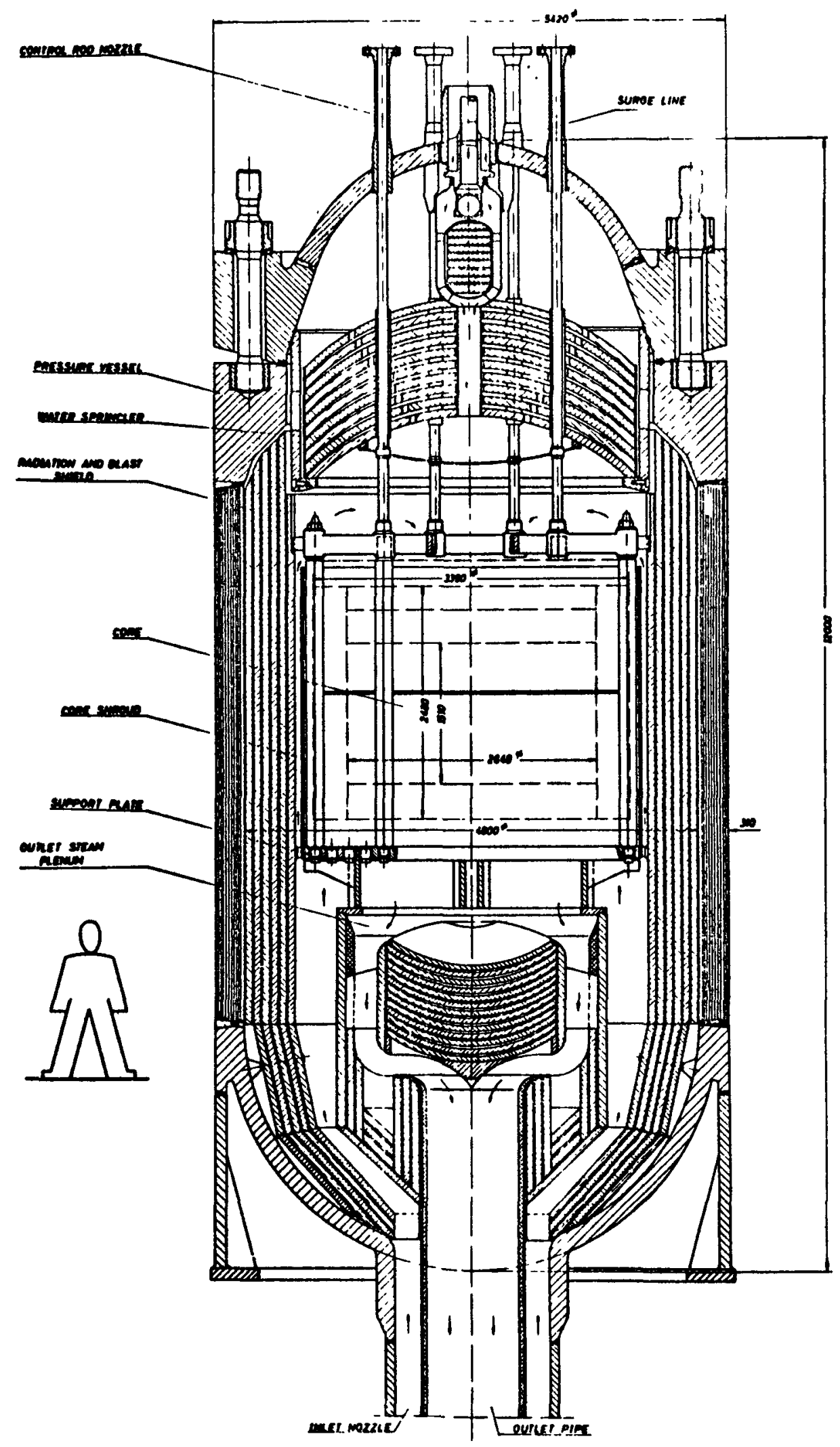

Fig. L. Ii. Vertical Cross-Sectional View of the Vessel for the Intermediate Pressure Steam-Cooled Breeder Reactor. 


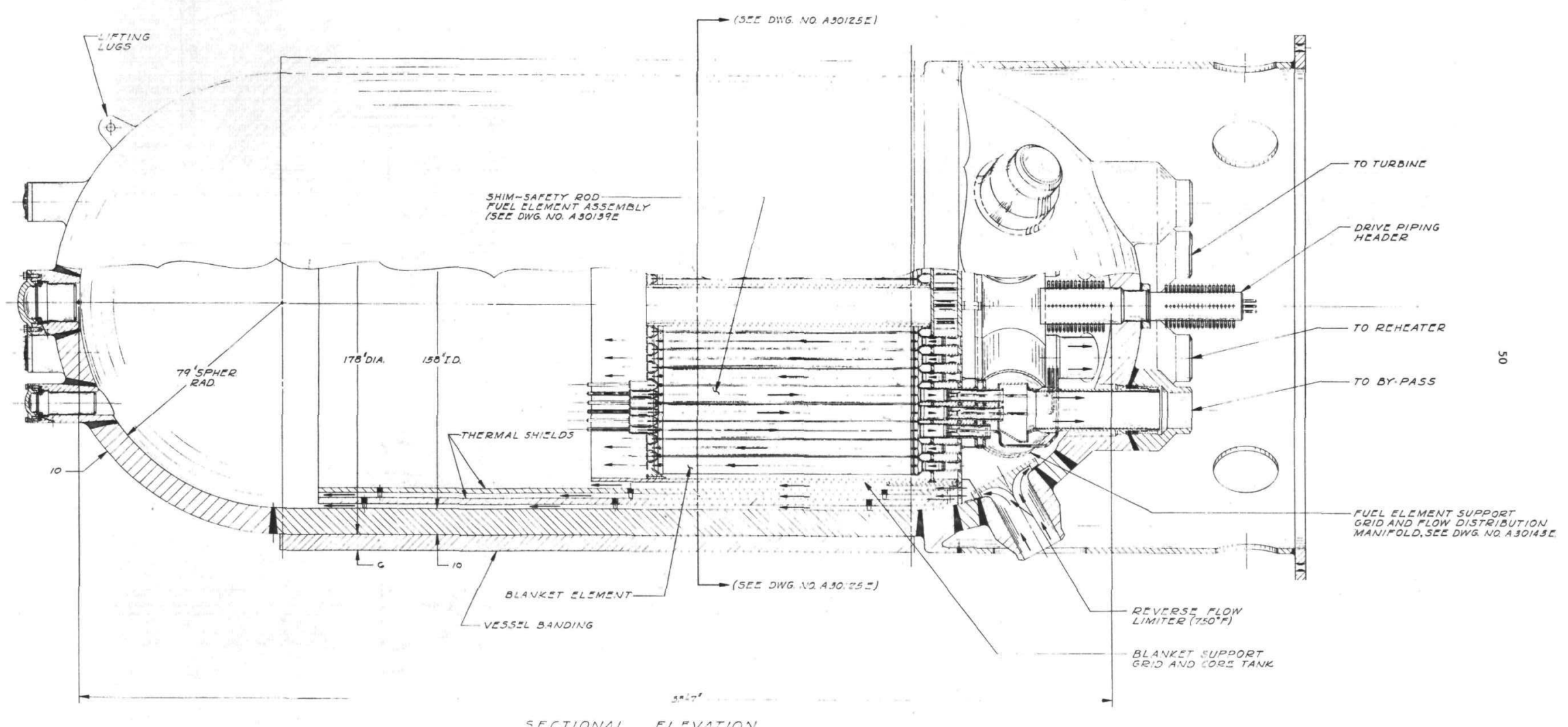

Fig. 4.12. Cross-Sectional View of the Vessel for the High-Pressure

Steam-Cooled Breeder Reactor 
by the incorporation of the steam generator and circulators within the vessel in the low pressure steam-cooled system. The German design differs from the B\&W designs shown here in having a removable head that permits access for complete removal of all components inside the reactor vessel. Later versions of the B\&W 1250-psi SCBR may also incorporate a flanged. upper head in addition to the refueling ports now shown. This added convenience appears justified in view of the modest additional cost involved.

The vessels for the low and high pressure steam-cooled systems are designed for fuel handling machines that operate through ports in the head or wall of the vessels. It is hoped that this practice will reduce the cost of construction, even though it may be necessary at some future time to cut the heads off the vessels to remove major components.

The German steam-cooled reactor has conventional control rod drive systems that require penetrations through the head of the vessel. The 1250- and 3700-psi systems designed by the Babcock \& Wilcox Company contain internal control rod drive mechanisms built into approximately half of the fuel element assemblies. These mechanisms are actuated by hydraulic pressure supplied from an external source through individual command lines penetrating the bottom of the vessel in a manifolded penetration. This is a novel means for driving control rods that will require some development. Iacking adequate development or success in developing the design of these mechanisms, it is reasonable to assume that the more conventional approach adopted in the German design is also applicable in the other steam-cooled systems.

\subsubsection{Steam Generators}

The steam for cooling all concepts is generated by what is known as a Ioeffler boiler in which steam from the reactor is mixed with the feedwater to produce equilibrium saturated steam, which is then piped to the suction of the steam circulator. In the intermediate and high pressure steam-cooled systems, this boiler is outside the reactor vessel. The high pressure "boiler" is simply a mixing tee because no change of phase is required in the supercritical region. In the intermediate pressure steam-cooled system, the boiler consists of a separate vessel outside the reactor vessel in which the feedwater is sprayed into the entering 
steam flow at the top of a vessel, the mixture falls downward, reverses direction, deposits excess water in the bottom of the vessel, and leaves at an exit near the top. Steam from the boiler is then pumped back to the reactor vessel to cool the reactor.

At a lower pressure, the latent heat of vaporization is higher, and a greater amount of superheated steam is required in the boiler for the low pressure steam-cooled system. This makes it advantageous to circulate the heating steam within the vessel rather than through pipes outside the vessel because the size of the pipes carrying the steam would be very large. Therefore, the steam generators for the low pressure steam-cooled reactor are located in the bottom of the reactor vessel, and the circulators are inserted through penetrations in the wall of the vessel. Thus, all the recirculated steam remains inside the vessel, and only that required for driving the turbines is carried outside the vessel through pipes.

\section{1 .7 Circulators}

Centrifugal circulators are used in all but the intermediate pressure steam-cooled system, which has a multistage axial flow machine. All circulators are turbine driven, with the drive turbines exhausting either to feedwater heaters, condensers, or the low pressure cylinder of the main turbines. In most cases, throttle steam for these drive turbines is taken directly from the main steam leaving the reactor core.

\subsubsection{Containment}

Containment philosophy for the steam-cooled breeder reactors varies according to the designer and his current thinking. The cross-sectional view of the reactor vessel for the low pressure steam-cooled reactor, Fig. 4.10, shows the closely fitting secondary containment structure around the primary reactor vessel. This containment vessel is designed so that a rupture of the primary system within its confines would result in only a partial reduction of pressure. As long as the external piping remained intact and the cooling system remained functional, it would be possible to continue cooling the reactor by pumping feedwater into the boiler section of the vessel, generating steam, and circulating it through the core. 
If the coolant system were not functional, the pressure resulting from this type of failure would still be high enough for some convective cooling and for adequate cooling by use of the emergency and shutdown cooling systems. A third vessel designed for a low pressure surrounds the entire system to contain the fluids released in event of rupture of the secondary vessel shown in the figure.

The intermediate pressure steam-cooled breeder reactor is contained in a secondary gastight container designed for a pressure of approximately $37 \mathrm{psig}$. This container is cast into the foundation of the reactor building. The reactor building is also gastight, and both the building and the containment vessel are entered only through air locks. The containment systems for all three concepts are described more completely in Ref. 20 .

\subsubsection{Shutdown and Emergency Cooling Systems}

The shutdown and emergency cooling system proposed for use in the low pressure steam-cooled reactor system is illustrated in Fig. 4.13, and

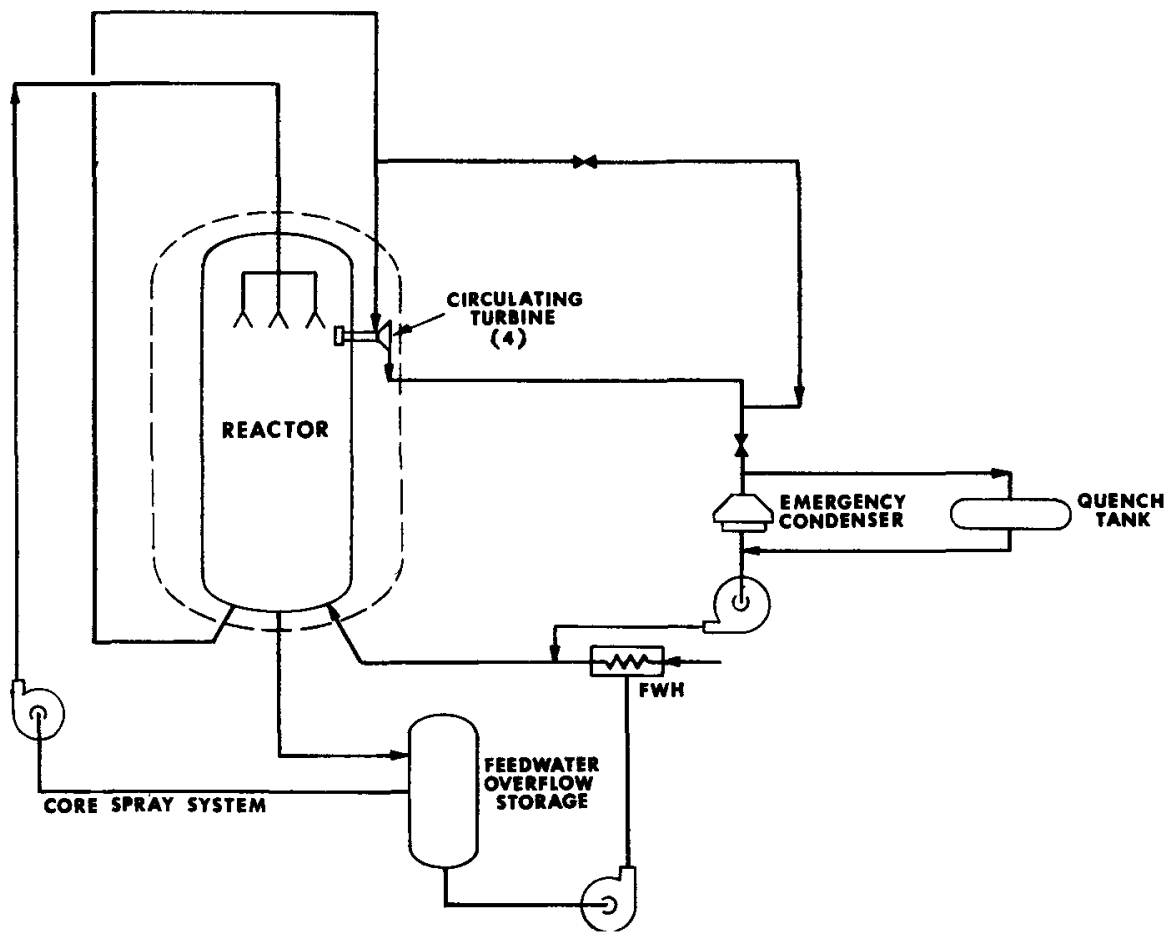

Fig. 4.13. Diagram of Shutdown and Emergency Cooling Systems t'or ow. Pressure Steam-Cooled Fast Breeder Reactor. 
a diagram of the system proposed for use in the intermediate pressure steam-cooled reactor system is shown in Fig. 4.14. The low pressure system provides for operation of the circulators under shutdown conditions by diverting the drive-turbine exhaust steam to an emergency condenser so that normal flow of the coolant within the reactor can be maintained. As a last resort, the core spray system is provided to supply water from the feedwater storage tank to sprays above the reactor core. The intermediate pressure steam-cooled reactor design includes two secondary steam

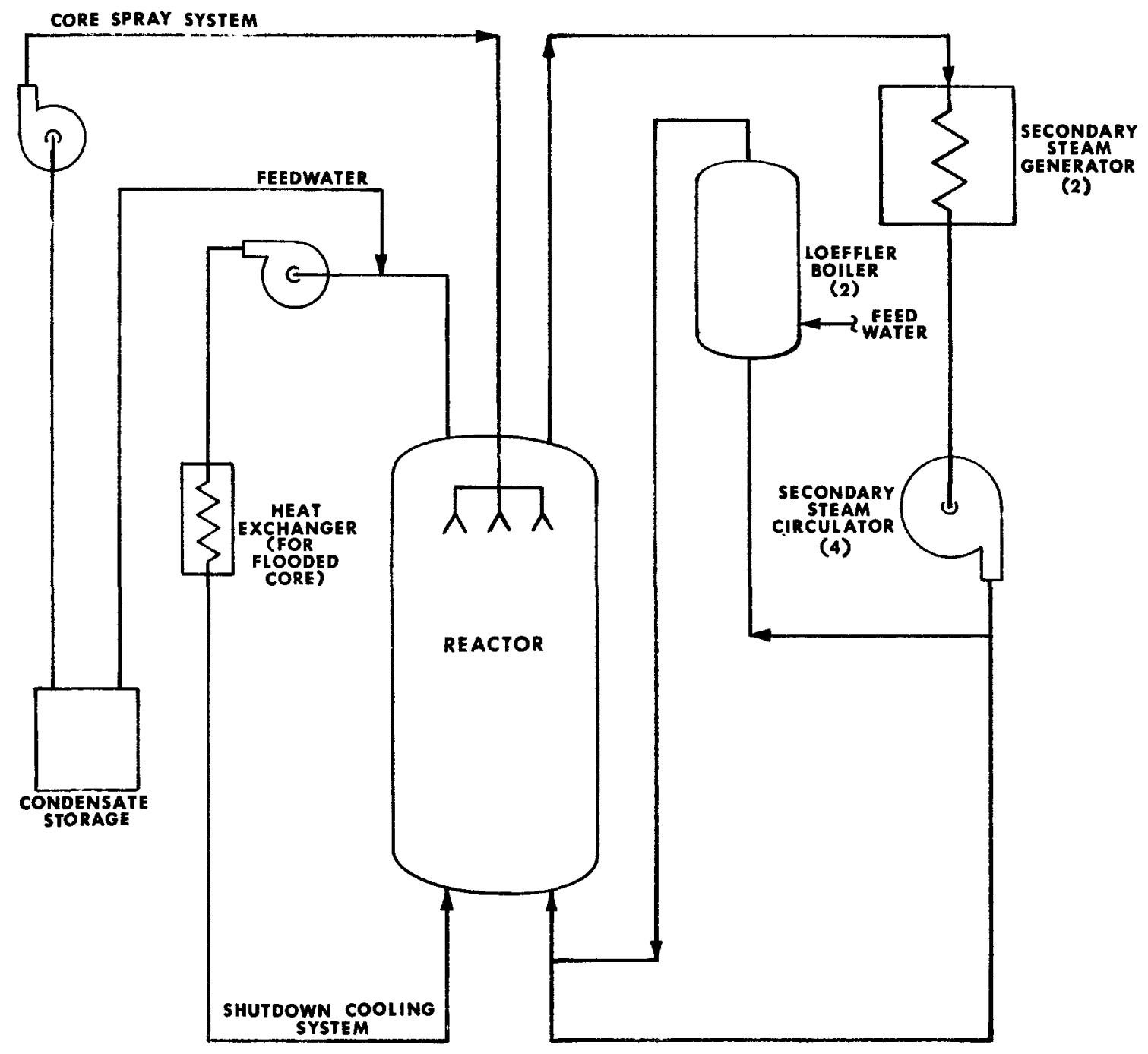

Fig. 4.14. Shutdown and Emergency Cooling Systems for Intermediate Pressure Steam-Cooled Fast Breeder Reactor. 
systems operating continuously during reactor operation, and a special cooling system in parallel with the secondary and primary steam systems for operation when the reactor is flooded after shutdown. An emergency core spray system is provided as backup for those systems.

\subsection{Gas-Cooled Fast Reactors (GCFR)}

The gas-cooled fast breeder reactor (GCFR) is a helium-cooled reactor that utilizes stainless steel-clad, small diameter oxide fuel pins. The reactor core, helium circulation system, and steam generators are housed in a prestressed concrete pressure vessel, which also serves as the biological shield. Electricity is generated from a high pressure steam cycle with a net plant thermal efficiency of about $40 \%$.

Three GCFR designs were developed by GGA. These are:

1. reference oxide fueled design with relatively high values for maximum pin heat rating and cladding temperature (GCFR-4);

2. derated oxide fueled design (GCFR-4D); limit on cladding temperature set $50^{\circ} \mathrm{C}$ below that for reference design; and

3. reference carbide fueled design (GCFR-C).

4.2.1 Oxide Fueled GCFR-4

The oxide fueled GCFR-4 designs are intended to illustrate the prospects of the gas-cooled fast breeder system in its early stages of development; it will have a well-understood fuel (mixed oxides in round stainless steel tubing), and the coolant pressure will be limited to present containment capability. The designs have not been fully optimized but should be representative of the cost potential to be realized from fully developed GCFR designs with oxide fuels. The reference design, GCFR-4, is considered by GGA to represent performance characteristics achievable after a reasonable amount of research and development. The derated design, GCFR-4D, has slightly more conservative temperature requirements and is based on a $650^{\circ} \mathrm{C}$ maximum nominal cladding temperature, compared with $700^{\circ} \mathrm{C}$ for the reference design. Steam conditions were altered to suit the new core temperature rather than arbitrarily requiring that the steam conditions be the same as for the reference design. Some 
principal characteristics of the two oxide fueled designs are given in Table 4.2 .

The entire primary system, including the steam generators, the helium circulators, and the reactor core, is housed within a prestressed concrete pressure vessel (PCRV), as illustrated in Fig. 4.15. The design features use of a horizontal PCRV that houses a centrally located vertical reactor core, with four boilers and associated circulators located in internally isolated compartments at either end of the vessel. The PCRV has double containment of all penetrations, individual access standpipes above each core and blanket element, and a water-cooled, but uninsulated, steel liner. The whole primary circuit flow path is confined within insulated ducting and shells surrounding the reactor and

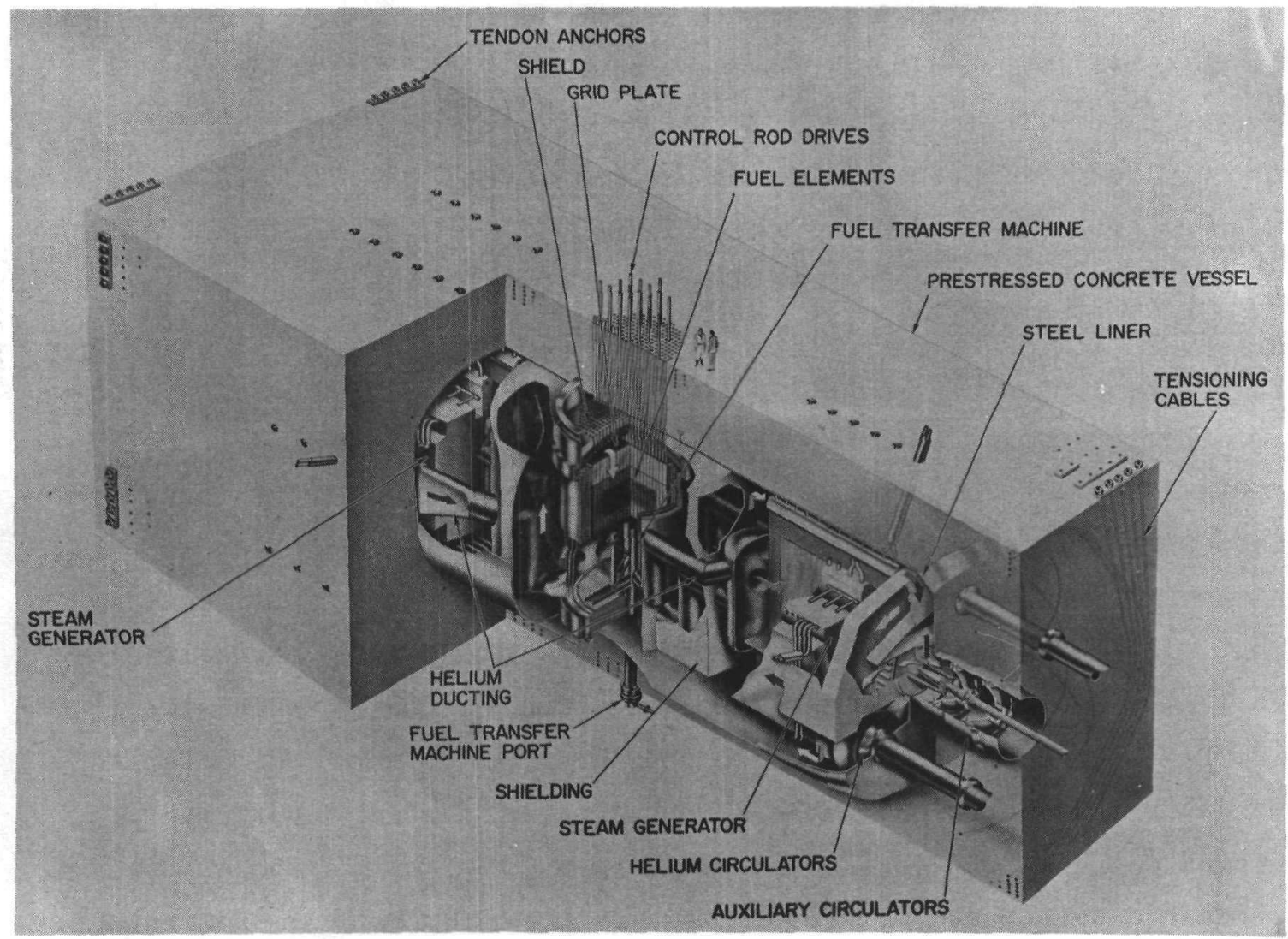

Fig. 4.15. Artist's Concept of the Prestressed Concrete Reactor Vessel and Internals for the 1000-Mw(e) Gas-Cooled Fast Reactor. 
Table 4.2. Summary of Oxide-Fueled GCFR Design Characteristics ${ }^{\text {it }}$

\begin{tabular}{|c|c|c|}
\hline & GCFR-4 Reference Design & GCFR-4D Derated Design \\
\hline \multicolumn{3}{|l|}{ Power } \\
\hline Reactor nuclear power, Mw & 2530 & 2681 \\
\hline Net electrical power, Mw & 1000 & 1000 \\
\hline Net thermodynamic efficiency, $\not$ & 39.5 & 37.3 \\
\hline \multicolumn{3}{|l|}{ Coolant } \\
\hline Composition & Helium & Helium \\
\hline Core inlet pressure, psia & 1250 & 1250 \\
\hline Reactor pressure drop, psi & 42.6 & 42.6 \\
\hline Flow rate, $\mathrm{lb} / \mathrm{hr}$ & $12.53 \times 10^{6}$ & $14.44 \times 10^{6}$ \\
\hline \multicolumn{3}{|l|}{ Temperatures, ${ }^{\circ} \mathrm{F}\left({ }^{\circ} \mathrm{C}\right)$} \\
\hline Reactor inlet & $629(332)$ & $589(308)$ \\
\hline Core inlet & $635(334)$ & $595(313)$ \\
\hline Core outlet & $1183(639)$ & $1088(587)$ \\
\hline Reactor outlet & $1190(643)$ & $1094(590)$ \\
\hline \multicolumn{3}{|l|}{ Steam plant conditions } \\
\hline \multicolumn{3}{|l|}{ Leaving superheater } \\
\hline Pressure, psia & 2515 & 1850 \\
\hline Temperature, ${ }^{\circ} \mathrm{F}$ & 1000 & 900 \\
\hline Condenser pressure, in. $\mathrm{Hg}$ & 1.5 & 1.5 \\
\hline \multicolumn{3}{|l|}{ Core thermal performance (at $100 \%$ power) } \\
\hline $\begin{array}{l}\text { Peak linear heat rating, } \mathrm{kw} / \mathrm{ft} \\
\text { Maximum cladding surface temperature, }{ }^{\circ} \mathrm{F}\left({ }^{\circ} \mathrm{C}\right)\end{array}$ & 17.8 & 16.3 \\
\hline Nominal & $1315(713)$ & $1205(652)$ \\
\hline Local hot spot & 1435 (779) & $1315(713)$ \\
\hline \multicolumn{3}{|l|}{ Maximum interior fuel temperature, ${ }^{\mathrm{b}}{ }^{\circ} \mathrm{F}\left({ }^{\circ} \mathrm{C}\right)$} \\
\hline Nominal & $4935(2724)$ & $4765(2629)$ \\
\hline Local hot spot & $5205(2824)$ & $5039(2787)$ \\
\hline reak-to-average core power ratio & 1.47 & 1.47 \\
\hline Mean core power density, kw(th)/Iitex & 280 & 260 \\
\hline Mean fissile fuel rating, Mw $(\mathrm{th}) / \mathrm{kg}$ & 0.86 & 0.82 \\
\hline \multicolumn{3}{|l|}{ Core and blanket description } \\
\hline Active core volume, liters & 8510 & 9712 \\
\hline Active core length, cm (in.) & $148.2(58.4)$ & $154.8(60.9)$ \\
\hline Active core diameter, $\mathrm{cm}$ (in.) & $269.5(106.0)$ & $281.5(110.8)$ \\
\hline Axial blanket thickness, cm (in.) & $60(23.6)$ & $60(23.6)$ \\
\hline Radial blanket thickness, cm (in.) & $51(20.1)$ & $51(20.1)$ \\
\hline Core length-to-diameter ratio & 0.55 & 0.55 \\
\hline Fuel material (core) & Mixed $\mathrm{Pu}$ and depleted $\mathrm{UO}_{2}$ (90\% T.D.) & Mixed $\mathrm{Pu}$ and depleted $\mathrm{UO}_{2}$ (90\% T.D.) \\
\hline Fuel material (blanket) & Depleted $\mathrm{UO}_{2}$ ( $90 \%$ T.D.) & Depleted $\mathrm{UO}_{2}$ (90\% T.D.) \\
\hline Fuel distribution & $\begin{array}{l}\text { Uniform axially; zoned radially to give } \\
1.2 \text { radial maximum-to-mean ratio }\end{array}$ & $\begin{array}{l}\text { Uniform axially; zoned radially to give } \\
1.2 \text { radial maximum-to-mean ratio }\end{array}$ \\
\hline
\end{tabular}

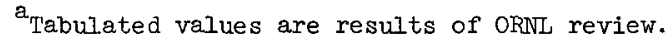

${ }^{b}$ Calculated fuel temperatures above melting point of the oxide $\left(4950^{\circ} \mathrm{F}\right)$ indicate that, according to ORNL calculations, local melting will probably occur. 


\begin{tabular}{|c|c|c|}
\hline & GCFR-4 Reference Design & GCFR-4D Derated Design \\
\hline \multicolumn{3}{|l|}{ Core fuel box } \\
\hline Structure & Fuel in square pitched boxes of 225 rods & Fuel in square pitched boxes of 225 rods \\
\hline \multicolumn{3}{|l|}{ Fuel box length } \\
\hline Active length, cm (in.) & $148.3(58.4)$ & $1.54 .7(60.9)$ \\
\hline Top and bottom blankets (each), cm (in.) & $60(23.6)$ & $60(23.6)$ \\
\hline Total length, cm (in.) & $284.5(112)$ & $289.6(114)$ \\
\hline Fuel box inside dimension (square), cm (in.) & $17.12(6.75)$ & $16.95(6.67)$ \\
\hline Fuel box thickness, cm (in.) & $0.23(0.09)$ & $0.23(0.09)$ \\
\hline Core pin design & Pressure equalized, partially roughened & Pressure equalized, partially roughened \\
\hline Fuel pellet diameter, cm (in.) & $0.739(0.291)$ & $0.716(0.283)$ \\
\hline Fuel pellet central hole diameter, cm (in.) & $0.147(0.058)$ & $0.142(0.056)$ \\
\hline Can thickness, cm (in.) & $0.0295(0.0116)$ & $0.0287(0.0123)$ \\
\hline Can material & Stainless steel & Stainless steel \\
\hline Fuel rod diameter, cm (in.) & $0.805(0.317)$ & $0.708(0.307)$ \\
\hline Fuel rod pitch (square), cm (in.) & $1.141(0.450)$ & $1.130(0.445)$ \\
\hline \multicolumn{3}{|l|}{ Number of rods per box } \\
\hline Standard boxes & 225 & 225 \\
\hline Control-rod boxes & 189 & 189 \\
\hline \multicolumn{3}{|l|}{ Number of boxes } \\
\hline Control-rod boxes & 21 & 21 \\
\hline \multicolumn{3}{|l|}{ Core volume fractions } \\
\hline Fuel (90\% T.D.) & 0.2896 & 0.2772 \\
\hline Central hole & 0.0120 & 0.0114 \\
\hline Cladding & 0.0501 & 0.0480 \\
\hline \multirow{3}{*}{$\begin{array}{l}\text { Box structure, gaps, and control-rod blockage } \\
\text { Coolant }\end{array}$} & 0.1000 & 0.1000 \\
\hline & 0.5483 & 0.5634 \\
\hline & 1.0000 & 1.0000 \\
\hline \multicolumn{3}{|l|}{ Radial blanket box ${ }^{c}$} \\
\hline Fuel pellet diameter (no central hole), $\mathrm{cm}$ (in.) & $1.092(0.430)$ & $1.092(0.430)$ \\
\hline Can thickness, cm (in.) & $0.051(0.020)$ & $0.051(0.020)$ \\
\hline Fuel rod diameter, cm (in.) & $1.194(0.470)$ & $1.194(0.470)$ \\
\hline Fuel rod pitch, cm (in.) & $1.321(0.520)$ & $1.321(0.520)$ \\
\hline Roughening & None & None \\
\hline Coolant void fraction in box & 0.354 & 0.354 \\
\hline \multicolumn{3}{|l|}{ Number of boxes } \\
\hline Standard boxes & 1.54 & 162 \\
\hline Control-rod boxes & 8 & 8 \\
\hline
\end{tabular}

\footnotetext{
Uunless noted, blanket specifications are identical to those for the core.
} 
the boilers, and thus the main internal compartments are at substantially room temperature. These compartments are continuously purged by clean helium. The PCRV has an exterior shape of a square prism $140 \mathrm{ft}$ long and 55 ft square. The internal cavity has a transverse cross section which is that of a supercircle with a maximum span dimension of $35 \mathrm{ft}$ and a minimum span dimension of $31 \mathrm{ft}$. The cavity length is $110 \mathrm{ft}$. Prestressing in the PCRV is accomplished by a system of posttensioned steel tendons running axially, circumferentially, and across the ends.

The reactor core is assembled inside a vertical cylindrical steel pressure shell, called the core barrel, which spans the PCRV from top to bottom. The core barrel serves the multiple purpose of supporting the core grid plate, containing and directing the flow of coolant, and acting as a thermal shield. The core consists of bundles of small diameter fuel rods contained in thin walled square metal boxes. These fuel boxes are cantilevered downward from the deep section grid plate. A pictorial schematic view of the fuel element and grid plate arrangement is shown in Fig. 4.16. Figure 4.17 shows a plan view of the core and cross sections of the standard core and blanket elements.

Both oxide fueled designs have stainless steel clad oxide fuel pins about $0.3 \mathrm{in}$. in diameter. The cladding surface is intentionally roughened over approximately 60 to $70 \%$ of the active core length to optimize pumping power versus maximum cladding temperature. This roughening is designed to enhance the heat transfer coefficient in the downstream portion of the core and, thereby, prevent excessive cladding surface temperatures.

Previous GCFR designs by GGA had hermetically sealed fuel pins, with the internal fission product gas pressure buildup being limited by providing a void extension about 3 ft long at the upper end of each fuel pin. The designs reviewed in this study incorporate an alternate fuel element design recommended by GGA $^{19}$ that has a pressure equalizing collection system to vent the fission product gases to a receptacle that is isolated from the coolant system. This manifolding system eliminates the large gas pressure differential across the cladding but does not allow the fission product gases to escape into the local coolant, as has been proposed for sodium-cooled reactors. 


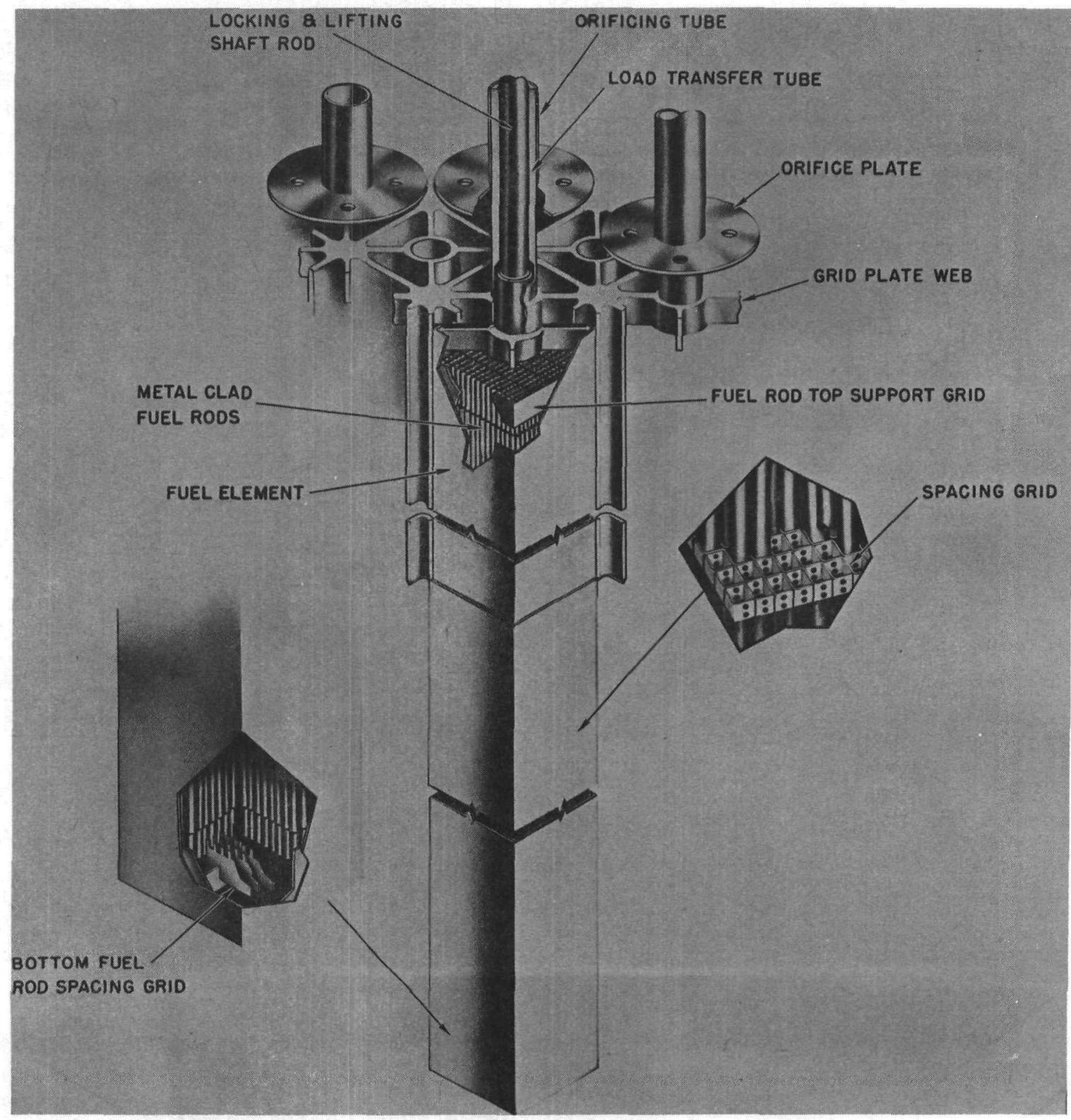

Fig. 4.16. Artist's Concept of Fuel Element for 1000-Mw(e) GCFR-4.

Refueling is carried out with the reactor shut down and at atmospheric pressure, with either air or helium in the vessel. The fuel handling machine is placed in the large plenum space beneath the core by raising it through a port in the botttom of the vessel. This machine has a vertical receptacle tube that can be positioned under any core or blanket element. Spent fuel elements are removed from the core by lowering 

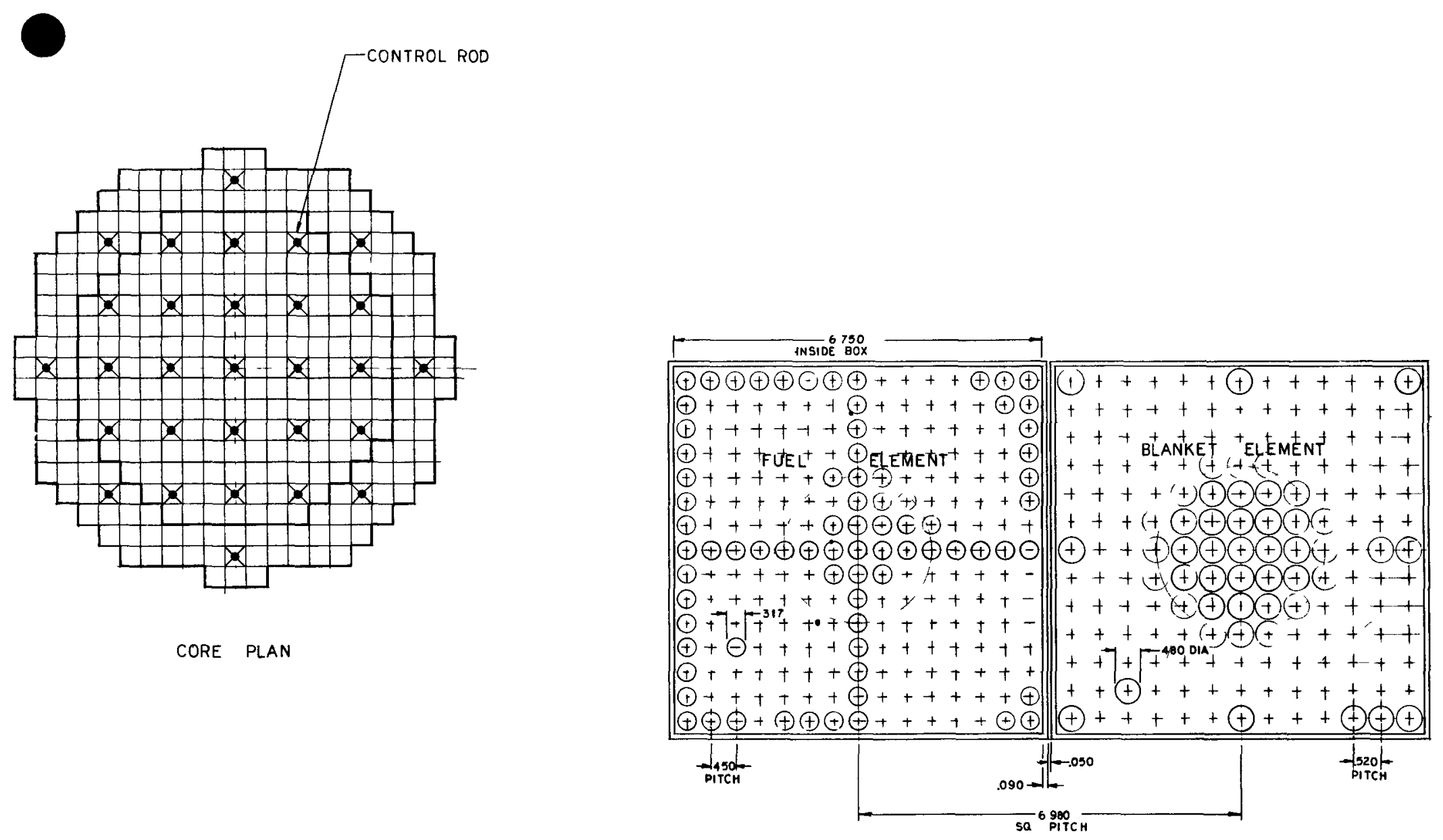

Fig. 4.17. Plan View of Core, Fuel Element, and Blanket Element of GCFR-4 
them into the receptacle tube by means of reach rods extending through the nozzles in the top of the pressure vessel. They are then transferred to a spent fuel removal port in the bottom of the vessel, through which they are discharged to a storage pit beneath the vessel. New fuel is handled with the reverse of this procedure through another bottom port. Cooling of the fuel is provided during all stages of the fuel transfer.

The fuel cycle utilizes single batch loading of the core with the plutonium-to-uranium ratio chosen to give roughly flat reactivity as a function of time. The axial blankets are replaced with each core loading, since the core and axial blankets are loaded in a continuous fuel rod. The inner third of the radial blanket is replaced with each core loading, and the outer two-thirds is replaced every third cycle.

\subsubsection{Reference Carbide Fueled Design (GCFR-C)}

The carbide fueled design is intended to demonstrate the performance potential achievable in a more advanced version of the GCFR, such as might be available by the end of the period 1980 to 1990. The performance goals for an improved reactor include breeding with short doubling times and the production of low cost power. To achieve these ends, carbide fuel was selected because of its advantages in fuel density, thermal conductivity, and conversion ratio. In addition, the working pressure was raised from 1250 to 1750 psi, vich allows a considerable increase in core power density and fuel specific power.

Principal characteristics of oxide and carbide fueled GCFR's are compared in Table 4.3. The use of carbide fuel and a higher working pressure leads to core volumes about one-half those of the oxide design, and an increase in specific power of about 70\%. Since carbide fuel permits the fuel elements to be operated at higher linear heat ratings due to its improved conductivity compared with that of oxide fuel, $30 \mathrm{kw} / \mathrm{ft}$ is specified as the heat rating for this new design. However, film heat transfer requires lower gas outlet temperatures with higher linear heat ratings unless the cladding temperature is increased. For this reason, the carbide fueled design is based on an outlet temperature of $1088^{\circ} \mathrm{F}$, as compared with $1175^{\circ} \mathrm{F}$ for the oxide fueled design; and therefore the carbide fueled design utilizes a $900^{\circ} \mathrm{F}$ steam cycle rather than the $1000^{\circ} \mathrm{F}$ cycle 
Table 4.3. Comparison of Oxide- and Carbide-Fueled GCFR Designs ${ }^{a}$

\begin{tabular}{|c|c|c|}
\hline & $\begin{array}{l}\text { GCFR-4, Reference } \\
\text { Oxide-Fueled } \\
\text { Reactor }\end{array}$ & $\begin{array}{c}\text { GCFR-C, Reference } \\
\text { Carbide-Fueled } \\
\text { Reactor }\end{array}$ \\
\hline \multicolumn{3}{|l|}{ Common conditions } \\
\hline Coolant & Helium & Helium \\
\hline $\begin{array}{l}\text { Total pumping power fraction, } \not \circ \text { of } \\
\text { thermal }\end{array}$ & 4 & 4 \\
\hline Design maximum cladding temperature, ${ }^{\circ} \mathrm{F}$ & 1292 & 1292 \\
\hline $\begin{array}{l}\text { Cladding (stainless steel) thickness-to- } \\
\text { diameter ratio }\end{array}$ & 0.04 & 0.04 \\
\hline Control-rod and structure blockage, $\not 6$ & 10 & 10 \\
\hline Net electric output, Mw & 1,000 & 1,000 \\
\hline $\begin{array}{l}\text { Average enrichment of fresh core fuel, } \\
{ }^{3{ }^{39}} \mathrm{Pu}+24{ }^{2} \mathrm{Pu} / \mathrm{U}+\mathrm{Pu}\end{array}$ & 0.127 & 0.127 \\
\hline Plutonium isotopic content & $\begin{array}{l}\text { Equilibrium from } \\
\text { core-blanket mix }\end{array}$ & $\begin{array}{l}\text { Equilibrium from } \\
\text { core-blanket mix }\end{array}$ \\
\hline \multicolumn{3}{|l|}{ Appropriate core proportions } \\
\hline Core length-to-diameter ratio & 0.55 & 0.40 \\
\hline Core volume, liters & 8,510 & 4,030 \\
\hline Active length, cm & 148 & 93 \\
\hline Active diameter, $\mathrm{cm}$ & 270 & 234 \\
\hline Fuel volume fraction & 0.29 & 0.30 \\
\hline Coolant volume fraction & 0.55 & 0.53 \\
\hline Rod diameter, cm & 0.805 & 0.736 \\
\hline Number of rods & 40,000 & 37,000 \\
\hline \multicolumn{3}{|l|}{ Operating conditions } \\
\hline Thermal power, $\mathrm{Mw}$ & 2,530 & 2,680 \\
\hline Core pressure, psi & 1,250 & 1,750 \\
\hline Gas inlet temperature, ${ }^{\circ} \mathrm{F}$ & 644 & 599 \\
\hline $\begin{array}{l}\text { Gas outlet temperature, }{ }^{\circ} \mathrm{F} \\
\text { Steam conditions }\end{array}$ & 2175 & 1088 \\
\hline Outlet temperature, ${ }^{\circ} \mathrm{F}$ & 1000 & 900 \\
\hline Reheat temperature, ${ }^{\circ} \mathrm{F}$ & 1000 & 900 \\
\hline Feed temperature, ${ }^{\circ} \mathrm{F}$ & 375 & 275 \\
\hline Pressure, psi & 2,400 & 1,800 \\
\hline Net plant efficiency & 0.395 & 0.373 \\
\hline \multicolumn{3}{|l|}{ Performance } \\
\hline Maximum rod heat load, $\mathrm{kw} / \mathrm{ft}$ & 18 & 30 \\
\hline $\begin{array}{l}\text { Specific power, total } \mathrm{Mw}(\mathrm{th}) / \mathrm{kg} \text { core } \\
\text { fissile at startup }\end{array}$ & 0.90 & 1.50 \\
\hline Power density, kw/Iiter & 277 & 615 \\
\hline Conversion ratio, average & 1.51 & 1.60 \\
\hline Assumed maximum burnup, Mwd/MT & $10^{5}$ & $1.4 \times 10^{5}$ \\
\hline Core life, years & 2.29 & 2.49 \\
\hline Out-of-pile time, year & 1.0 & 0.5 \\
\hline $\begin{array}{l}\text { Fractional increase in fissile pluto- } \\
\text { nium per cycle }\end{array}$ & 0.27 & 0.62 \\
\hline Exponential doubling time, years & 8.8 & 4.3 \\
\hline
\end{tabular}

Q Unevaluated GGA data taken from Ref. 16. 
of the oxide fueled design. The core plan for the carbide fueled GCFR is illustrated in Fig. 4.18. The fuel element for this reactor incorporates the pressure equalizing vented fuel concept discussed previously for the oxide fueled designs.

The GCFR-C design, being of a later type of GCFR, is based on use of a multicavity PCRV. The multicavity PCRV comprises a cylindrical block of prestressed and reinforced concrete containing multiple cavities in which the reactor core and the steam generators are individually contained. The core is located in the central cavity of the vertical, cylindrical vessel and is surrounded by six steam generators in individual cavities. The main circulators are located in the PCRV head above the steam generators. Auxiliary circulators are located in individual cavities and connected by passages to the core and steam generator cavities. This design was chosen over the single cavity arrangement, partly because it appears better suited to the higher coolant pressure.

The vertical, cylindrical exterior of the PCRV is adaptable to prestressing with either tendons or wire. Preliminary studies on the HTGR indicate that wire winding is cheaper than tendon prestressing and, on this basis, it is tentatively planned that the GCFR-C multicavity vessel be wire wound. Another notable feature of the multicavity PCRV is the considerable alleviation of the problem of prestressing and reinforcing steels in the region of the closely spaced vessel penetrations above the core. In the multicavity PCRV, there will be no need for tendons to pass through this region. The prestressing of the vessel heads will be done by means of the circumferential winding around the vessel. Vertical tendons surrounding the cavities and reinforcing steel above and below will complete the head restraints. It is significant that the freedom from head tendon space restrictions permits use of triangular fuel rod and box pitches that benefit hydraulic and mechanical core performance.

The fuel management program for the GCFR-C provides batch movement for the core with four radial zones of varying enrichment, as was selected for the oxide fueled designs. The average core enrichment is chosen to give uniform reactivity as a function of time. At each core reloading, inner blanket elements from blanket zone 1 are discharged, 

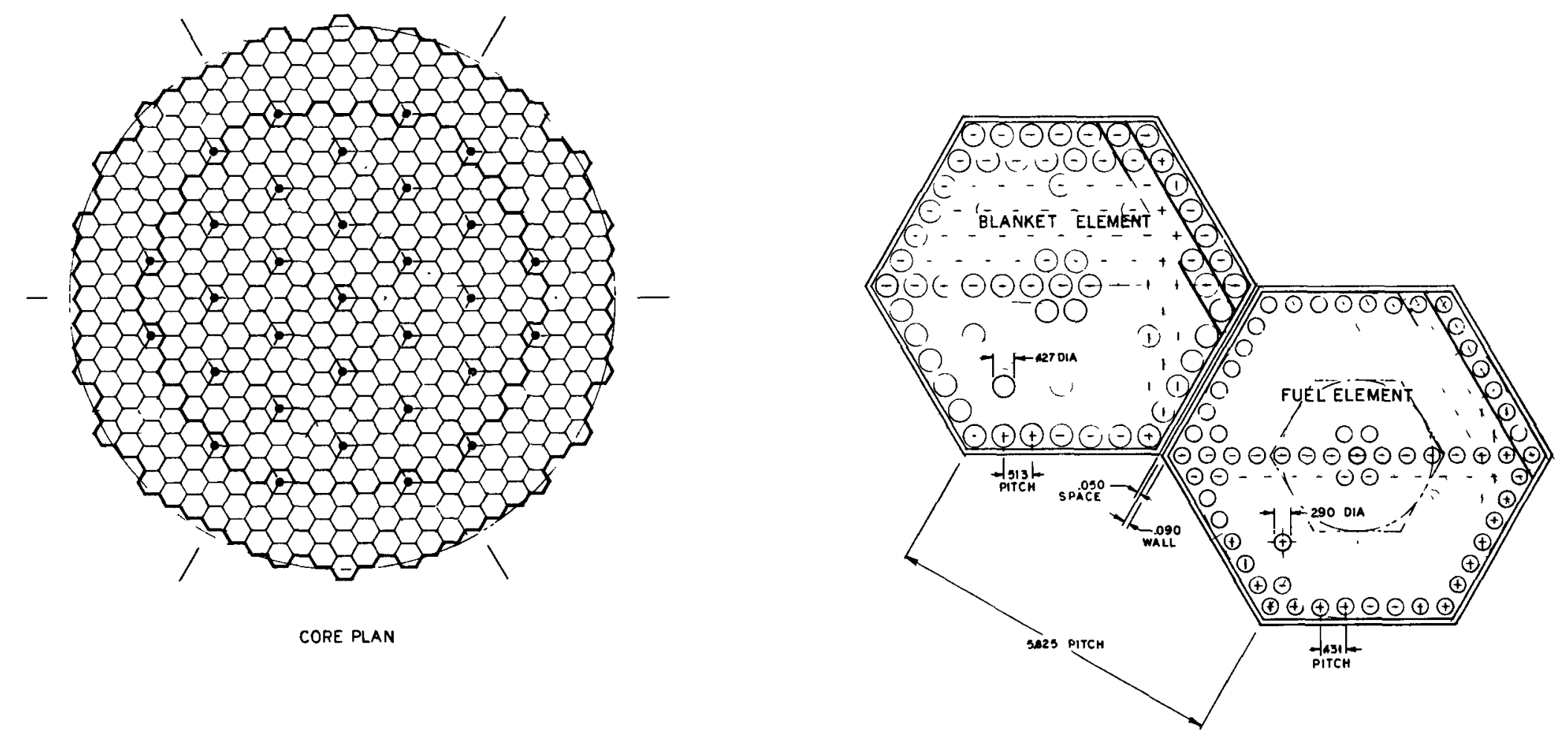

Fig. 4.18. Plan View of Core, Fuel Element, and Blanket Element of Carbide Fueled GCFR. 
outer elements are moved inward, and blanket zone 2 is charged with fresh material. (As a proposed method of handling in the GCFR-4, the blanket was divided into two zones, with the inner one comprising one-third of the blanket volume and the outer one two-thirds. The inner zone was to be discharged every core cycle and the outer one every three core cycles.) The design data for the GCFR-C were generated by GGA late in the evaluation studies reported here. Consequently, there was not sufficient time for ORNL to carry out a technical evaluation. The results of GGA design studies are presented in other sections of this report, along with ORNL estimates of power costs based on those results. 


\section{TECHNICAL EVALUATION}

\subsection{Steam-Cooled Breeder Reactors}

The three steam-cooled reactors covered by this evaluation do not comprise a set of comparable concepts representing optimum designs for each set of conditions. The two B\&W designs (supercritical and low pressure) are not directly comparable because neither is a fully optimized design and because of evolution in design approaches in the time interval between the two studies. The intermediate pressure design by the Karlsruhe group represents the thinking of an entirely different group, who approached the problem on a more conservative basis. The evaluation work followed the ground rules stated in Chapter 3 in that all concepts were reviewed and analyzed with the use of the best available current data on physics, thermal-hydraulic analysis, fabrication and engineering practices, and cost data. Attempts were also made to incorporate equivalent engineered safeguards where they were lacking so that all three concepts would be essentially equal in that respect. Even if each design had been optimized by its proponent, application of the ground rules of this evaluation would probably have shifted the optimum in each case.

This chapter contains the summaries of the various parts of the evaluation carried out at ORNL.

\subsubsection{Physics}

Physics evaluation of the concepts was devoted to determining power distributions, Doppler and density coefficients, complete mass balances throughout the life of the reactors, and the resultant breeding ratios and doubling times. As was expected, the presence of steam in the core and its softening effect on the neutron spectrum reduces breeding ratios relative to those obtainable in other fast reactors in which hydrogen is not present. The physics characteristics of the three concepts are summarized in Table 5.1.

5.1.1.1 Reactivity Effects of Coolant Density. Effective multiplication factors were calculated for conditions ranging from complete loss pf coolant to complete flooding with room temperature water. In these 
Table 5.1. Physics Characteristics of Steam-Cooled Fast Reactors

\begin{tabular}{|c|c|c|c|}
\hline & $\begin{array}{l}\text { Low-Pressure } \\
\text { System }\end{array}$ & $\begin{array}{c}\text { Intermediate-Pressure } \\
\text { System }\end{array}$ & $\begin{array}{l}\text { High-Pressure } \\
\text { System }\end{array}$ \\
\hline Inlet steam pressure, psi & 1,250 & 2,680 & 3,700 \\
\hline \multicolumn{4}{|l|}{ Fuel-cycle data } \\
\hline \multicolumn{4}{|l|}{ Fuel management } \\
\hline Core and axial blanket & Batch & One-third scatter & Batch \\
\hline Radial blanket & Batch & $\begin{array}{l}\text { One-third each alternate } \\
\text { cycle }\end{array}$ & $\begin{array}{l}\text { One-third each cycle; two-thirds } \\
\text { each alternate cycle }\end{array}$ \\
\hline Core heavy-metal inventory, $\mathrm{kg}$ & 33,012 & 31,800 & 14,492 \\
\hline Axial blanket heavy metal, kg & 34,900 & 14,162 & 4,600 \\
\hline Radial blanket heavy metal, kg & 20,860 & 38,595 & 36,200 \\
\hline Total heavy-metal inventory, kg & 88,772 & 84,556 & 55,292 \\
\hline Average core fissile inventory, $\mathrm{kg}$ & 3,554 & 3,530 & 1,980 \\
\hline Average axial blanket fissile inventory, $\mathrm{kg}$ & 322 & 60 & 19 \\
\hline Average radial blanket fissile inventory, $\mathrm{kg}$ & 207 & 247 & 327 \\
\hline Average out-of-reactor fissile inventory, $\mathrm{kg}$ & 1,354 & 1,320 & 1,472 \\
\hline Total fissile inventory, $\mathrm{kg}$ & 5,437 & 5,157 & 3,798 \\
\hline Fissile specific power, $\mathrm{kw}(\mathrm{th}) / \mathrm{kg}$ (total) & 533 & 488 & 612 \\
\hline Median fission energy, kev & 160 & 120 & 30 \\
\hline Core conversion ratio ( $\mathrm{Pu}$ only) & 0.98 & 1.01 & 0.63 \\
\hline Total breeding ratio ( $\mathrm{Pu}$ only) & 1.38 & 1.14 & 1.11 \\
\hline Fuel yield, $\%$ per year & 5.90 & 1.84 & 1.70 \\
\hline Doubling time, years & 12 & 38 & 41 \\
\hline Maximum fuel exposure, Mwd/MT & 100,000 & 100,000 & 100,000 \\
\hline \multicolumn{4}{|l|}{ Average fuel exposure, Mwd/MT heavy metal } \\
\hline Core & 70,000 & 57,500 & 58,000 \\
\hline Axial blanket & 5,800 & 4,100 & 5,400 \\
\hline Radial blanket & 2,000 & 4,000 & 5,100 \\
\hline Core life, years at 0.80 power factor & 3.02 & 2.65 & 1.58 \\
\hline Out-of-reactor Pu holdup, year & 1.0 & 1.0 & 1.0 \\
\hline \multicolumn{4}{|l|}{ Power-peaking factors } \\
\hline Axial & & $\bullet$ & \\
\hline Beginning of life & 1.21 & 1.33 & 1.72 \\
\hline End of life & 1.16 & 1.33 & 1.39 \\
\hline \multicolumn{4}{|l|}{ Radial } \\
\hline Beginning of life & 1.21 & 1.44 & 1.11 \\
\hline End of life & 1.48 & .1 .44 & 1.09 \\
\hline \multicolumn{4}{|l|}{ Reactivity coefficients } \\
\hline \multicolumn{4}{|l|}{ Doppler, $\Delta \mathrm{k} /{ }^{\circ} \mathrm{K}$} \\
\hline Normal conditions & $-8.6 \times 10^{-6}$ & $-16.0 \times 10^{-6}$ & $-7.2 \times 10^{-6}$ \\
\hline Voided core & $-7.6 \times 10^{-6}$ & & \\
\hline \multicolumn{4}{|l|}{ Density effects of complete voiding, $\Delta k$} \\
\hline Beginning of life & 0.0094 & 0.0209 & 0.0050 \\
\hline \multirow{2}{*}{\multicolumn{4}{|c|}{ Effect of flooding at $62.4 \mathrm{lb} / \mathrm{ft}^{3}, \Delta \mathrm{k}$}} \\
\hline & & & \\
\hline Beginning of life & 0.1664 & & \\
\hline Find of equilibrium cycle & 0.0691 & 0.0115 & 0.0438 \\
\hline
\end{tabular}


calculations, the control rods were assumed to remain in their operating positions during the change in coolant density. For the intermediate and low pressure systems, the normal steam density is at or near the density for minimum reactivity. Loss of coolant at beginning of life results in increases in the effective multiplication factors of $0.009,0.021$, and 0.005 for the low, intermediate, and high pressure systems, respectively. Flooding at end of life results in increases in the effective multiplication factors of $0.069,0.012$, and 0.044 for low, intermediate, and highpressure systems, respectively. The maximum effect of flooding occurs at beginning of life in the low pressure system when the change in effective multiplication factor is $0 . \mathbf{l 6 6}$. If flooding is determined to be a credible situation, the reactivity worth of the control system will have to be increased to insure the control of this condition in the low pressure system.

5.1.1.2 Breeding Ratios. The breeding ratios calculated for the SCBR's are about 1.38 for the low pressure system, 1.14 for the intermediate pressure system, and 1.12 for the high pressure system. The differences between these values and those calculated by the design sponsors are not large relative to the uncertainties involved in calculating this parameter.

Figure $5.1^{*}$ indicates the limits of coolant volume fraction and water density of the core that must be maintained in order for breeding ratios greater than 1.0 to be achieved. The areas below the curves represent the conditions for breeding; those above the curves represent lower conversion ratios.

The breeding ratio for the supercritical system cannot be meaningfully plotted on Fig. 5.1. The data in this figure are based on Inconel fuel cladding, whereas the revised high pressure system has 19-9DL stainless steel fuel cladding. Estimates show that the use of Inconel cladding would, indeed, lower the breeding ratio for the high pressure system to well below 1.0. In addition the data of Fig. 5.1 were developed for a core volume of 8000 liters, which is nearly the volume of the intermediate and low pressure systems but is nearly twice that of the present

\footnotetext{
*This figure was taken from Fig. 15 of Ref. 8.
} 
ORNL-OWG 68-6482

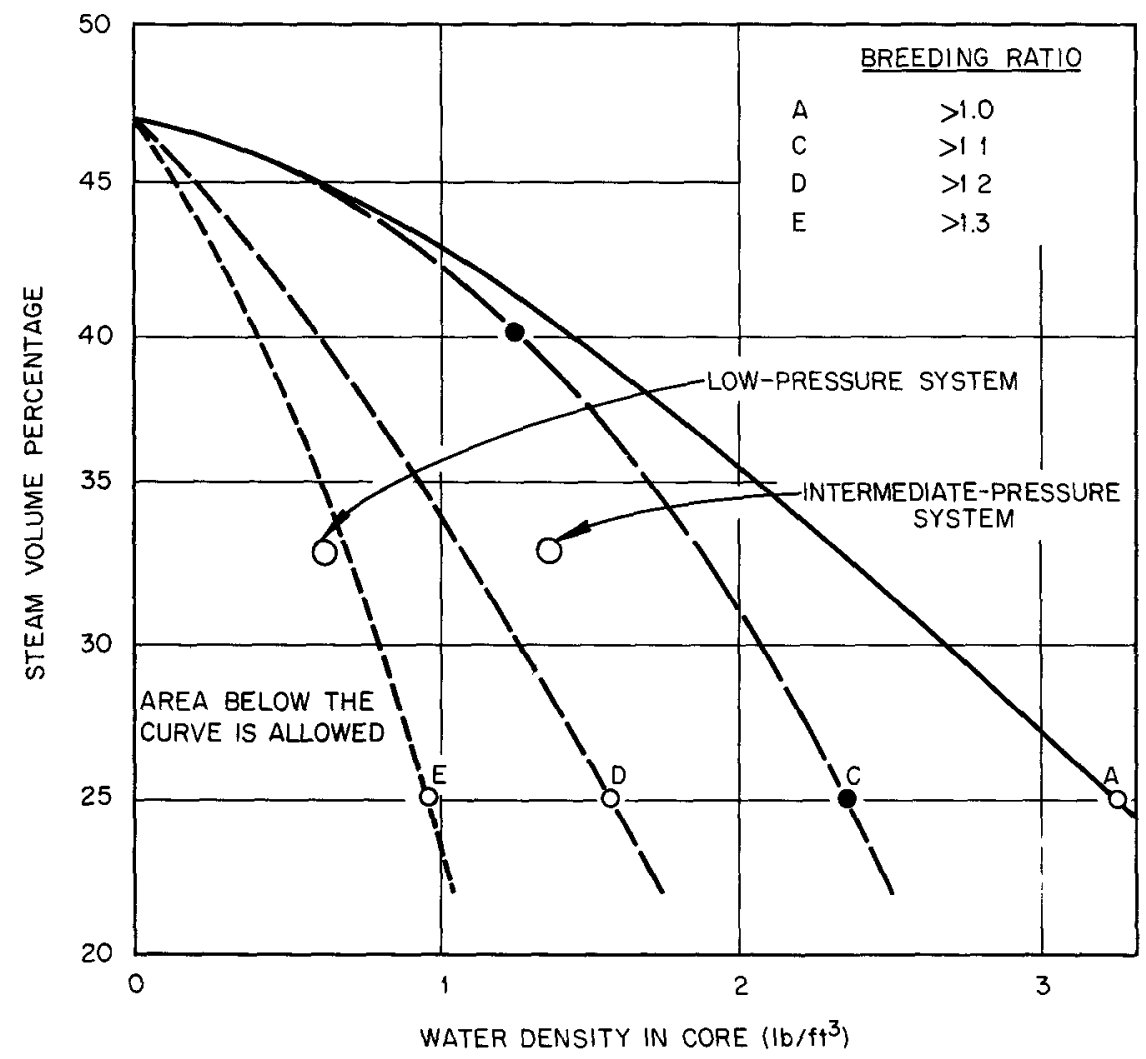

Fig. 5.1. Allowed Combinations of Water Density and Steam Volume in an 8000-liter SCBR Core.

high pressure system. It may be seen from the curves for breeding ratios of 1.0, 1.1, and 1.2, that the locations of the low and intermediate pressure reactor designs on the chart are in fairly good agreement with the breeding ratios calculated in the evaluations of these reactors.

5.1.1.3 Doubling Times. The doubling times calculated are 12 years for the low pressure system, 38 years for the intermediate pressure system, and 41 years for the high-pressure system.

5.1.1.4 Power Distributions. The power distributions obtained by ORNL are slightly less favorable than those presented by the proponents of the intermediate and low pressure systems. Maximum radial peak-toaverage power distributions calculated by ORNL are 1.48, 1.44, and 1.12 for the low, intermediate, and high pressure cores, respectively. These distributions are very sensitive to small changes in relative enrichments of fuel zones. The distributions quoted by ORNL can be improved by small 
adjustments in the relative enrichments. The improvement may be possible only at one time during a cycle, so the power density must be evaluated carefully as a function of time. In these calculations of power distributions, the poison in the control rods was assumed to be uniformly distributed so that any effect the control rods would have on power distribution was not considered.

In the high pressure design, B\&W appears to have been successful in their goal of shifting the axial power peak toward the low temperature inlet end of the core. Whether this is of significant advantage to the design was not evaluated.

\subsubsection{Thermal-Hydraulic Analysis}

All three designs were analyzed to determine the flows, pressure drops, and temperature distributions throughout the cores and blankets. The points of concern in this analysis were overall pressure arop, the flow distribution across the core in relation to the power distribution, the maximum temperature of the fuel cladding surface, and the maximum temperature at the center of the fuel.

Based on the Heineman correlation, 23 with a leading coefficient of 0.0133 , and engineering factors that accounted for variations in flow, dimensions, and fuel composition, it was found that the fuel cladding surface temperature in the low pressure reactor was below the maximum permissible temperature of $1350^{\circ} \mathrm{F}$, and in the intermediate pressure reactor it was below $1200^{\circ} \mathrm{F}$. The Westinghouse correlation ${ }^{24}$ for heat transfer to supercritical steam gave a maximum surface temperature about equal to the design limit of $1350^{\circ} \mathrm{F}$ for the high pressure design.

5.1.2.1 Possibility of Fuel Melting. If the melting point of the irradiated mixed uranium and plutonium oxides is assumed to be about $4900^{\circ} \mathrm{F}$, only the intermediate pressure design meets the criterion of no fuel center melting. It is estimated that some center melting would occur in the other two designs for which the linear heat ratings reach maximum values of 15 to $16 \mathrm{kw} / \mathrm{ft}$. It was estimated that for a temperature of $1532^{\circ} \mathrm{F}$ at the surface of the vibration packed powder inside the cladding and a center-line temperature of $4900^{\circ} \mathrm{F}$, the maximum heat that could be removed from the fuel per unit length of fuel rod would be about 
$13 \mathrm{kw} / \mathrm{ft}$. For the concepts being examined, the surface temperature of $1532^{\circ} \mathrm{F}$ at the surface of the vibration packed fuel is representative. The use of pelletized fuel would yield a higher linear rating without centerline melting for the given fuel surface temperature, and both fuel forms would yield higher fuel ratings if the surface temperature were reduced.

5.1.2.2 Linear Heat Ratings and Surface Temperatures for No Fuel

Melting. The maximum linear heat rating compatible with the requirement that no center melting occur was calculated as a function of the outer cladding surface temperature. The maximum center-line temperature was taken as $4900^{\circ} \mathrm{F}$, and two types of fuel were considered: (1) vibration packed mixed oxides of uranium and plutonium with a theoretical density of $85 \%$ and (2) sintered pellets of the mixed oxides with a theoretical density of $95 \%$. The first is the fuel that is proposed for the designs in the present steam-cooled fast breeder reactor study, and the second is representative of the fuels proposed for the liquid metal-cooled fast breeder reactors.

Where the cladding surface temperature is $1350^{\circ} \mathrm{F}$, the results indicate linear heat ratings of about $17 \mathrm{kw} / \mathrm{ft}$ for pelletized fuel and about $13 \mathrm{kw} / \mathrm{ft}$ for vibration packed oxide fuel. It should be kept in mind that these linear heat ratings are those which occur at the same position on the rod that the selected surface temperature occurs, whereas the peak temperature and the peak heat generation do not necessarily occur at the same point in the reactor.

\section{1 .3 Materials}

A possible area of concern may be oxidation and potential swelling of the $\mathrm{UO}_{2}-\mathrm{PuO}_{2}$ fuel in a defective or failed fuel element if sufficient free oxygen is present in the steam. It appears that compatibility between fuel and steam will be satisfactory if no excess oxygen is present. The compatibility of coolant and cladding appears satisfactory for Inconel 625 and/or Incoloy 800. The type 19-9DI stainless steel cladding may suffer stress corrosion cracking and also is much less resistant to oxidation than Inconel and Incoloy. Radiation effects on cladding are recognized as a potential problem in that reduced ductility would reduce stress rupture life at the low strain rates involved. On this basis, the 
fuel element life was limited to that at which the increasing cladding stress from fission gas pressure would develop 1\% cladding strain. Average burnup levels in the peak rod based on this criterion are approximately 100,000, 56,000, and 62,000 Mwd/MT for the low intermediate and high pressure designs, respectively. These values may be increased if more plenum volume is provided. The high and intermediate pressure concepts were designed for 50,000- and 55,000-Mwd/Mr peak burnup, respectively, and would require additional void plenum volume to achieve 100,000-Mwd/MI maximum burnups. The low pressure concept was designed for 100,000-Mwd/MT average burnup and appears satisfactory from the aspect of fission gas pressures.

For all the steam-cooled reactors, it is proposed to use prepressurization of the fuel rods to prevent cladding collapse under initial operating conditions. Calculations indicate that in the high and low pressure designs the internal pressures for this prepressurization should be increased. For the low pressure design this is a relatively minor problem, and the necessary increase could probably be accommodated in the high pressure design if Inconel 625 cladding could be used. The 19-9 DL stainless steel cladding is not so strong, and there is not sufficient data to allow an estimate of the burnup that might be allowable.

All three designs were assumed to operate to a point maximum fuel burnup of 100,000 Mwd/MT for purposes of economic comparisons. It appears possible to achieve a suitable combination of fission product gas plenum volume and initial prepressurization to accommodate the fission product gases while holding cladding stresses to an acceptable level. It should be pointed out in reference to fuel pin pressurization that problems of quality control and inspection may be significant.

The development of cladding strain from fuel swelling is dependent on the creep strength of the cooler outer layer of fuel, which may be a function of stress, rate of stress application, character and amount of pore volume, fission rate, and external restraint. Thus, rapid thermal cycling may create plastic cladding strain through differential thermal expansion, whereas similar increases in fuel volume that developed more slowly would be accommodated by yielding of the fuel. This problem is common to all proposed fast reactor designs, and we believe that experimental tests will be required to evaluate effects of such fuel cladding 
mechanical interactions on burnup limits as a function of the operation environment.

\subsubsection{Components}

In comparing the three plants, it was apparent that differences in design philosophy accounted for as much or more difference in the three designs than the difference in steam conditions. The intermediate pres sure design is more conservative than the other two in thermal performance of the reactor and in the design of the external heat transfer and steam circulation systems. The high pressure design has a more compact layout than the other two. Further differences among the three concepts are in the containment system designs, the emergency cooling system designs, and the turbine-generator selections.

5.1.4.1 Reactor Vessel. The proposed reactor vessels are considered feasible to build in present day manufacturing facilities, except that constmuction of the two-layer vessels for the 3700- and 2680-psi designs may require some development. The welded-on heads for the two B\&W designs will require assembly and postweld heat treatment in the field to avoid damage to vessel internals during shipment. Elimination of the bolted flanges reduces the costs of the vessels but complicates the initial assembly and later access if replacement of internals becomes necessary.

The maximum integrated neutron dose ( $E>1 \mathrm{Mev}$ ) to the three reactor vessels was calculated to be $1.4 \times 10^{20}$ neutrons $/ \mathrm{cm}^{2}$ for the $3700-p s i$ design, $2.5 \times 10^{18}$ neutrons $/ \mathrm{cm}^{2}$ for the $2680-p s i$ design, and $2.6 \times 10^{20}$ neutrons $/ \mathrm{cm}^{2}$ for the 1250-psi design for a 30-year life of the vessel. Present design practice for SA-302, grade $B$, steel is to limit the exposure of the vessels to below $2 \times 10^{19}$ to $4 \times 10^{19}$ neutrons $/ \mathrm{cm}^{2}$ ( $\mathrm{E}>1 \mathrm{Mev}$ ) over the life of the vessel. To meet this criterion, additional thermal shield thickness will be required in the vessels for the high and low pressure reactors.

5.1.4.2 Steam Generators. In general the direct contact steam generators proposed for all three systems appear to be satisfactory. The means for moisture separation are widely used and reliable. Spray nozzles are also quite common and should present no problems; however, data on spray distribution, droplet size, etc., would be required, and the 
performance of each steam generator concept needs to be demonstrated. Since there are very limited data on supercritical fluid heat transfer, the ability of the mixing tees proposed in the 3700-psi design to produce a homogeneous fluid should be investigated.

5.1.4.3 Circulators. The circulator designs proposed for the steam systems all represent an extension of present technology. Although gases at these pressures and in these volumes are being handled today, there are few if any situations where these combinations exist. The highest pressure used to date in a gas-cooled reactor is of the order of $1000 \mathrm{psi}$. The shaft seals and bearings are perhaps the most significant problem areas, and the majority of the development work and proof-testing will be needed on these components. Since the circulators are extrapolations of the current state of the art and do not depend on new concepts, the development work does not represent a major effort and should not be a controlling factor in the time required to build a reactor system.

\subsubsection{Safety and Control}

The types of accident that have been considered for SCBR's in this evaluation include reactivity accidents, thermal accidents, plant startup and control accidents, and destructive nuclear bursts.

The safety problems of all fast reactors differ from those of thermal reactors in that (1) the fast reactors operate at higher power density, (2) the larger quantity of fissile material present in the core of each fast reactor provides a potential of several critical assemblies in a thermal neutron environment, (3) the fast reactors have a weaker negative reactivity response to changes in power and fuel temperature, and (4) in a fast reactor there is a positive reactivity effect of a coolant void in the core, either locally or totally. The steam-cooled fast reactor has all these problems except local voiding (due to change of phase). Because of its low density coolant it has a low heat storage capacity, with the result that there would be a very rapid fuel temperature change if loss of coolant or reactivity insertions occurred. The effect of the latter would be partially cancelled by the negative Doppler coefficient. 
5.1.5.1 Reactivity Accidents. Except for the power-limiting effect of the Doppler coefficient associated with the fuel, the SCBR does not have an inherent shutdown mechanism, so an applied reactivity shutdown will be required to cancel a reactivity transient. A general review was therefore made of possible causes of reactivity transients in the SCBR. Based on this review, it appears that for realistic reactivity insertion rates, a well-designed fast safety system and shutdown mechanism would be able to terminate an accident before the fuel was damaged.

A highly reliable applied shutdown would require the use of two complete and independent sets of safety systems and fast-scram mechanisms. The reference systems do not include any form of reserve shutdown system, so the addition of a second automatic safety system and fast-scram mechanism is recommended. In order to minimize common failure modes (systematic failures), the two systems must be of different design and construction, and both must have adequate time response.

Although flooding of the core may not be feasible in the loss-ofcoolant type of accident, it is possible that under some conditions the core could be flooded. In fact, in two of the designs the reactor is flooded for normal shutdown cooling. The calculations indicate (I) that a large reactivity increase must be counteracted if the rods remain in the operating position when the core is flooded and (2) that the rods do not have sufficient worth to keep the core subcritical when it is flooded. This situation will require the provision of some form of poison injection system that could add sufficient negative reactivity to make the core subcritical regardless of the source of flooding water.

Further study of the kinetics of the steam-cooled fast reactor cores is necessary to provide information on which to base adequate safety system designs.

5.1.5.2 Thermal Accidents. The emergency cooling problem is more difficult in the SCBR concept than in large light water reactors because the fuel will heat up at a rate four to five times faster if it is not cooled. Thus, the time margin for starting emergency cooling will be much shorter. The evaluation indicates that the cladding temperature will reach the failure point within 1 to 5 sec after a piping failure if emergency cooling has not started, and that fuel melting would occur within 
1 to 4 min without emergency cooling. Since cladding failure might allow the fuel to move into a more reactive configuration or obstruct cooling, cladding failure is probably more significant than fuel melting in determining the allowable time margins.

The SCBR reference designs do not provide the degree of redundancy in emergency cooling systems that is employed in current light water reactor systems, where both spray and flooding systems are provided or where multiple systems are used. The SCBR primary vessel designs, because of their bottom connections, prevent the use of rapid flooding systems for emergency cooling following a failure in one of those lines.

Direct core spray is the main form of low pressure emergency cooling provided in these designs. This is contrasted to the gas cooled and sodium-cooled reactors that depend on forced circulation of the coolant for this function. The spray systems in the SCBR designs probably have the required spray cooling capacity if it can be demonstrated that the flow is distributed properly and the reliability of the system is high enough. In general, the designs provide one spray system with redundant pumps. Since these are essential systems, it is recommended that, as a minimum, two independent full-capacity spray systems be provided, each with a separate spray ring and source of water. The auxiliary boilers may be used to inject steam for fog cooling to serve as a diverse form of low pressure emergency cooling.

It will probably be necessary to add some form of high pressure emergency cooling for cases such as loss of forced circulation or slow depressurizations. In the intermediate pressure design, the Loeffler boilers in the secondary steam systems partially serve for this purpose. In the high pressure steam-cooled design, the pressure in the pressurized head tank could be increased so that it could partially serve this purpose. Current BWR designs have steam-driven pumps, and PWR designs have pressurized storage tanks for injection of water for high-pressure emergency cooling. These designs can probably be adapted for application to the steam-cooled fast reactor.

The SCBR designs incorporate several features that are intended to minimize the effects of a primary system rupture. Valves and automatic 
isolation systems are provided to isolate a broken line or coolant loop. In most instances, multiple lines and coolant loops are used to minimize the loss of coolant from a failure in an individual line. The low pressure design has an integral reactor vessel arrangement that reduces the number and size of possible rupture points. The high and low pressure designs include high. pressure containment vessels that will reduce the effects of a break in the main reactor vessel or nozzles. The intermediate and low pressure designs have. sources of water in the primary system that can flash and provide some makeup steam in the event of a system rupture.

5.1.5.3 Plant Startup and Control Accidents. The plant startup procedure was not completely analyzed in this evaluation; however, three incidents were considered that may be associated with the startup procedure. They are (.l) inadvertent rod withdrawal during startup, (2) inadvertent flooding of the core, and (3) sudden changes in flow of steam from the reactor. A reasonably fast scram can handle reactivity insertion rates in the range from $\$ 2$ to $\$ 20 / \mathrm{sec}$, so it will be necessary to limit the number of rods withdrawn at one time or the rate of withdrawal. The effect of flooding is discussed above, and some means of dealing with it are suggested.

Preliminary dynamics studies indicated that these plants will have load-following characteristics in which an increase in turbine steam flow will cause an increase in reactor power (by means of the density-reactivity effect). In general, this is a desirable characteristic; however, any large rapid increases in steam flow might produce power increases that would require a reactor scram. These studies have also indicated that these plants will be stable for flux perturbations (with the control rods in a fixed position).

5.1.5.4 Destructive Nuclear Excursion and Meltdown Containment Capability. The maximum hypothetical accident for the SCBR could involve a nuclear excursion with a sudden release of energy. The magnitude of this energy release has not been completely analyzed for these concepts, but potential energy releases of the order of 1000 to $1600 \mathrm{MWsec}$ ( 500 to $800 \mathrm{lb}$. of TNT) have been postulated. Calculations performed by Nuclear Technology Corporation as part of this evaluation 25 indicate that, for an ultimate strain of approximately 
$7 \%$ or more, the vessels proposed for the three reactors could withstand explosions equivalent to more than $1000 \mathrm{lb}$ of TNT in the cases of the two higher pressure designs, and about $600 \mathrm{lb}$ of TNT in the case of the 1250-psi design. These estimates are based on the vessels being empty at the time of the excursion, and it is estimated that if they were full of water the magnitude of the explosion they could contain would be reduced by a factor of 2. The criterion of $7 \%$ ultimate strain is based on the assumption that the SA-302, grade $B$, material will remain ductile with an ultimate strain in excess of $7 \%$ throughout its life. The high pressure containment vessels included in the high and low pressure designs will increase the capabilities of containing a destructive excursion, but the effect of these vessels was not considered in these calculations. The designs do not include provision for cooling the debris after an excursion. Further study is required to establish the credibility of such an excursion, the upper limit of the energy release, and reliable means for containing and cooling the fuel after a core meltdown or a destructive excursion.

5.1.5.5 Conclusion. The conclusion of the safety evaluation is that the safety problems of the steam-cooled fast reactor, including emergency cooling, reactor kinetics under both normal and accident conditions, coping with destructive excursion, and containing the debris after a core meltdown, have not been solved in the design studies considered, and that more study of these problems is required. The problems of inadvertent rod withdrawal, core flooding, and steam density changes during startup are less difficult and can be solved satisfactorily to provide a degree of safety in these reactors equivalent to that now provided in thermal reactors.

\subsection{Gas-Cooled Fast Breeder Reactors}

\subsubsection{Physics}

The physics calculations performed by ORNL specifically pertain to the 8510-1iter oxide fueled reference design. However, the results of these calculations are applicable to the derated design, except for the higher fuel inventory which affects the fuel cycle costs. The reference 
design characteristics of interest in neutronic calculations are summarized in Table 5.2 .

Two dimensional multigroup burnup calculations made with the code ASSAULT $^{26}$ were used throughout the study. In these calculations the reactivity was kept near unity by adjusting the concentration of boron (uniformly distributed in the core) at the start of each depletion step.

5.2.1.1 Breeding Ratio. The fuel cycle loadings and breeding performance of the reference GCFR-4 design during approach to equilibrium

Table 5.2. Physics Characteristics of GCFR-4 Core and Blanket

Core dimensions

Volume, Iiters

Core height, $\mathrm{cm}$

Core diameter, cm

Axial blanket thickness, $\mathrm{cm}$

Radial blanket thickness, $\mathrm{cm}$

Fuel cladding material

Structural material

Coolant

Control poison material

Fuel

Fuel material

Equilibrium recycle $\mathrm{Pu}$ isotopic composition

Uranium isotopic composition

Core average U-to-Pu ratio

Core average fertile-to-fissile Pu ratio

Core average $\mathrm{Pu}$ enrichment ( $\mathrm{g}$ fissile

$\mathrm{Pu} / \mathrm{g}$ fuel)

Volume fractions in core and axial blanket

Fuel, 90\% T.D.

Cladding

Structure

Helium and voids

Volume fractions in radial blanket

Fuel, 90\% T.D.

Structure and cladding

Helium
8510

148.2

269.5

60

51

Type 316 stainless steel Type 304 stainless steel

Helium

Enriched $\mathrm{B}_{4} \mathrm{C}$

Mixed $\mathrm{PuO}_{2}-\mathrm{UO}_{2}$

$83 \%{ }^{239} \mathrm{Pu}, 14 \% 240 \mathrm{Pu}$, $2 \%{ }^{24} \mathrm{Pu}, 1 \% 242 \mathrm{Pu}$

$0.35 \%{ }^{23}{ }^{5} \mathrm{U}, 99.65 \%{ }^{238} \mathrm{U}$

5.46

6.65

0.13

0.2896

0.0501

0.0699

0.5904 
with different startup plutonium concentrations are shown in Table 5.3. The equilibrium cycles of this concept were estimated by extrapolating results obtained from the approach-to-equilibrium calculations made with PWR-discharge plutonium as the startup material. These calculations covered about 25 full-power years of operation ( 13 cycles of about 720 fullpower days each) and approached quite near to equilibrium conditions.

Table 5.3. Summary of GCFR-4 Breeding Performance ${ }^{a}$ with Different Startup Plutonium Compositions

\begin{tabular}{|c|c|c|c|}
\hline & \multicolumn{3}{|c|}{ Selected Startup Material } \\
\hline & $\begin{array}{l}\text { PWR } \\
\text { Discharge } \\
\text { Plutonium }\end{array}$ & $\begin{array}{c}\text { PWR } \\
\text { Recycled } \\
\text { Plutonium }\end{array}$ & $\begin{array}{c}\text { FBR } \\
\text { Blanket } \\
\text { Plutonium }\end{array}$ \\
\hline $\begin{array}{l}\text { Length of history calculated, full- } \\
\text { power years }\end{array}$ & 25.2 & 21.4 & 17.8 \\
\hline Initial core loading, $\mathrm{kg}$ fissile $\mathrm{Pu}$ & 2,566 & 2,280 & 3,014 \\
\hline $\begin{array}{l}\text { Total fissile } \mathrm{Pu} \text { feed (including } \\
\text { initial loading), } \mathrm{kg}\end{array}$ & 35,627 & 28,990 & 26,345 \\
\hline $\begin{array}{l}\text { Total fissile Pu discharged (in- } \\
\text { cluding final inventory), kg }\end{array}$ & 46,718 & 38,387 & 33,628 \\
\hline Net excess of bred fissile $\mathrm{Pu}, \mathrm{kg}^{\mathrm{e}}$ & 10,552 & 8,955 & 6,894 \\
\hline Average fissile Pu yield, kg/year & 335 & 335 & 310 \\
\hline $\begin{array}{l}\text { Average in-reactor inventory, } \mathrm{kg} \text { fis- } \\
\text { sile } \mathrm{Pu}\end{array}$ & 3,424 & 3,331 & 3,604 \\
\hline Average breeding ratiof & 1.50 & 1.53 & 1.44 \\
\hline Exponential doubling time, years & 10 & 10 & 11 \\
\hline
\end{tabular}
$242 \mathrm{Pu}$.

at 0.80 plant factor.

${ }^{\mathrm{b}}$ Isotopic composition: $\quad 56 \%{ }^{239} \mathrm{Pu}, 23.7 \%{ }^{240} \mathrm{Pu}, 15 \%{ }^{241} \mathrm{Pu}$, and $5.3 \%$ $242 \mathrm{Pu}$.

${ }^{C}$ Isotopic composition: $35 \%{ }^{239} \mathrm{Pu}, 32 \%{ }^{240} \mathrm{Pu}, 15 \%{ }^{241} \mathrm{Pu}$, and $18 \%$

${ }^{\mathrm{d}}$ Isotopic composition: $96 \%{ }^{239} \mathrm{Pu}$ and $4 \%{ }^{240} \mathrm{Pu}$.

feed Pu.

$\mathrm{e}_{\text {With }} 1 \%$ loss deducted from discharged $\mathrm{Pu}$ and $0.2 \%$ loss added to

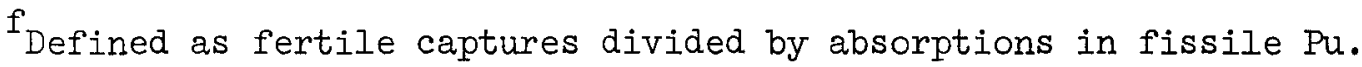


In the assumed fuel management program, the core, axial blanket, and inner radial blanket are replaced each cycle, while the outer radial blanket remains in place for three core fuel cycles. Thus, rather than a simple equilibrium cycle, the equilibrium situation is described by a repeating three cycle sequence. These three cycles are identified as E-1, E-2, and E-3 in Table 5.4. Mass balance data for GCFR's are given in detail in Ref. 16.

The reference carbide fueled design (GCFR-C) was not subjected to as complete a technical evaluation as were the oxide-fueled designs.

Table 5.4. Summary of Equilibrium Breeding Performance of GCFR-4

\begin{tabular}{|c|c|c|c|c|}
\hline & \multicolumn{3}{|c|}{ Repeating Three-Cycle Sequence } & \multirow{2}{*}{$\begin{array}{c}\text { Three-Cycle } \\
\text { Average }\end{array}$} \\
\hline & Cycle E-I & Cycle E-2 & Cycle E-3 & \\
\hline Cycle length, full-power days & 720 & 720 & 720 & 720 \\
\hline \multicolumn{5}{|l|}{ Fissile $\mathrm{Pu}$ charged, kg } \\
\hline Core & 2812 & 2812 & 2812 & 2812 \\
\hline Radial blanket & & 0 & 0 & 0 \\
\hline Axial blanket & & 0 & 0 & 0 \\
\hline Total & 2812 & 2812 & 2812 & 2812 \\
\hline \multicolumn{5}{|l|}{ Fissile $\mathrm{Pu}$ discharged, $\mathrm{kg}$} \\
\hline Core & 2642 & 2643 & 2643 & 2643 \\
\hline Radial blanket & 423 & 425 & 1201 & 683 \\
\hline Axial blanket & 364 & 362 & 357 & 361 \\
\hline Total & 3429 & 3430 & 4201 & 3687 \\
\hline $\begin{array}{l}\text { Net excess fissile } \mathrm{Pu} \text { (discharged } \mathrm{Pu} \\
\text { minus charged } \mathrm{Pu} \text { ), } \mathrm{kg}\end{array}$ & 617 & 618 & 1389 & 875 \\
\hline Cycle average fissile $\mathrm{Pu}$ inventory, $\mathrm{kg}$ & 3262 & 3532 & 3776 & 3523 \\
\hline \multicolumn{5}{|l|}{ Core breeding ratio ${ }^{a}$} \\
\hline Beginning of life & 0.91 & 0.91 & 0.91 & 0.91 \\
\hline End of life & 0.80 & 0.89 & 0.89 & 0.89 \\
\hline Average & 0.90 & 0.90 & 0.90 & 0.90 \\
\hline \multicolumn{5}{|l|}{ Total breeding ratioa } \\
\hline Beginning of life & 1.59 & 1.57 & 1.55 & 1.57 \\
\hline End of life & 1.41 & 1.39 & 1.38 & 1.39 \\
\hline Average & 1.50 & 1.48 & 1.46 & 1.48 \\
\hline $\begin{array}{l}\text { System average exponential doubling, } \\
\text { time, } b \text { years }\end{array}$ & & & & 9.6 \\
\hline
\end{tabular}
in ${ }^{239} \mathrm{Pu}$ plus $24{ }^{3} \mathrm{Pu}$.

$b_{\text {Based on }} 0.8$ plant factor and one year out-of-core inventory time per cycle. 
However, the neutronics calculations performed by GGA were reviewed, and the results were judged to be representative of the performance of a carbide fueled GCFR. The GGA physics results are summarized in Table 5.5 .

5.2.1.2 Power Distributions. Power distributions were obtained from the ORNI neutronics calculations for the oxide fueled GCFR and used in the core thermal-hydraulic evaluations discussed in Section 5.2.3. The power split between core and blankets and the core peak-to-average power ratios are listed in Table 5.6 for an equilibrium three cycle sequence.

Power distributions calculated by GGA ${ }^{16}$ for the carbide fueled designs are presented in Table 5.7. As previously mentioned, these results were not verified by ORNL calculations, but they appear to be reasonable.

\subsubsection{Pressure-Equalized Manifolded Fuel Element}

The principal novel feature of this element is that a means is provided for continuous extraction of the fission product gases generated within the fuel rods. These gases are conveyed through a tubing system

Table 5.5. Equilibrium Nuclear Performance of Carbide Fueled GCFR

Beginning of cycle

Fissile $\mathrm{Pu}$ charged, $\mathrm{kg}$ 1783

Total fissile Pu inventory, $\mathrm{kg}$ 1966

End of cycle

Fissile $\mathrm{Pu}$ discharged, $\mathrm{kg}$

Total fissile Pu inventory, $\mathrm{kg}$ 3074

Cycle length, full-power days 720

Cycle average breeding ratio 1.60

Fractional increase in average fissile $\mathrm{Pu} \quad 0.44$ inventory per cycle ${ }^{*}$

Exponential doubling time, ${ }^{*}$ years

With one year out-of-core holdup

With one-half year out-of-core holdup 4.7 
Table 5.6. Summary of Power Distribution Results for 8510-Liter GCFR-4

\begin{tabular}{lccc}
\hline & Cycle l & Cycle 2 & Cycle 3 \\
\hline Reactor nuclear power, Mw & 2530 & 2530 & 2530 \\
Thermal power by region, Mw & & & \\
Beginning of life & & & \\
Core & 2401 & 2368 & 2337 \\
Axial blanket & 42 & 42 & 42 \\
Inner radial blanket & 67 & 68 & 69 \\
Outer radial blanket & 20 & 52 & 82 \\
End of life & 2153 & 2123 & 2094 \\
Core & 136 & 133 & 130 \\
Axial blanket & 185 & 188 & 191 \\
Inner radial blanket & 56 & 86 & 1.15 \\
Outer radial blanket & & & \\
peak-to-average power ratio & & & \\
Core & & 1.26 & 1.26 \\
Beginning of life & 1.26 & 1.17 & 1.17 \\
Axial & 1.17 & 1.47 & 1.47 \\
Radial & 1.47 & & 1.21 \\
Overall & 1.21 & 1.21 & 1.16 \\
End of life & 1.16 & 1.16 & 1.40 \\
Axial & 1.40 & 1.40 & \\
Radial & & & \\
Overall & & & \\
\hline
\end{tabular}

Table 5.7. General Equilibrium Reactor Power Characteristics ${ }^{a}$ of $(\mathrm{U}, \mathrm{Pu}) \mathrm{C}_{2}$-Fueled GCFR

\begin{tabular}{ll} 
Net electric output, Mw & 1,000 \\
Total thermal power, Mw & 2,678 \\
Average thermal power by region, Mw (\%) & \\
Core & $2,199(82.1)$ \\
Axial blanket & $292(7.2)$ \\
Radial blanket & \\
Average fuel (U + Pu) specific power by region, & \\
Mw(th)/MT & 155.8 \\
Core & 10.6 \\
Axial blanket & 6.2 \\
Radial blanket & \\
Region average burnup at discharge, Mwd/MT & \\
Coreb & 112,200 \\
Axial blanket & 7,600 \\
Radial blanket & 8,900 \\
\hline
\end{tabular}

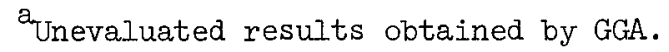

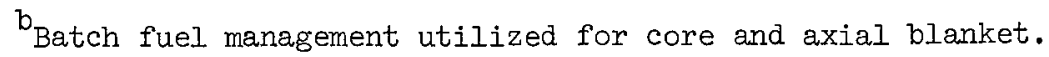

${ }^{c}$ Out-in management of radial blanket with inner half removed each core cycle. 
to a common storage plenum located outside the core but within the PCRV. The primary objective of this system is to minimize the difference in gas pressure between the interior of the fuel tubes and the reactor helium system. This reduces the pressure loading on the fuel tubes and,thus, reduces the problems associated with cladding performance. An experimental program to establish the feasibility and reliability of this approach will be required.

5.2.2.1 Manifolding System. The fuel pins are interconnected by passages drilled through the upper end fittings to which the pins are securely attached for end location (see Fig. 5.2). This represents a straightforward modification of the end fittings employed in earlier GGA designs of a hermetically sealed fuel element. These interconnecting passages converge to a common plenum located in the fuel box extension, which protrudes into otherwise empty space in the grid plate region. This plenum contains a charcoal trap to strip off the heat-producing fission products and ease cooling problems in the storage system.

The fuel box plenum is connected to gas passages in the grid plate by means of a spigot connection that is tightly clamped by the thrust tubes which clamp the fuel element to the grid plate. The passages in the grid plate lead to junctions at the outer edge of the core. From these junctions the fission products are piped through a relief valve to storage bottles located within the PCRV in a shielded and cooled compartment.

More details on the manifolding system are given in Ref. 12 .

5.2.2.2 Pressure-Equalizing System. The primary purpose of the manifolding system is to minimize the difference in gas pressure between the interior of the fuel pins and the reactor coolant system. This is accomplished by means of an arrangement of pressure relief valves that will either bleed fission products to the storage bottles or feed helium into the pins. These valves are controlled so that the pressure inside the fuel pins is maintained at a value between 10 and 100 psi below the coolant pressure.

The pressure equalizing system functions as follows in the valving arrangement shown in Fig. 5.3. The fission product gases pass through a relief valve $(V-I)$ to storage bottles. This relief valve is set to pass ission products to the bottle when the internal pressure within the 



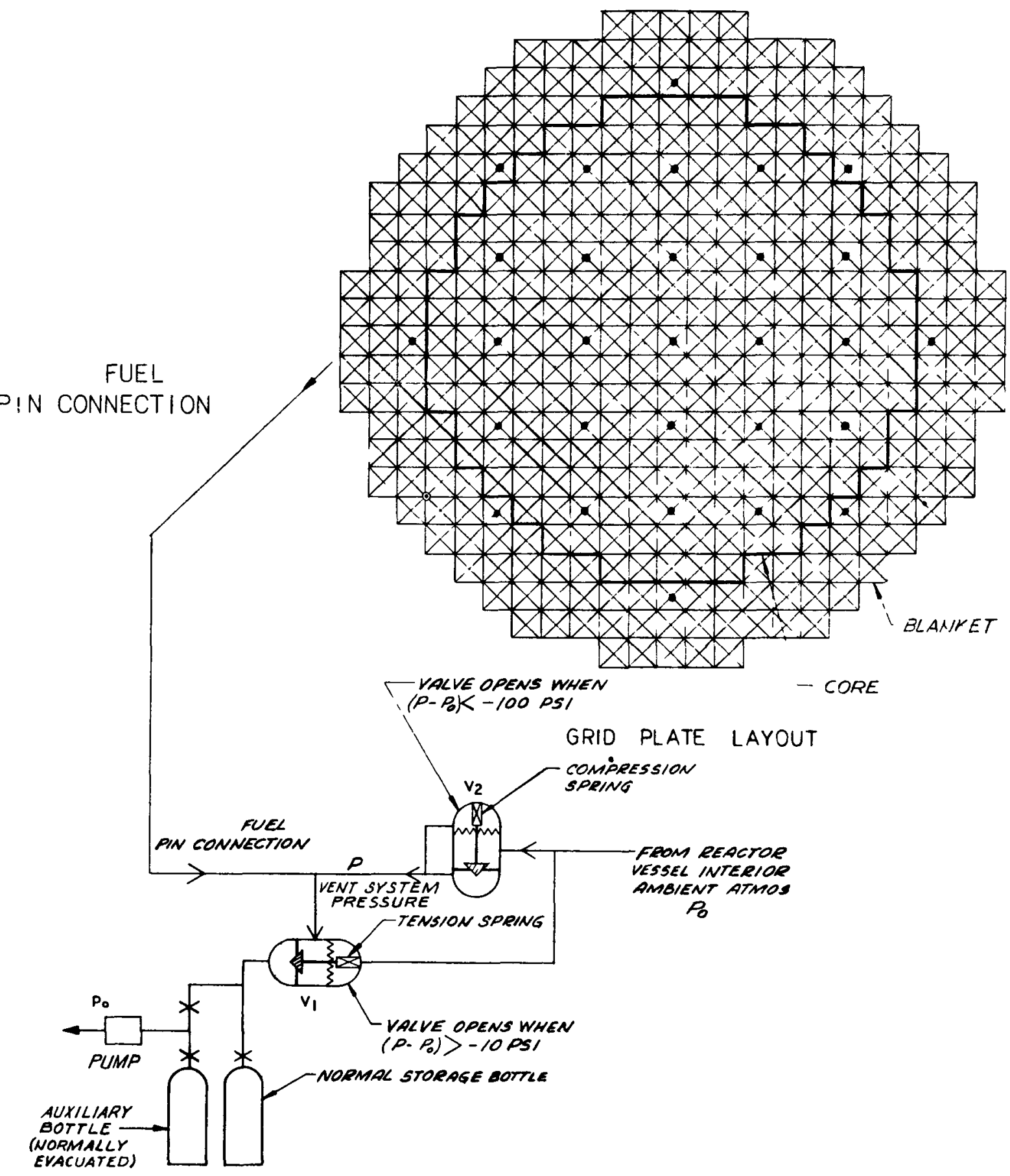

Fig. 5.3. Schematic Diagram of Pressure Equalizing System. 
fuel pin system rises to within $10 \mathrm{psi}$ of the ambient coolant pressure at the particular time. Thus, if the ambient coolant pressure is 1250 psi, this valve will keep a back pressure of 1240 psi within the fuel pins. If the fission-gas pressure within the pin is low (e.g., at reactor startup), valve $\mathrm{V}-2$ opens and allows coolant to leak into the fission product collection system until the internal pressure rises to within 100 psi of the ambient coolant pressure.

Thus valves $\mathrm{V}-1$ and $\mathrm{V}-2$ function together to maintain the internal pressure within a range of 10 to 100 psi below the ambient coolant pressure. This is accomplished by either bleeding fission product gases through valve $\mathrm{V}-\mathrm{l}$ to the storage bottles or feeding coolant into the pins through valve V-2. More details on this system are given in Ref. 12.

5.2.2.3 Evaluation of the Pressure Equalized Manifolding System. Approximately 1000 liters of gaseous fission products at reactor operating pressure must be accommodated during one core life; however, it appears that the gas storage system will have to accommodate a somewhat larger gas volume, since the fission products will probably be diluted with helium during plant shutdown. This dilution will result if the reactor is shut down and started up again while normal coolant pressure is maintained, because the gas within the fuel pins will cool off, perhaps by over $1000^{\circ} \mathrm{F}$ and, thus, decrease the fuel pin internal pressure considerably below the helium system pressure. This in turn will cause the valving system to feed helium into the fuel pins. Then, when the reactor is started up again, the fuel temperature and consequently the fuel pin internal gas pressure will rise, and the relief valve $(\mathrm{V}-1)$ will open and pass the excess gas from the pins to the storage bottles. This cycle will be repeated whenever the reactor is shut down and started up again while normal coolant pressure is maintained.

Some development would be required for the fuel venting system, including development of techniques for remote coupling and uncoupling of the fuel tubes to the gas-collection system, leak testing of the collection system and the various joints, and means for isolating the vent system when handling fuel. Behavior of vented fuel under the proposed radiation, coolant, and temperature environment would also have to be verified. On the whole, the proposed system appears to offer an attractive 
eans of minimizing the cladding stresses produced by differences between the pin internal gas pressure and the ambient coolant pressure.

\subsubsection{Thermal-Hydraulics Analysis}

A detailed thermal-hydraulics analysis was carried out to verify whether the proposed GCFR design and operating conditions were technically feasible. The temperature distributions and the maximum temperatures for the fuel, cladding, and coolant were determined, along with the pressure drops in the system, based on the power ratings and distributions obtained from the physics calculations. The primary purpose of these calculations was to determine whether either the fuel or cladding temperature exceeded acceptable design values. Table 5.8 summarizes the thermal design parameters for the GCFR. Wherever ORNL-calculated values differed from GGA values, the ORNL value is tabulated.

5.2.3.1 Power Distribution. The core peak-to-average power ratios calculated by ORNL for the reference GCFR-4 were also applied to the derated design, since the core zoning and compositions do not change significantly between the two concepts. The radial power peaking factor was calculated to be 1.17. It was assumed that the coolant flow orificing could be adjusted in direct correspondence to the radial power distribution, so that the coolant temperature at the outlet from each bundle would be the same as the mixed mean reactor outlet temperature. Possible departure from this ideal orificing pattern is represented as a flow maldistribution component of the engineering factors.

5.2.3.2 Surface Roughening. The GCFR fuel pin design utilizes surface roughening to promote coolant turbulence and increase the effective heat transfer coefficient in order to hold the maximum cladding surface temperature to an acceptable value. It was assumed that, as stated by GGA, the effect of roughening would double the effective heat transfer coefficient at the expense of a threefold increase in the friction factor. To minimize the friction increase, surface roughening would be used only in the downstream portion of the core, starting at the axial position at which the temperature of the smooth cladding reaches the nominal limit specified for the cladding material. 
Table 5.8. Thermal-Hydraulic Characteristics of the GCFR Cores $\begin{array}{ll}\text { Reference Design } & \begin{array}{l}\text { Derated } \\ \text { Design }\end{array}\end{array}$

Coolant

Helium at 1250 psi Same

Cladding

Stainless steel

Same

Fuel distribution

Uniform axially; zoned Same radially to give 1.2 maximum-to-average power ratio

Axial blanket thickness, in.

23.6

23.6

Active core length, in.

58.4

60.9

Core pin design

Partial roughening

Same

Roughening heat transfer multiplier 2

Roughening friction factor multiplier 3

3

Thermal power, Mw

Core only

Axial blanket

Radial blanket

Temperatures, ${ }^{\circ} \mathrm{F}$

Inlet coolant to reactor

Inlet coolant to active core

outlet coolant from active core

Outlet coolant from the reactor

Maximum surface (nominal)

1315

1205

Maximum fuel (nominal)

4935

4765

Maximum heat rating, $\mathrm{kw} / \mathrm{ft}$

17.8

16.3

Coolant pressure drop over reactor, psi

42.6

42.6

Fuel box inside dimensions, in.

6.75

6.67

Maximum heat flux, Btu/hr.ft ${ }^{2}$

732,000

654,750

Fuel rods per standard box

225

225

Fuel rods per control-rod box

189

189

Fuel-pin diameter, in.

0.317

0.307

Thickness of cladding, in.

0.0116

0.0113

Fuel pellet outer diameter, in.

0.291

0.282

Fuel pellet inner hole diameter, in.

0.058

0.056

Number of fuel boxes (with 225 pins)

164

180

Number of control-rod boxes in core

21

21

(with 189 pins in each box)

Total number of boxes in core

201

Total number of pins in core

40,869 
5.2.3.3 Engineering Factors. The engineering hot channel factors used in these calculations were estimated by GGA and were used to calculate the most probable values for the cladding temperature. The maximum temperatures resulting from the inclusion of these factors are referred to as "local hot spot" temperatures.

5.2.3.4 Cladding and Fuel Temperatures. The pin surface heat flux, coolant temperature, and cladding outer surface temperatures were calculated as a function of axial position and were based on the zone power ratings and distributions. The fuel temperature was then calculated from the pin power rating and cladding surface temperature as a function of position.

The maximum temperatures calculated for the GCFR fuel pins are summarized in Table 5.9 and compared with the cladding surface design limits and a fuel temperature limit of $4950^{\circ} \mathrm{F}$. It may be seen that under certain conditions fuel temperatures will exceed this value, and melting will probably occur. Since it is anticipated that radiation effects might lower the melting point of the oxide fuel, the calculated temperatures for GCFR-4 indicate that some fuel melting may occur on the interior surface of the annular fuel pellets. Although the actual volume of fuel involved is quite small, current design practice would make this condition unacceptable.

Maximum fuel temperatures calculated for the derated design are also above the oxide melting point when hot channel factors are included. The volume of fuel approaching melting is very small in this case.

Interior fuel melting can be avoided by one of several design alternatives. The most obvious change is to further derate the pin heat rating. This would increase fuel costs, but the penalty would be small for the necessary decrease in pin rating. A second alternative would be to use a pellet density higher than $90 \%$ and increase the diameter of the center hole to maintain the same volumetric fuel loading. The combined effects of the larger center hole and higher thermal conductivity would provide a considerable reduction in fuel interior temperatures; however, the allowable density may be limited by the need to accommodate fission-gas buildup.

5.2.3.5 Pressure Drop. The coolant pressure drop was calculated, ith all losses through the reactor considered. The pressure loss across 
Table 5.9. Maximum Temperatures Calculated for GCFR Fuel Pins

\begin{tabular}{|c|c|c|c|c|c|c|}
\hline & \multicolumn{6}{|c|}{ Maximum Temperature $\left({ }^{\circ} \mathrm{F}\right)$} \\
\hline & \multicolumn{3}{|c|}{ Reference Design } & \multicolumn{3}{|c|}{ Derated Design } \\
\hline & Calculated & $\begin{array}{l}\text { GGA Design } \\
\text { Limit }\end{array}$ & Interior* & Calculated & $\begin{array}{l}\text { GGA Design } \\
\text { Limit }\end{array}$ & Interior* \\
\hline $\begin{array}{l}\text { Local hot spot: } 100 \% \text { design power } \\
\text { with engineering factors }\end{array}$ & 1435 & 1472 & 5205 & 1315 & 1380 & 5040 \\
\hline $\begin{array}{l}\text { Power overshoot plus local hot } \\
\text { spot: 110\% power with engineer- } \\
\text { ing factors }\end{array}$ & 1515 & & 5300 & 1385 & & 5160 \\
\hline
\end{tabular}

*Fuel temperature limit is $4950^{\circ} \mathrm{F}$. 
he reactor (plenum to plenum) was calculated to be $42.6 \mathrm{psi}$, which is in good agreement with the GGA design value of $45 \mathrm{psi}$.

\section{2 .4 Materials}

Fuel and cladding performance of the GCFR-4 were evaluated to define areas that might limit the life of the fuel element if operated at design conditions. The parameters investigated were fuel temperatures, cladding temperatures, and cladding stresses. Of principal concern is the ability of the fuel cladding to maintain its integrity over the life of the fuel element. Many factors can contribute to fuel element failure, and it is the improbable concurrence of a combination of circumstances that often causes fuel element failures. The probability of failure increases with severity of operating conditions, particularly with increased burnup and temperature and, thus, extensive testing will be required to determine that the fuel elements will perform as expected.

The maximum temperatures calculated for the fuel and cladding were summarized in Table 5.9 for the two oxide fueled GCFR designs. The highest temperatures were encountered in the GCFR-4 reference design, with the cladding surface temperature reaching $1435^{\circ} \mathrm{F}$ at the hot spot under 100\% power conditions.

Maximum heat ratings of $18.0 \mathrm{kw} / \mathrm{ft}$ and design burnups of 100,000 Mwd/MT (achieved in 17,000 hr) are proposed for the fuel rods. The proposed cladding material is type 316 stainless steel at a cladding thickness of 0.0116 in. The helium gas coolant operates at a pressure of $1250 \mathrm{psi}$. No experimental data on performance of the fuel elements have been obtained. Although pressure differentials are equalized by the venting system, there are no experimental data on any fast reactor fuel pins tested with gas coolants at comparable temperatures to any extended burnup. Thus, analyses of performance are based on considerable extrapolation. Many factors of importance cannot be definitely resolved until additional experimental evidence is attained under conditions more nearly representative of those proposed for GCFR-4. Several areas of concern are discussed briefly below. 
5.2.4.1 Cladding Temperature. Although GGA has specified a nominal design temperature limit of $1300^{\circ} \mathrm{F}$ for the reference design, the fuel cladding will operate at hot spot temperatures up to $1450^{\circ} \mathrm{F}$. The principal effect of the higher cladding temperatures will be to reduce the strength of the cladding, and the $150^{\circ} \mathrm{F}$ difference between design and maximum temperatures will reduce the creep strength of the cladding by nearly a factor of 2 for type 316 stainless steel and somewhat less for Hastelloy $X$. Further reductions in cladding strength may accrue from prolonged operation at high temperatures. Reactions with impurities in the helium coolant, for instance, may result in degradation of cladding strength.

5.2.4.2 Fuel-Cladding Compatibility. Fuel-cladding compatibility has been established ${ }^{27}$ in furnace tests with $\mathrm{UO}_{2}-20 \% \mathrm{PuO}_{2}$ in contact with various stainless steels (including type 316 stainless steel) for $1000 \mathrm{hr}$ at $1400^{\circ} \mathrm{F}$. No bonding or diffusion across the interface developed, although hyperstoichiometric oxide developed a l-mil-thick oxide film on the inner surface of the steel, and slight metallurgical effects (to a depth of 0.1 mil) were noted in adjacent metal.

Successful performance of mixed oxide fuel pins at 50,000 Mwd/MT at temperatures up to $1100^{\circ} \mathrm{F}$ has been reported, and pins irradiated at $1300^{\circ} \mathrm{F}$ do not indicate a general problem, although some instances of cladding reaction have been observed. 28 From thermodynamic considerations, Anselin and $\mathrm{Baily}^{29}$ concluded that irradiation of stoichiometric mixed oxide fuels to high burnup may release oxygen which can react with fuel cladding and that out-of-reactor compatibility tests may not be relevant. It appears that experimental testing will be required to establish the extent to which fuel-cladding compatibility and cladding temperature may influence fuel element performance.

5.2.4.3 Fuel Swelling. With the use of the pressure equalizing technique to avoid differential pressure loads on the cladding, fuel swelling will be a major source of cladding stress. The volume increase from solid fission product formation will be about 1\% or less per 10,000Mwd/MT burnup if a major fraction of the fission gas escapes. ${ }^{28-30}$ Gas 
lease is a function of temperature and burnup and ranges from about 50 to $95 \%$ at high heat ratings and burnups of 50,000 to $125,000 \mathrm{Mwd} / \mathrm{MT} .^{31-32}$

At maximum temperature regions in the GCFR-4, it seems reasonable (although conservative) to assume that gas release will be about $90 \%$ and that fuel swelling will be about 1\% per 10,000-Mwd/MT burnup. At lower temperature regions, where less gas is released, swelling may be greater but the burnups will be less. Internal void space has been provided in the GCFR-4 designs to accommodate fuel swelling if most of the fission gases generated are released and the external restraint is sufficient to cause the fuel to flow inward to the void spaces.

The pressures generated at the fuel cladding interface as a result of swelling are relieved to some extent by plastic and elastic deformations of the fuel and cladding. The criterion limiting fuel element life will probably be the development of about $1 \%$ cladding creep strain. 28 Cladding strength must therefore be sufficient to insure that most of the volume increase is accommodated by the flow of the fuel to the internal porosity and the void space at the interior of the cored fuel pellets.

At the high temperatures proposed for the GCFR-4, the cladding will offer little restraint against fuel swelling. However, the parameters controlling creep strength of fast reactor fuels have not been established. Available data on fast reactor fuels at high burnups have been examined with reference to the effect of restraining pressures on fuel rod swelling. These data were obtained on sodium-cooled pins tested in DFR or EBR-II. ${ }^{31,33}$ observers concluded that the tests indicated that the fuel pins were capable of achieving 5.0-at. \% mean burnup ( 6.0 -at. \% peak burnup) but that fuel swelling would cause excessive cladding strain at 7 -at. \% mean burnup. However, one rod achieved 7.7 -at. $\%$ peak burnup with only $0.5 \%$ cladding strain. Data suggest that fuel diametral expansion increases with burnup, probably as a result of increasing resistance to swelling accommodation. For EBR-II tests, no rods with more than about 5\% void volume suffered excessive swelling. The one rod that had 0.010 -in.-thick cladding showed $0.9 \%$ strain at 6 -at. $\%$ burnup. 31

It is apparent that the cladding in the gas-cooled reactor designs studied here offers less restraint against fuel swelling than the cladding 
proposed for use with other fast reactor designs because of the higher operating temperature. Other factors being equal, it might be expected that comparable swelling rates would be achieved at a comparable restraining pressure. However, fuel temperatures in GCFR-4 are somewhat higher, and it is possible that this effect in causing greater fuel plasticity and fission gas release may indeed require less restraint. Because of the unknown interaction of many processes, it is concluded that the effect of cladding temperature and cladding thickness on burnup limitations of the fuel element cannot now be established.

5.2.4.4 Fuel Melting. The heat ratings proposed for the GCFR designs ( 18 and $16.5 \mathrm{kw} / \mathrm{ft}$ ), coupled with the high surface temperatures, are sufficient to cause central fuel melting at some regions of the fuel. Initial melting may be avoided if it is feasible to allow fuel to densify by an initial slow increase in operating power. However, subsequent fission-induced fuel swelling, coupled with a possible decrease in thermal conductivity, may override this effect and result in fuel melting. The high fuel temperature will also result in greater plastic strain on thermal cycling and will tend to reduce cladding fatigue life from strain cycling. Experimental testing will be required to define maximum heat ratings that allow successful operation to the desired burnup.

5.2.4.5 Radiation Damage Effects. The primary radiation effect will be a reduction in fracture ductility of the cladding. Apparently as an effect of helium generation by transmutation from fast neutron absorption, the ductility of cladding material will be reduced to $1 \%$ or less. This problem is common to all fast reactor claddings, and is recognized as a major problem that may limit performance of fast reactor fuel elements.

Preliminary information also indicates that fast neutron damage may generate voids that can cause volume increases in fuel cladding materials. At exposures of approximately $10^{22}$ neutrons $/ \mathrm{cm}^{2}$, the volume increase is approximately $0.1 \%$, and data suggest that at $10^{23}$ neutrons $/ \mathrm{cm}^{2}$, volume increases may approach 10\%. 32 Experimental testing at reference conditions will be required to define the effect of these factors on performance of 
GCFR fuel elements which, under design conditions, will experience an integrated fast neutron dose of $10^{23}$ neutrons $/ \mathrm{cm}^{2}$.

5.2.4.6 other Effects. Many other factors not discussed above can contribute to failure of the fuel elements. For example, effects of thermal stresses, coolant drag forces, surface roughening, or fabrication tolerances are not considered because of lack of detailed information on fuel-element design. These factors should be evaluated by experimental testing as the information becomes available.

5.2.4.7 Conclusions. It is concluded that the fuel element proposed for the GCFR-4 represents a considerable extrapolation of current technology, and that much experimental testing will be required to define effects of various parameters on the burnup attainable. A major limitation results from reduced cladding ductility, which is recognized as a major problem for development of any fast reactor design. Maximum cladding temperatures for GCFR-4 of $1435^{\circ} \mathrm{F}$ are about $250^{\circ} \mathrm{F}$ higher than proposed for sodium-cooled fast reactors. Higher cladding temperatures will adversely affect compatibility and cause development of metallurgical changes that may reduce cladding strength. It is concluded that the maximum allowable cladding temperatures cannot now be determined.

With use of the pressure-equalized design to avoid fuel rod collapse under the coolant pressure, the gas-cooled reactor fuel element offers considerably less restraint to fuel swelling than fuel elements for other proposed reactor systems. Since the higher fuel temperatures favor additional gas release and greater fuel plasticity, successful operation with less restraint may indeed be feasible. It is concluded that experimental testing will be required to establish burnup limitations of the fuel element as a function of temperature, heat rating, and restraint.

\section{2 .5 Components}

The plant systems of the two GCFR designs are described in the design reports referenced previously. Supplementary information on both the reference and derated designs was supplied by GGA to ORNL through correspondence, telephone calls, and meetings during the course of this evaluation. 
The performance of individual components of the reactor and the heat removal and power generation systems were checked out in detail. The evaluations of individual components are discussed in the following sections.

5.2.5.1 Prestressed Concrete Reactor Vessel. The PCRV for the GCFR differs in some respects from those being used in European reactors and also from the vessel designed by GGA for the Fort St. Vrain HTGR plant. Data for a number of PCRV designs, are given in Ref. 34. While the GCFR vessel is no larger than some of the other PCRV's, the horizontally oriented supercircle geometry represents a different approach. The working pressure of $1250 \mathrm{psi}$ also is considerably beyond operating pressures of the other plants. Because of these extrapolations of current operating experience, substantial experimental verification of the design will be needed, including model tests.

Construction of the PCRV proposed for the GCFR appears to be feasible. However, major difficulties could be encountered in its construction, and therefore considerable work must be done to demonstrate suitable construction techniques. Also, the time schedule is highly uncertain, with estimates of the PCRV construction time ranging from one and one-half to four years.

Tolerances appear to be the key issue with this structure. Until these are established and their maintainability demonstrated for the vessel life, the question of feasibility cannot be completely resolved. At the least, some significant compromise in design could be required.

5.2.5.2 Reactor Core Support Structure. Vibration of the core structure due to physical loads imposed by the flow of coolant could be a problem. Flow studies on a mockup of the core structure will be necessary to determine vibration susceptibility of the design.

The 30-year fast neutron ( $E>0.5 \mathrm{Mev}$ ) exposure for the grid plate was calculated to be $6 \times 10^{21}$ neutrons $/ \mathrm{cm}^{2}$. This exposure is not excessive if the grid plate is constructed of austenitic stainless steel.

5.2.5.3 Helium Circulators. The helium coolant is circulated through the reactor and heat transfer system by four single stage centrifugal circulators. Each circulator is connected by a jackshaft arrangement to a steam powered drive turbine located outside the PCRV. 
Emergency circulation of coolant is provided by two independent single stage turbo-circulators driven by Pelton water turbines.

Although a thorough engineering review and evaluation of the proposed helium circulators was beyond the scope of this study, it appears that the designs represent reasonable extrapolations of current technology. A research and development program would nevertheless be required to establish performance characteristics and reliability.

5.2.5.4 Helium Coolant Loops. The primary coolant system consists of four loops, in each of which one-fourth of the total reactor flow passes through a steam generator and on to one of the four main circulators. The pressurized helium is discharged from the circulator through ducting back to the reactor inlet.

The pressure drop through the main helium circuit is about 60 psi, which implies that large differential pressures will exist across the walls of the ducting. The ambient pressure in the boiler room is maintained about halfway between boiler gas inlet and outlet pressures. Thus the differential pressure tending to burst the ducting will be in excess of $50 \mathrm{psi}$ at the circulator discharge. The design specifies that the rectangular ducting be reinforced against bursting by use of typical boiler stay rods.

5.2.5.5 Steam Generators. An evaluation was made to determine the minimum heat transfer areas required for the reheater, economizer, boiler, and superheater sections of the Sulzer steam generator described in Ref. 12. This steam generator is of the multipass cross flow type and is one of three designs under study by GGA for use with the GCFR. The helium coolant enters a large central plenum and then flows horizontally outward through two separate heat exchange assemblies. The feedwater enters through conventional high-pressure headers and flows countercurrently through tubes in which it is heated, vaporized, and superheated.

ORNL calculations of the required heat transfer area in the steam generators indicated that a minimum of about $66,500 \mathrm{ft}^{2}$ would be needed. With the addition of a 10\% allowance for possible tube plugging, the total area required is about 73,200 $\mathrm{ft}^{2}$. This may be compared with the estiGated area in the Sulzer unit of $52,000 \mathrm{ft}^{2}$. This indicates a shortare 
of about $28 \%$ based on the minimum requirements or about $40 \%$ based on the area with plugging allowance.

Proposals for similar steam generator units were provided to GGA by $B \& N$ and Foster-Wheeler. The areas estimated by these vendors were 45,700 and $61,550 \mathrm{ft}^{2}$ with plugging allowances. Since the area proposed for the Sulzer unit is intermediate to these values and the vendors had more detailed information about the units than was available to ORNL, it was concluded that the Sulzer unit probably provides adequate heat transfer area. It must be recognized that the range of values given can be caused by uncertainties due to lack of reliable heat transfer correlations for helium flowing across banks of tubes.

\subsubsection{Safety and Control}

The GCFR has several inherent safety advantages and disadvantages when compared with other types of fast reactors. These features are discussed in the following review of the potential major accident situations that might be encountered.

5.2.6.1 Review of Reactivity Accidents. In general, fast reactors are more sensitive to reactivity accidents than are themal reactors, since they have a shorter prompt-neutron lifetime, smaller delayed-neutron fraction, and smaller negative-reactivity feedback effects. Except for the power-limiting effect of the Doppler temperature coefficient associated with the fuel, the GCFR does not have an inherent shutdown mechanism, so an applied reactivity shutdown will be required to cancel a reactivity transient.

A general review was therefore made of possible causes of reactivity transients in the GCFR. Based on this review, it appears that for realistic reactivity insertion rates, a well-designed fast safety system and shutdown mechanism would be able to terminate an accident before the fuel was damaged.

A highly reliable applied shutdown requires the use of two complete and independent sets of safety systems and fast scram mechanisms. The reference systems do not include any form of reserve shutdown system, so the addition of a second'automatic safety system and fast scram mechanism is recommended. 
Large fast reactors usually will have an increase in reactivity associated with a loss of coolant, while thermal reactors will usually have a reactivity decrease. The reactivity increase associated with loss of coolant in the GCFR is considerably smaller than that associated with many steam- or liquid metal-cooled fast breeder reactor designs. Also, the PCRV concept may make very high blowdown rates more unlikely for the GCFR concept than for the conventional steel piping cooling system used in the SCBR designs.

The GCFR does not have the problem of reactivity effects from local voiding that might be experienced in large liquid metal fast breeder reactors. Flooding of the core with unpoisoned water would give a large addition of reactivity in both the GCFR and the SCBR; however, accidental flooding of the core appears to be less likely in the GCFR.

Further study of the kinetics of the gas-cooled fast reactor is necessary to provide information on which to base adequate safety system designs.

5.2.6.2 Loss of Cooling. Perhaps the most crucial consideration in the successful operation of the GCFR is that of core cooling. The GCFR concept depends on maintaining forced circulation of the coolant at all times for normal and emergency cooling of the core. If the coolant flow is interrupted, a very short time interval is available in which to scram the reactor and restore forced circulation cooling. If the fuel is uncooled while operating at full power, it will heat up at an average rate of about $500^{\circ} \mathrm{F} / \mathrm{sec}$ (compared with about $90^{\circ} \mathrm{F} / \mathrm{sec}$ in a light water thermal reactor). The heatup rate is only about $17^{\circ} \mathrm{F} / \mathrm{sec}$ after reactor shutdown, and the time margin then for automatic startup of the auxiliary circulators is about $1 \mathrm{~min}$.

A more serious aspect to the problem of core cooling is the possibility of a loss-of-coolant or depressurization accident. The reactivity increase due to loss of coolant is not a severe problem in the GCFR, but the decrease in coolant mass flow upon depressurization would cause a large decrease in core cooling ability. If the main circulators remained operative following a loss of coolant, the number of circulators required remove the decay heat and limit the fuel temperature to a safe value 
would be strongly dependent on the depressurization rate, as illustrated by results of GGA calculations given in Table 5.10 (from Fig. 13-3 of Ref. 12).

The data of Table 5.10 indicate that if the loss-of-coolant accident is such that main circulator failure may also be induced, the depressurization rate must be fairly slow before there is any redundancy in the number of main circulators available to remove decay heat. (GGA has subsequently indicated that these calculations are somewhat pessimistic for the cases with reduced numbers of the circulators in operation; however, the figures shown above should be indicative of the magnitudes of pressure-decay rates that reduced numbers of circulators can handle.)

Transient analyses made by GGA indicate that if the main circulators fail during the depressurization accident, two axial flow auxiliary blowers with a power of about $500 \mathrm{hp}$ each could deal with exponential pressure decay with time constants as low as 1 min without inclirring damaging temperatures. The cladding temperatures would, however, exceed the design limit for a brief interval. ORVL estimates predict that one such auxiliary blower could handle a depressurization with a time constant of about 10 to $30 \mathrm{~min}$ without damaging temperatures being reached.

Thus, the design appears to have sufficient redundancy in circulators to accommodate small coolant leaks that would result in depressurizations with time constants no less than 10 to $30 \mathrm{~min}$; however, the design does not appear to have sufficient redundancy in decay-heat removal equipment

Table 5.10. Results of GGA Calculation of Number of Operative Circulators Required Following a

Loss-of-Coolant Accident

\begin{tabular}{ccc}
\hline $\begin{array}{c}\text { Minimum } \\
\text { Depressurization } \\
\text { Time Constant }\end{array}$ & $\begin{array}{c}\text { Required Number } \\
\text { of Operative Main } \\
\text { Circulators }\end{array}$ & $\begin{array}{c}\text { Minimum Total } \\
\text { Depressurization } \\
\text { Time }\end{array}$ \\
\hline $30 \mathrm{sec}$ & 4 & $2 \mathrm{~min}$ \\
$9 \mathrm{~min}$ & 2 & $40 \mathrm{~min}$ \\
$1.7 \mathrm{hr}$ & 1 & $8 \mathrm{hr}$ \\
\hline
\end{tabular}


if larger breaks ( 90 in. ${ }^{2}$ ) are considered credible. The requirements placed on the circulators are more severe than those of emergency cooling systems in current thermal reactors, and further study is needed to demonstrate that an adequate level of reliability can be achieved.

One way of reducing the blower requirements following a depressurization accident would be to construct a pressure sustaining secondary containment building around the PCRV. If this secondary containment vessel could hold the equalized pressure up to something like $60 \mathrm{psi}$, the mass flow capability of the operative circulators would be increased considerably.

5.2.6.3 Reactor Containment. The containment design for the GCFR houses the primary reactor system within the PCRV, which is in turn housed in a low-leakage building maintained at slightly negative pressures by a ventilation system discharging to the plant stack through a filtering system. In order for this to be an acceptable scheme, the PCRV integrity must be of such a high order as to guarantee that no more than perhaps $0.01 \%$ of the core fission product inventory will escape to the reactor building, even under the worst accident conditions.

Consideration of emergency cooling requirements, possibilities of PCRV penetration failures, and the severe consequences of a fission product release led the ORNL reviewers to recommend that a pressure sustaining secondary containment vessel be used in place of the controlled leakage containment building specified by GGA. Costs for this secondary containment vessel were included in the capital cost estimates.

5.2.6.4 Steam-Generator Leak. A large steam-generator leak would present a unique problem, since it might lead to overpressurization of the PCRV and also involve a reactivity addition. The detection and automatic isolation of the loop with the faulty steam generator would be difficult, and the problem would be complicated by the requirement for continuous forced cooling of the core.

5.2.6.5 Destructive Excursion and Meltdown Containment Capability. The high power densities and low heat capacities of large fast reactor cores and the need for continuous coolant circulation make meltdown more likely than in current light water reactors. Fast reactors contain several critical masses that become more reactive as the core is compacted, so 
they can become critical and continue to produce fission power after core meltdown or a collapse; whereas thermal reactors become subcritical. This feature and the short prompt-neutron lifetime make a destructive nuclear excursion a problem for fast reactors that thermal reactors do not have. The range of possible energy releases was estimated; however, it will be difficult to establish either the credibility of a distinctive excursion or an upper limit on the energy release. The capabilities of the PCRV to withstand a destructive energy release have not been determined. Further study is required to develop reliable means for containing the fuel after a core meltdown or a destructive energy release and removing the heat to prevent reactor vessel melt-through. 


\section{ECONOMIC COMPARISON OF CONCEPTS}

\subsection{Capital Costs}

Capital costs of the low pressure SCBR were developed by B\&W and Sargent \& Lundy, the intermediate pressure SCBR costs were estimated by the Karlsruhe Nuclear Research Center, and the high pressure design costs were established by B\&W and American Electric Power. Costs for the reference GCFR-4 and derated GCFR-4D designs were developed by GGA and the East Central Nuclear Group.

For the purpose of comparing costs of alternate coolant fast breeders with costs of other concepts, three other designs were considered; namely, a light water reactor (PWR), a liquid metal-cooled fast breeder reactor (LMFBR), and a high temperature gas-cooled reactor (HTGR). Costs for these concepts were submitted to ORNI by the Light water Reactor Task Force, ${ }^{35}$ the IMFBR Task Force, ${ }^{36}$ and Gulf General Atomic, ${ }^{37}$ respectively.

Capital costs were normalized by using the ground rules described in Chapter 3 to develop a comparative set of construction costs in which the relative cost differences among the concepts were influenced as little as possible by differences in ground rules, indirect costs, and other factors that were not functions of differences in design features. Also, costs were updated where appropriate to reflect construction costs as of June 1967, since some of the estimates had been made in earlier periods than others.

Direct costs submitted by each of the sponsors were compared, system by system, by both ORNL and Sargent \& Lundy. Adjustments were made when it appeared that unit cost data used in the estimate submitted were not consistent with unit cost data adopted for this study, or when a common cost, such as a site-dependent cost, was considered applicable to all concepts.

The capital cost normalization study did not involve a detailed review of the design requirements of special components of the plants, such as reactor vessel components and other nuclear items, since these requirements were reviewed in the concept evaluation studies. The costs of these components represent from as little as $26 \%$ to as much as $50 \%$ of the direct 
costs, depending on the concept considered. The sponsor's judgment of these costs was generally used; however, some adjustments were made when costs for given components appeared to be considerably out of line with costs of their counterparts in other plant systems. The remaining 50 to $75 \%$ of the direct costs for more conventional components, such as structures, steam and feedwater systems, turbine-generators, and electrical system components were more amenable to capital cost normalization based on specific design parameters.

Only a moderate amount of design normalization (as distinguished from cost normalization) was attempted in this study. Common designs were assumed for all concepts in assigning costs for ground improvements and for miscellaneous power plant equipment, and some amount of design normalization was assumed for safety equipment and turbine-generator plant components. However, basic design features of the reactor plant equipment reported by the designer or evaluator were left unchanged. The costs reported here represent ORNI's judgment of appropriate relative capital costs for the concepts described based on the evaluation study rules, cost estimates of the designer and the evaluators, and the cost normalization study performed by Sargent \& Lundy.

\subsubsection{Sargent \& Lundy Participation}

Sargent \& Lundy participation in the capital cost normalization study consisted of examining reported and evaluated design requirements and costs for the concepts, recommending areas where uniform costs should be applied, and recommending cost adjustments based on their experience in reactor plant design and cost estimating. Sargent \& Lundy worked closely with ORNL with regard to design interpretation and ground rules to be used, but they presented to ORNL a set of direct cost data for each of the concepts based on their separate study. The Sargent \& Iundy effort was restricted by scope to using evaluated design conditions as bases for their estimates, and thus they did not attempt further evaluations of design requirements. The normalized direct costs presented here are in close agreement with the direct costs recommended by Sargent \& Iundy. 
6.1.2 Estimated Capital Costs

Normalized capital cost estimates for the 1000-Mw(e) alternate coolant breeder reactor plants are summarized by the major cost accounts in Table 6.1. A more detailed summary of direct costs of these reactors is given in Table 6.2, along with direct costs of other concepts considered in the system analyses studies.*

The costs shown include costs for coolant and moderator inventories other than $\mathrm{D}_{2} \mathrm{O}$ inventories. Although $\mathrm{D}_{2} \mathrm{O}$ inventory is a capital cost item, its cost is reported as a separate component of power production costs in the evaluation reports. The ground rules observed in the capital cost normalization study are summarized in section 3.3.

Except for the PWR, the following contingency allowances were made:

1. $18 \%$ on reactor equipment accounts $221,222,223,225,226$, and 229.

2. $2 \%$ on account 231 (turbine-generator) because estimates were based on list prices.

3. $10 \%$ on remainder of plant.

In the case of the PWR, the nuclear package and turbine-generator contingency allowance was only $2 \%$ because costs were based on manufacturers quoted prices. The contingency allowance for the remainder of the plant was $5 \%$.

The total unit costs of $1000-\mathrm{Mw}(e)$ concepts derived on this basis are summarized in Table 6.3. Since all costs were adjusted to 1000-Mw (e) plants, costs shown in Table 6.3 are also equivalent millions of dollars. Thus Table 6.3 can be used to show the differential cost of any given component or system of components.

The normalized costs thus developed in this study have the influences of different ground rules factored from the results and show, insofar as feasible, the relative costs of the various concepts. However, the normalization study would have to be much more detailed than it was to assure that the relative cost differences presented are entirely indicative of true differences due alone to inherent differences in design features because several designers were involved. Relative costs that might change

*Results of these studies are to be reported in USAEC Report WASH-1098, "Potential Nuclear Power Growth Patterns" 
Table 6.1. Capital Costs of Alternate Coolant Breeder Reactors

\begin{tabular}{|c|c|c|c|c|c|}
\hline & \multicolumn{5}{|c|}{ Costs (thousands of dollars) } \\
\hline & \multicolumn{3}{|c|}{ SCBR } & \multicolumn{2}{|c|}{ GCFR } \\
\hline & $1250 \mathrm{psi}$ & $2680 \mathrm{psi}$ & $3700 \mathrm{psi}$ & Derated & Reference \\
\hline \multirow{2}{*}{\multicolumn{6}{|c|}{$\begin{array}{l}\text { Direct construction cost } \\
\text { Account }\end{array}$}} \\
\hline & & & & & \\
\hline 21 - structures and improvements & 19,003 & 15,391 & 15,200 & 10,802 & 10,752 \\
\hline 22 - Reactor plant equipment & 34,909 & 47,230 & 39,240 & 48,585 & 50,545 \\
\hline 23 - Turbine plant equipment & 32,853 & 25,213 & 24,307 & 26,491 & 25,073 \\
\hline 24 - Accessory electrical equipment & 4,254 & 4,000 & 3,800 & 4,200 & 4,200 \\
\hline 25 - Miscellaneous power plant equipment & 1,250 & 1,250 & 1,250 & 1,250 & 1,250 \\
\hline Total direct construction costs & 92,269 & 93,084 & 83,797 & 91,328 & 91,820 \\
\hline \multirow[t]{2}{*}{ Indirect and land costs } & 37,992 & 38,316 & 35,067 & 38,016 & 38,214 \\
\hline & 130,261 & 131,400 & 118,864 & 129,344 & 130,034 \\
\hline Total unit costs, $\$ / k w(e)$ & 129.1 & 131.4 & 121.7 & 129.3 & 130.0 \\
\hline
\end{tabular}




\begin{tabular}{|c|c|c|c|c|c|c|c|c|c|c|c|c|c|c|c|c|c|c|}
\hline & \multirow{3}{*}{ Account } & \multicolumn{17}{|c|}{ Costs (thousands of dollars) } \\
\hline & & \multirow{2}{*}{ PWR } & \multicolumn{5}{|c|}{ HWOCR } & \multirow{2}{*}{$\begin{array}{l}\text { HWBLW } \\
\text { Reactor }\end{array}$} & \multicolumn{2}{|c|}{ HITGR } & \multirow{2}{*}{ MFBR } & \multicolumn{3}{|c|}{ SCBR } & \multicolumn{2}{|c|}{ acri } & \multicolumn{2}{|c|}{ 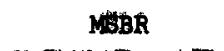 } \\
\hline & & & guC & $\operatorname{sen}$ & $\mathbf{s u c}$ & TuO & TUM & & Becloup & Reference & & $1250 \mathrm{psi}$ & $2680 \mathrm{pAI}$ & $3700 \mathrm{pq1}$ & Derated & Reference & 4 core & 1 Care \\
\hline 21 & Structures and Improvements & $14, \infty 20$ & 13,923 & 16,183 & 16,117 & 14,268 & 13,670 & 14,356 & 8,255 & 7,090 & 15,110 & 19,003 & 15,391 & 15,200 & 10,800 & 10,752 & 10,643 & 10,136 \\
\hline $\begin{array}{l}211 \\
212\end{array}$ & \multicolumn{7}{|c|}{212 Structures } & $1, \infty 00$ & 1,000 & 1,000 & 2,000 & 1,000 & 1,000 & 1,000 & 1,000 & 1,000 & 1,000 & 1,000 \\
\hline & $\begin{array}{l}\text { A. Administration } \\
\text { B. Control room } \\
\text { C. General service }\end{array}$ & $\begin{array}{l}600 \\
\text { In } 212 A \\
\text { In } 212 A\end{array}$ & 400 & 400 & $\begin{array}{r}400 \\
\text { In } 212 A-136 \\
136\end{array}$ & 400 & 400 & $\begin{array}{l}\text { In } 2120 \\
\text { In } 2120 \\
\text { In } 2120\end{array}$ & $\begin{array}{r}540 \\
\text { In } \\
\text { In }\end{array}$ & $2124=$ & $\begin{array}{l}235 \\
280 \\
375\end{array}$ & $\begin{array}{l}1,250 \\
\text { In } 2120 \\
\text { In } 212 \mathrm{~A}\end{array}$ & In $\begin{array}{r}330 \\
212 \mathrm{C} \\
618\end{array}$ & In $\begin{array}{r}330 \\
212 \mathrm{C} \\
550\end{array}$ & $\begin{aligned} & 650 \\
- & \text { In } \\
& \text { In }\end{aligned}$ & $2120 \div$ & $\begin{aligned} & 1,160 \\
= & \operatorname{In} 2 \\
= & \operatorname{In} 2\end{aligned}$ & 121,160 \\
\hline & $\begin{array}{l}\text { C. Gurbine plant } \\
\text { D. Turber } \\
\text { E. Cooling water } \\
\text { F. Steam generator }\end{array}$ & $\begin{array}{r}\ln 21400 \\
2,400 \\
850\end{array}$ & $\begin{array}{r}2,400 \\
800 \\
1,280\end{array}$ & $\begin{array}{r}136 \\
2,400 \\
800 \\
1,540\end{array}$ & $\begin{array}{r}1300 \\
2,800 \\
1,474\end{array}$ & $\begin{array}{r}136 \\
2,400 \\
800 \\
1,225\end{array}$ & $\begin{array}{r}136 \\
2,400 \\
800 \\
1,317\end{array}$ & $\begin{array}{r}\text { In } 2120 \\
4,930 \\
850\end{array}$ & $\begin{array}{c}2,015 \\
700\end{array}$ & $\begin{array}{r}212 A \\
1,900 \\
650\end{array}$ & $\begin{array}{r}375 \\
2,300 \\
681 \\
1,300\end{array}$ & $\begin{array}{r}\text { In } 212 \mathrm{~A} \\
4,400 \\
850\end{array}$ & $\begin{array}{r}616 \\
3,840 \\
700\end{array}$ & $\begin{array}{r}550 \\
3,800 \\
650\end{array}$ & $\begin{array}{l}2,415 \\
750^{\circ}\end{array}$ & $\begin{array}{r}2,415 \\
700\end{array}$ & $\begin{array}{l}2,445 \\
650\end{array}$ & $\begin{array}{r}2 ., 445 \\
650\end{array}$ \\
\hline & $\begin{array}{l}\text { G. React or auxiliaries } \\
\text { H. Miscelleneous }\end{array}$ & $\begin{array}{r}1,620 \\
50\end{array}$ & $\begin{array}{r}1,357 \\
50\end{array}$ & $\begin{array}{r}1,357 \\
50\end{array}$ & $\begin{array}{r}1,357 \\
50\end{array}$ & $\begin{array}{r}1,357 \\
50\end{array}$ & $\begin{array}{r}1,357 \\
50\end{array}$ & $\begin{array}{r}1,070 \\
50\end{array}$ & ]$_{50}^{\text {In }}$ & $2 1 9 \longdiv { 5 0 }$ & $\begin{array}{r}524 \\
50\end{array}$ & $\begin{array}{r}420 \\
50\end{array}$ & $\begin{array}{r}2,133 \\
50\end{array}$ & $\begin{array}{r}360 \\
50\end{array}$ & $\begin{array}{r}800 \\
50\end{array}$ & $\begin{array}{r}800 \\
50\end{array}$ & $\begin{array}{r}550 \\
50\end{array}$ & $\begin{array}{r}550 \\
50\end{array}$ \\
\hline 218 & Stack & 100 & 100 & 100 & 100 & 100 & 100 & 100 & & & In 219 & 100 & 100 & 100 & 100 & 100 & 100 & 100 \\
\hline \multicolumn{19}{|c|}{219 Reactor structures } \\
\hline & $\begin{array}{l}\text { A. Confinement } \\
\text { B. Containment }\end{array}$ & 7,400 & 6,400 & 8,400 & 8,400 & 6,800 & 6,110 & 6,356 & 3,950 & 2,950 & 8,365 & $\begin{array}{l}3,950 \\
6,983\end{array}$ & $\begin{array}{l}2,000 \\
4,620\end{array}$ & $\begin{array}{l}2,940 \\
5,420\end{array}$ & 5,037 & 5,037 & 4,698 & 4,181 \\
\hline 22 & Reactor plant equipment & 47,750 & 43,570 & 53,068 & 51,483 & 47,017 & 42,270 & 44,867 & 48,117 & 49,245 & 61,173 & 34,909 & 47,230 & 39,240 & 48,585 & 50,545 & 57,061 & 51,565 \\
\hline 221 & Reactor equipment & 13,371 & 12,131 & 19,218 & 18,683 & 16,782 & 10,136 & 27,091 & 17,350 & 14,115 & 6,545 & 11,145 & 12,620 & 12,470 & 12,175 & 22,195 & 11,780 & 6,784 \\
\hline & $\begin{array}{ll}.1 & \text { Vessel and intemals } \\
.2 & \text { Controls } \\
.3 & \text { Shieldipg }\end{array}$ & $\begin{array}{l}7,165 \\
2,340\end{array}$ & $\begin{array}{l}7,791 \\
1,320 \\
1,562\end{array}$ & $\begin{array}{r}13,800 \\
1,500 \\
2,460\end{array}$ & $\begin{array}{r}12,500 \\
2,414 \\
2,311\end{array}$ & $\begin{array}{r}11,501 \\
2,045 \\
1,778\end{array}$ & $\begin{array}{r}6,423 \\
876 \\
1,379\end{array}$ & $\begin{array}{l}9,800 \\
3,520 \\
1,216\end{array}$ & \multirow[t]{2}{*}{$\begin{array}{r}11,755 \\
2,955 \\
\text { In } \\
2,400\end{array}$} & $\begin{array}{r}9,400 \\
2,265 \\
221.1\end{array}$ & \multirow{2}{*}{$\begin{array}{r}1,085 \\
884 \\
1,564 \\
75 \\
2,737 \\
200\end{array}$} & $\begin{array}{r}7,600 \\
1,200 \\
120\end{array}$ & $\begin{array}{r}9,700 \\
1,000 \\
120\end{array}$ & $\begin{array}{r}8,700 \\
1,000 \\
120\end{array}$ & $\begin{array}{l}9,725 \\
1,750 \\
\text { II }\end{array}$ & $\begin{array}{r}9,725 \\
1,750 \\
221.1\end{array}$ & \multirow{2}{*}{$\begin{array}{l}3,930 \\
500 \\
3,800 \\
1,250 \\
2,100 \\
200\end{array}$} & \multirow{2}{*}{$\begin{array}{r}1,932 \\
250 \\
2,113 \\
1,089 \\
1,200 \\
200\end{array}$} \\
\hline & $\begin{array}{l}.4 \text { Reflector } \\
.5 \text { Auxiliary heating and cooling } \\
.6 \text { Cranes and hoists }\end{array}$ & $\begin{array}{r}3,716 \\
150\end{array}$ & $\begin{array}{r}1,297 \\
161\end{array}$ & $\begin{array}{r}1,297 \\
161\end{array}$ & $\begin{array}{r}1,297 \\
161\end{array}$ & $\begin{array}{r}1,297 \\
161\end{array}$ & $1,297$. & $\begin{array}{r}2,465 \\
90\end{array}$ & & $\begin{array}{r}2,400 \\
50\end{array}$ & & $\begin{array}{r}2,075 \\
150\end{array}$ & $\begin{array}{r}1,650 \\
150\end{array}$ & $\begin{array}{r}2,500 \\
150\end{array}$ & $\begin{array}{l}500 \\
200\end{array}$ & $\begin{array}{l}500 \\
200\end{array}$ & & \\
\hline 222 & Heat transfer systems & 18,937 & 13,768 & 14,665 & 13,896 & 12,290 & 15,267 & 8,728 & 13,117 & 12,720 & 36,928 & 6,264 & 16,160 & 7,670 & 19,560 & 20,620 & 24,406 & 24,406 \\
\hline & $\begin{array}{ll}.1 & \text { Reactor coolant } \\
.2 & \text { Intermediate coolant }\end{array}$ & 4,628 & 5,322 & 5,800 & 5,320 & 5,122 & 6,562 & 5,719 & 2,577 & 2,320 & $\begin{array}{r}6,888 \\
11,411\end{array}$ & 5,464 & 12,300 & 3,370 & 7,300 & 6,900 & $\begin{array}{l}2,240 \\
8,806\end{array}$ & $\begin{array}{l}2,240 \\
8,806\end{array}$ \\
\hline & $\begin{array}{ll}.3 & \text { Steam generators } \\
.4 & \text { Reheaters (live steam) }\end{array}$ & $\begin{array}{r}10,010 \\
1,700\end{array}$ & 5,901 & 6,300 & 6,011 & 4,623 & 6,160 & 1,720 & 8,930 & 9,000 & 15,525 & & 3,360 & ,500 & 9,500 & 11,000 & 12,810 & 12,810 \\
\hline & $\begin{array}{l}.5 \text { Coolant receiving and treatment } \\
.6 \text { Moderator auxiliaries }\end{array}$ & 2,589 & $\begin{array}{r}947 \\
1,318\end{array}$ & $\begin{array}{r}947 \\
1,328\end{array}$ & $\begin{array}{r}947 \\
1,318\end{array}$ & $\begin{array}{r}947 \\
2,318\end{array}$ & $\begin{array}{r}947 \\
1,318\end{array}$ & $\begin{array}{l}328 \\
961\end{array}$ & 1,035 & 900 & 2,604 & 200 & 200 & 200 & 2,900 & 1,900 & 100 & 100 \\
\hline & $\begin{array}{l}.7 \text { Coolant inventory } \\
.8 \text { Auxiliary steam supply }\end{array}$ & & 280 & 300 & 300 & 280 & 280 & & $\begin{array}{l}225 \\
350\end{array}$ & $\begin{array}{l}150 \\
350\end{array}$ & 500 & 600 & 300 & 600 & $\begin{array}{l}220 \\
600\end{array}$ & $\begin{array}{l}220 \\
600\end{array}$ & 450 & 450 \\
\hline 223 & Nuclear fuel-handling and storage equipment & 1,692 & 3,405 & 3,700 & 3,700 & 3,405 & 3,405 & 2,225 & 3,200 & 3,720 & 3,050 & 2,500 & $2, \infty 00$ & 2,500 & 3,000 & 3,000 & 1,700 & 1,700 \\
\hline 225 & Radioactive waste treatment and disposal & 450 & 300 & 300 & 300 & 300 & 300 & 400 & 750 & 750 & 450 & 400 & 400 & 400 & 1,000 & $1, \infty 00$ & 450 & 450 \\
\hline 226 & Instrumentation and control & 3,710 & 6,662 & 7,730 & 7,600 & 7,200 & 5,772 & 5,930 & 3,000 & 3,000 & 5,500 & 3,100 & 3,900 & 3,000 & 3,000 & 3,000 & 4,125 & 3,625 \\
\hline 227 & Feedwater supply and treatment & 3,600 & 3,189 & 3,270 & 3,189 & 3,040 & 3,230 & 4,843 & 4,070 & 4,850 & 3,700 & 5,600 & 5,150 & 6,300 & 4,010 & 3,600 & 4,800 & 4,800 \\
\hline 228 & Steam, condensate, and feedwater piping & 5,200 & 3,515 & 3,585 & 3,515 & 3,400 & 3,560 & 4,950 & 5,800 & 9,260 & 4,000 & 5,100 & 6,200 & 6,100 & 5,040 & 6,350 & 4,800 & 4,800 \\
\hline 229 & Other reactor plant equipment & 800 & 600 & 600 & 600 & 600 & 600 & 800 & 830 & 830 & 1,000 & 800 & 800 & 800 & 800 & 800 & 5,000 & 5,000 \\
\hline 23 & Turbine-generator plant & 34,754 & 32,970 & 33,003 & 33,810 & 33,120 & 32,668 & 34,252 & 25,625 & 24,233 & 25,232 & 32,853 & 25,213 & 24,307 & 26,492 & 25,073 & 23,455 & 23,455 \\
\hline 231 & Turbine-generator & 27,624 & 26,667 & 26,700 & 27,253 & 26,770 & 26,467 & 27,130 & 20,192 & 19,103 & 19,909 & 26,075 & 19,976 & 19,174 & 20,861 & 20,143 & 18,874 & 18,874 \\
\hline 232 & Cooling-water system & 2,400 & 1,980 & 1,980 & 2,080 & 2,000 & 1,940 & 2,250 & 1,650 & 1,500 & 1,847 & 2,070 & 1,575 & 2,500 & 1,900 & 1,650 & 1,460 & 1,460 \\
\hline 233 & Condensers & 3,400 & 3,083 & 3,083 & 3,237 & 3,110 & 3,021 & 3,540 & 2,553 & 2,300 & 2,486 & 3,253 & 2,429 & 2,300 & 2,500 & 2,050 & 2,131 & 8,131 \\
\hline 234 & Central lube-oil system & 80 & 80 & 80 & 80 & 80 & 80 & 80 & 80 & 80 & 80 & 80 & 80 & 80 & 80 & 80 & 80 & 80 \\
\hline 235 & Instrumentation and control & 600 & 600 & 600 & 600 & 600 & 600 & 600 & 400 & 400 & 400 & 600 & 400 & 400 & 400 & 400 & 400 & 400 \\
\hline 236 & Piping - bypass and miscellaneous & 450 & 360 & 360 & 360 & 360 & 360 & 452 & 550 & 650 & 310 & 575 & 553 & 653 & 550 & 550 & 310 & 310 \\
\hline 237 & Generator auxillary equipment & 75 & 75 & 75 & 75 & 75 & 75 & 75 & 75 & 75 & 75 & 75 & 75 & 75 & 75 & 75 & 75 & 75 \\
\hline 238 & Other turbine plent equipment & 125 & 125 & 125 & 125 & 125 & 125 & 125 & 125 & 125 & 125 & 125 & 125 & 225 & 125 & 125 & 125 & 125 \\
\hline 24 & Accessory electric equipment & $4,59 \mathrm{~h}$ & 3,880 & 3,880 & 3,800 & 3,880 & $3,88 r$ & 1,396 & 25 & 4,015 & 4,500 & 4,254 & $4, \infty 00$ & 3,800 & 4,200 & 4,200 & 4,500 & 4,500 \\
\hline 25 & Miscellaneous power plant equipment & 1,250 & 1,250 & 1,250 & 1,250 & 1,250 & 1,250 & 1,250 & $1,-, 0$ & 1,250 & 1,250 & 1,250 & 1,250 & 1,250 & 1,250 & 1,250 & 1,250 & 1,250 \\
\hline & Total & 102,368 & 95,593 & 107,384 & 106,540 & 99,535 & 93,738 & 99,121 & 87,062 & 85,833 & 107,265 & 92,269 & 93,084 & 83,797 & 91,328 & 91,820 & 96,909 & 90,906 \\
\hline
\end{tabular}


Table 6.3. Total Unit Costs of Investor-Owned 1000-Mw(e) Nuclear Power Plants

\begin{tabular}{|c|c|c|c|c|c|c|c|c|c|c|c|c|c|c|c|c|c|c|}
\hline \multirow{3}{*}{\multicolumn{2}{|c|}{ Account }} & \multicolumn{17}{|c|}{ Unit Costs $[\$ / \mathrm{kw}(e)]$} \\
\hline & & \multirow{2}{*}{ PWR } & \multicolumn{5}{|c|}{ HWOCR } & \multirow{2}{*}{$\begin{array}{l}\text { HWBIW } \\
\text { Reactor }\end{array}$} & \multicolumn{2}{|c|}{ HTGR } & \multirow{2}{*}{ IMFBR } & \multicolumn{3}{|c|}{ SCBR } & \multicolumn{2}{|c|}{ GCFR } & \multicolumn{2}{|c|}{ MSBR } \\
\hline & & & EUC & NOM & NuC & TUO & TUM & & Backup & Reference & & $1250 \mathrm{psi}$ & $2680 \mathrm{psi}$ & 3700 ps1 & Derated & Reference & 4 Core & 1 Core \\
\hline \multicolumn{19}{|c|}{ 21 Structures and Improvements } \\
\hline $\begin{array}{l}212 D \\
212 F \\
212 G \\
219\end{array}$ & $\begin{array}{l}\text { Turbine building } \\
\text { Steam-generator building } \\
\text { Reactor auxiliaries building } \\
\text { Reactor building } \\
\text { Other account } 21\end{array}$ & $\begin{array}{l}3.17 \\
2.14 \\
9.77 \\
3.43 \\
\end{array}$ & $\begin{array}{l}3.19 \\
1.70 \\
1.82 \\
8.51 \\
3.28\end{array}$ & $\begin{array}{r}3.16 \\
2.02 \\
1.80 \\
11.05 \\
3.25\end{array}$ & $\begin{array}{r}3.06 \\
1.88 \\
1.74 \\
10.73 \\
3.18\end{array}$ & $\begin{array}{l}3.15 \\
1.62 \\
1.79 \\
8.95 \\
3.26\end{array}$ & $\begin{array}{l}3.24 \\
1.78 \\
1.83 \\
8.25 \\
3.35\end{array}$ & $\begin{array}{l}7.10 \\
1.54 \\
9.16 \\
2.89\end{array}$ & $\begin{array}{l}5.51 \\
3.22\end{array}$ & $\begin{array}{l}4.13 \\
3.13 \\
\end{array}$ & $\begin{array}{r}3.13 \\
1.77 \\
0.71 \\
11.41 \\
3.58 \\
\end{array}$ & $\begin{array}{r}6.16 \\
0.59 \\
15.31 \\
4.56 \\
\end{array}$ & $\begin{array}{l}5.36 \\
2.97 \\
9.23 \\
3.89 \\
\end{array}$ & $\begin{array}{r}5.50 \\
0.52 \\
12.10 \\
3.89 \\
\end{array}$ & $\begin{array}{l}3.36 \\
1.11 \\
7.04 \\
3.59 \\
\end{array}$ & $\begin{array}{l}3.37 \\
1.11 \\
7.04 \\
3.48 \\
\end{array}$ & $\begin{array}{l}3.40 \\
0.76 \\
6.51 \\
4.10 \\
\end{array}$ & $\begin{array}{l}3.41 \\
0.77 \\
5.82 \\
4.13 \\
\end{array}$ \\
\hline \multicolumn{18}{|c|}{22 Reactor plant equipment } & 14.13 \\
\hline \multirow{5}{*}{$\begin{array}{l}221.1 \\
221.2 \\
221.3 \\
221.4 \\
221.5 \\
222.1 \\
222.2 \\
222.3 \\
222.4 \\
222.5 \\
222.6 \\
223 \\
.225 \\
226 \\
227 \\
228 \\
229\end{array}$} & $\begin{array}{l}\text { Reactor vessel } \\
2 \text { Control rods and drives } \\
\text { Shielding (thermal) } \\
\text { Reflector }\end{array}$ & $\begin{array}{l}9.24 \\
3.02\end{array}$ & $\begin{array}{r}11.14 \\
1.88 \\
2.24\end{array}$ & $\begin{array}{r}19.52 \\
2.12 \\
3.48\end{array}$ & $\begin{array}{r}17.10 \\
3.29 \\
3.15\end{array}$ & $\begin{array}{r}16.29 \\
2.90 \\
2.52\end{array}$ & $\begin{array}{r}9.30 \\
1.28 \\
2.00\end{array}$ & $\begin{array}{r}15.11 \\
5.43 \\
1.88\end{array}$ & $\begin{array}{r}17.59 \\
4.43\end{array}$ & $\begin{array}{r}14.10 \\
3.40 \\
3.60\end{array}$ & $\begin{array}{l}1.59 \\
1.28 \\
2.28 \\
0.12\end{array}$ & $\begin{array}{r}11.41 \\
1.81 \\
0.18\end{array}$ & $\begin{array}{r}14.49 \\
1.49 \\
0.18\end{array}$ & $\begin{array}{r}13.47 \\
1.55 \\
0.18\end{array}$ & $\begin{array}{r}14.56 \\
2.62\end{array}$ & $\begin{array}{r}14.53 \\
2.62\end{array}$ & $\begin{array}{l}5.88 \\
0.75 \\
5.69 \\
1.87\end{array}$ & $\begin{array}{l}2.90 \\
0.38 \\
3.17 \\
1.64\end{array}$ \\
\hline & $\begin{array}{l}\text { Auxiliary heating and cooling } \\
\text { l Reactor coolant system } \\
\text { Intermediate coolant }\end{array}$ & $\begin{array}{l}4.80 \\
5.97\end{array}$ & $\begin{array}{l}1.86 \\
7.60\end{array}$ & $\begin{array}{l}1.84 \\
8.21\end{array}$ & $\begin{array}{l}1.78 \\
7.28\end{array}$ & $\begin{array}{l}1.84 \\
7.25\end{array}$ & $\begin{array}{l}1.87 \\
9.52\end{array}$ & $\begin{array}{l}3.80 \\
8.81\end{array}$ & 3.86 & 3.48 & $\begin{array}{r}4.01 \\
10.08 \\
16.69\end{array}$ & $\begin{array}{l}3.12 \\
8.19\end{array}$ & $\begin{array}{r}2.47 \\
18.39\end{array}$ & $\begin{array}{l}3.88 \\
5.22\end{array}$ & $\begin{array}{r}0.75 \\
10.92\end{array}$ & $\begin{array}{r}0.75 \\
10.30\end{array}$ & $\begin{array}{r}3.14 \\
3.35 \\
13.18\end{array}$ & $\begin{array}{r}1.80 \\
3.30 \\
13.23\end{array}$ \\
\hline & $\begin{array}{l}\text { Steam generators } \\
\text { t Reheaters (live steam) }\end{array}$ & $\begin{array}{r}12.91 \\
2.19\end{array}$ & 8.44 & 8.91 & 8.21 & 6.54 & 8.93 & 2.65 & 13.36 & 13.49 & 22.70 & & 5.03 & 5.43 & 14.31 & 16.43 & 19.17 & 19.24 \\
\hline & $\begin{array}{l}\text { Coolant receiving and treatment } \\
\text { Moderator auxiliaries }\end{array}$ & 3.34 & $\begin{array}{l}1.36 \\
1.87\end{array}$ & $\begin{array}{l}1.35 \\
1.86\end{array}$ & $\begin{array}{l}1.30 \\
1.81\end{array}$ & $\begin{array}{l}1.35 \\
1.87\end{array}$ & $\begin{array}{l}1.38 \\
1.91\end{array}$ & $\begin{array}{l}0.50 \\
1.48\end{array}$ & 1.56 & 1.35 & 3.80 & 0.30 & 0.30 & 0.31 & 2.84 & 2.84 & 0.15 & 0.15 \\
\hline & $\begin{array}{l}\text { Fuel handling and storage } \\
\text { Radioactive waste treatment } \\
\text { Instrumentation and control } \\
\text { Feedwater supply and treatment } \\
\text { Steam, condensate, and feedwater piping } \\
\text { Other reactor plant equipment } \\
\text { Other account } 22\end{array}$ & $\begin{array}{l}2.18 \\
0.58 \\
4.79 \\
4.75 \\
6.86 \\
1.03 \\
0.25\end{array}$ & $\begin{array}{l}1.01 \\
4.87 \\
0.43 \\
9.53 \\
4.24 \\
4.68 \\
0.86 \\
0.64\end{array}$ & $\begin{array}{r}1.00 \\
5.23 \\
0.43 \\
10.94 \\
4.30 \\
4.72 \\
0.85 \\
0.63\end{array}$ & $\begin{array}{r}1.01 \\
5.06 \\
0.49 \\
10.39 \\
4.07 \\
4.50 \\
0.82 \\
0.56\end{array}$ & $\begin{array}{r}4.83 \\
0.42 \\
10.19 \\
4.00 \\
4.47 \\
0.85 \\
0.61\end{array}$ & $\begin{array}{l}4.91 \\
4.94 \\
0.43 \\
8.37 \\
4.36 \\
4.80 \\
0.86 \\
0.67\end{array}$ & $\begin{array}{l}3.40 \\
3.29 \\
0.61 \\
9.14 \\
6.97 \\
7.13 \\
1.23 \\
0.17\end{array}$ & $\begin{array}{l}4.79 \\
1.22 \\
4.49 \\
5.68 \\
8.09 \\
1.24 \\
1.00\end{array}$ & $\begin{array}{r}5.57 \\
1.13 \\
4.50 \\
6.78 \\
12.94 \\
1.25 \\
0.83\end{array}$ & $\begin{array}{l}4.46 \\
0.66 \\
8.04 \\
5.05 \\
5.45 \\
1.46 \\
1.02\end{array}$ & $\begin{array}{l}3.75 \\
0.60 \\
4.66 \\
7.85 \\
7.15 \\
1.20 \\
1.14\end{array}$ & $\begin{array}{l}2.99 \\
0.60 \\
5.83 \\
7.18 \\
8.65 \\
1.19 \\
0.66\end{array}$ & $\begin{array}{l}3.88 \\
0.62 \\
4.65 \\
9.12 \\
8.83 \\
1.23 \\
1.16\end{array}$ & $\begin{array}{l}4.49 \\
1.50 \\
4.49 \\
5.61 \\
7.04 \\
1.20 \\
1.50\end{array}$ & $\begin{array}{l}4.48 \\
1.49 \\
4.48 \\
5.01 \\
8.85 \\
1.20 \\
1.51\end{array}$ & $\begin{array}{l}2.55 \\
0.67 \\
6.18 \\
6.66 \\
6.66 \\
7.48 \\
0.98\end{array}$ & $\begin{array}{l}2.56 \\
0.68 \\
5.45 \\
6.69 \\
6.69 \\
7.51 \\
0.99\end{array}$ \\
\hline \multicolumn{2}{|c|}{ Total account 22} & 61.91 & 61.64 & 74.39 & 69.81 & 65.93 & 60.62 & 68.20 & 70.99 & 72.42 & 88.70 & 51.36 & 69.45 & 59.53 & 71.80 & 74.48 & $\overline{84.36}$ & $\overline{76.44}$ \\
\hline \multicolumn{2}{|c|}{23 Turbine-generator plant } & & & & & & & & & & & & & 1 & & & & \\
\hline 231 & $\begin{array}{l}\text { Turbine-generator } \\
\text { Other account } 23\end{array}$ & $\begin{array}{r}35.13 \\
9.38\end{array}$ & $\begin{array}{r}33.03 \\
8.40\end{array}$ & $\begin{array}{r}32.44 \\
8.31\end{array}$ & $\begin{array}{r}32.10 \\
8.39\end{array}$ & $\begin{array}{r}32.79 \\
8.36\end{array}$ & $\begin{array}{r}33.32 \\
8.38\end{array}$ & $\begin{array}{l}36.09 \\
10.27\end{array}$ & $\begin{array}{r}26.12 \\
7.59\end{array}$ & $\begin{array}{r}24.79 \\
7.20\end{array}$ & $\begin{array}{r}25.17 \\
7.30\end{array}$ & $\begin{array}{r}33.92 \\
9.51\end{array}$ & $\begin{array}{r}25.85 \\
7.32\end{array}$ & $\begin{array}{r}25.62 \\
7.43\end{array}$ & $\begin{array}{r}27.02 \\
7.87\end{array}$ & $\begin{array}{r}26.04 \\
6.87\end{array}$ & $\begin{array}{r}24.31 \\
6.35\end{array}$ & $\begin{array}{r}24.41 \\
6.38\end{array}$ \\
\hline & tal account 23 & 44.51 & 41.43 & 40.75 & 40.49 & 41.15 & 41.70 & 46.36 & 33.71 & 31.99 & 32.47 & 43.43 & 33.17 & 33.05 & 34.89 & 32.91 & 30.66 & 30.79 \\
\hline & tal accounts 24 and 25 & 7.71 & 6.71 & 6.74 & $6.56^{\circ}$ & 6.75 & 6.93 & 8.14 & 7.07 & 7.38 & 7.85 & 7.71 & 7.32 & 7.31 & 7.61 & 7.60 & 7.98 & 8.01 \\
\hline & tal unit costs (accounts 2l to 25) & 132.7 & 128.4 & 143.2 & 137.4 & 132.6 & 127.7 & 143.4 & 123.3 & 121.7 & 149.6 & 129.1 & 131.4 & 121.7 & 129.3 & 130.0 & 137.8 & 129.4 \\
\hline
\end{tabular}


if designs were prepared for a consistent set of design ground rules are building costs, reactor equipment costs, and reactor containment and safety system costs. Some of the reasons for capital cost differences among the various concepts and some uncertainties in relative cost differences are discussed in this report.

\subsubsection{Comparison of Unit Costs}

Although the direct costs of the various concepts provide a rough basis for comparing capital investment costs, a more accurate comparison is obtained by adding indirect costs to each of the individual accounts. In order to do this, it is necessary to take into consideration differences in net electrical ratings of the plants being considered, and also to apply appropriate contingency factors to the individual accounts.

It may be seen in Table 6.3 that unit costs for the low, intermediate, and high pressure SCBR's are $\$ 129.1 / \mathrm{kw}(\mathrm{e}), \$ 131.4 / \mathrm{kw}(\mathrm{e})$, and $\$ 121.7 / \mathrm{kw}(e)$, respectively. Unit costs for the derated and reference GCFR's are $\$ 129.3 / \mathrm{kW}(\mathrm{e})$ and $\$ 130.0 / \mathrm{kW}(\mathrm{e})$, respectively. These costs may be compared with $\$ 132.7 / \mathrm{kW}(\mathrm{e})$ for a $\mathrm{PWR}$ and $\$ 149.6 / \mathrm{kW}(\mathrm{e})$ for an LMFBR. The reasons for these differences in costs are summarized in the following paragraphs.

\subsubsection{Discussion of Unit Costs}

6.1.4.1 LMFBR. The reference LMFBR is an oxide fueled sodium-cooled fast breeder reactor operating with a primary coolant temperature of $800^{\circ} \mathrm{F}$ at the inlet and $1100^{\circ} \mathrm{F}$ at the outlet of the reactor. Superheated steam at turbine throttle conditions of $2400 \mathrm{psig} / 900^{\circ} \mathrm{F}$ (with $900^{\circ} \mathrm{F}$ reheat) is produced in the steam generators. Principal parameters of the LMFBR plant systems and components were given in a letter from Argonne National Laboratory ${ }^{36}$ that included the LMFBR Task Force cost estimate. This capital cost estimate was normalized by ORNL and several adjustments were made to the direct costs. Some of the reactor system account 22 costs were reduced where it appeared that contingencies we account for in the indirect costs had been included in the direct costs. Account 227 and 228 costs were increased to bring them in line with these costs for the other concepts based on differences in design requirements. Account 211, 
ground improvements, and account 25, miscellaneous power plant equipment, costs were adjusted to the normalized value for all concepts. A major cost reduction of about $\$ 4$ million was made in the turbine-generator account 23 costs by the substitution of a tandem compound unit for the cross compound unit specified, since the former was assumed for all the concepts. Turbine-generator building costs were also reduced because of this change. Higher costs due to the lower net thermal efficiency (40.2 versus $40.6 \%$ ) resulting from using the tandem compound unit would be more than offset by the lower equipment and building costs.

As the result of this normalization study ORNL arrived at the direct cost of $\$ 107$ million and a total capital cost of $\$ 149.6$ million (excluding coolant inventory of $\$ 0.6$ million) for the LMFBR reference plant, as compared with a direct cost of $\$ 112.9$ million and a total capital cost of from $\$ 142.9$ million to $\$ 152.9$ million reported by the LMFBR Task Force.

From this study, it is indicated that the LMFBR capital costs are higher than the costs of the other $1000-\mathrm{Mw}(\mathrm{e})$ reactor concepts investigated. It is estimated to cost about $\$ 17 / \mathrm{kw}(e)$ more than a $1000-\mathrm{Mw}(e)$ PWR. This difference is due largely to the much higher costs of the heat transfer system components that more than offset savings in other areas, such as the turbine-generator plant costs, which are $\$ 12 / \mathrm{kw}(\mathrm{e})$ lower for the PWR. Principal cost differences between these two plants are compared in Table 6.4.

It may be seen in Table 6.4 that the variations in unit costs (i.e., variation of sum of higher and lower cost accounts, respectively) are $+\$ 43.2 / \mathrm{kw}(\mathrm{e})$ and $-\$ 26.3 / \mathrm{kw}(\mathrm{e})$. This implies a larger difference in design and distribution of costs than indicated by the net differential of total unit costs. A large part of this is attributable to accounts 222.2 and 222.3, as well as accounts 221.I and 23 .

The LMFBR reactor buildings are larger than the PWR buildings, and more extensive shielding is required in the LMFBR primary cells. The IMFBR requires a containment building $176 \mathrm{ft}$ in diameter, as compared with a containment building about $145 \mathrm{ft}$ in diameter for the PWR. However, the design pressure for the LMFBR containment building is much lower, and thus its cost is only $\$ 1.6 / \mathrm{kw}(\mathrm{e})$ higher than the cost of the 
Table 6.4. Comparison of IMFBR and PWR Unit Costs

\begin{tabular}{lll} 
Account & Unit Costs $[\$ / k W(e)]$ \\
\cline { 2 - 3 } & LMFBR PWR $\quad \begin{array}{c}\text { Difference } \\
(\text { IMFBR - PWR) }\end{array}$
\end{tabular}

21 Structures and improvements

$212 \mathrm{~F}$ Steam generator building

212G Reactor auxiliary building

219 Reactor building

22 Reactor plant equipment

221.I Reactor vessel

221.2 Control rods and drives

221.3 Shielding (thermal)

222.I Reactor coolant system

222.2 Intermediate coolant system

222.3 Steam generators

222.4 Reheater (Iive steam)

223 Fuel handling

226 Instrumentation and control

228 Steam, condensate, and feedwater piping

23 Turbine-generator plant

231 Turbine-generator other 23

Other accounts

Total

Variations

$\begin{array}{rrr}1.8 & & 1.8 \\ 0.7 & 2.1 & -1.4 \\ 11.4 & 9.8 & 1.6\end{array}$

1.6

1. 3

9.2

$-7.6$

2.3

3.0

$-1.7$

10.1

6.0

2.3

16.7

22.7

12.9

4.1

16.7

9.8

2.2

$-2.2$

$4.5 \quad 2.2$

2.3

$8.0 \quad 4.8$

3.2

5.5

6.9

$-1.4$

\begin{tabular}{rrr}
25.2 & 35.1 & -9.9 \\
7.3 & 9.4 & -2.1 \\
30.5 & 29.1 & 1.4 \\
\hline 149.6 & 132.7 &
\end{tabular}

$-26.3$

$+43.3$

PWR containment structure. The remaining buildings are estimated to total to another $\$ 0.4 / \mathrm{kW}(\mathrm{e})$ higher for the LMFBR plant.

The reactor equipment costs (account 221) are estimated to be about $\$ 8 / \mathrm{kW}(\mathrm{e})$ lower for the LMFBR than for the PWR. This is due mainly to the much more expensive high pressure PWR pressure vessel and higher cost PWR control rods and drives.

The IMFBR heat transfer systems are estimated to cost about $\$ 30 / \mathrm{kw}(\mathrm{e})$ more than (or over twice as much as) the PWR heat transfer system. The 
LMF'BR has an intermediate heat transfer loop, which the PWR does not have, and the cost of this loop is estimated to be about $\$ 16.7 / \mathrm{kw}(\mathrm{e})$. Moreover, unit costs $\left(\$ / f t^{2}\right)$ of LMFBR steam generators are estimated to average about three times the unit cost of PWR steam generators because of the complications brought about by sodium-to-steam heat exchange. As a result, the 121,600 $\mathrm{ft}^{2}$ of heat transfer area required for the LMFBR steam generators costs about $\$ 9.8 / \mathrm{kw}(\mathrm{e})$ more than the 206,000 $\mathrm{ft}^{2}$ of heat transfer area required for the PWR steam generators.

The principal cost uncertainties for the LMHBR appear to be involved in the amount of technical optimism used in the design and in estimating the cost of components such as the heat exchangers and pumps. The LMFBR Task Force provided a cost estimate for an advanced LNFBR that included their evaluation of the cost reductions that might be expected with improved layouts and lower costs of components. The ORNL normalization of this estimate indicated that the cost of the LMFBR may reduce to $\$ 136 / \mathrm{kW}(\mathrm{e})$ or $\$ 14 / \mathrm{kW}(\mathrm{e})$ less than the estimate for the "reference" design. Similar types of savings might be realized for the other concepts as well; however, ORNL did not attempt to evaluate such reductions in this study.

6.1.4.2 SCBR. The steam-cooled breeder reactors are all direct cycle plants operating on a Loeffler boiler principle with superheated steam. Reactor inlet pressures are 1250, 2680, and 3700 psia for the three designs considered in this study. Design features of the containment systems and heat transfer systems differ considerably among the three designs. The 1250-psi design has a double containment scheme, with steam circulators and feedwater injectors inside the reactor vessel. The 2680psi design has a single containment vessel, with the reactor and emergency cooling system inside and the recirculating pumps and feedwater injectors (direct Loeffler boilers) outside the vessel. The 3700-psi design has a single high pressure containment vessel enclosing the reactor vessel as for the 1250-psi design, but it does not have the backup containment vessel of the 1250-psi design. However, in arriving at the reference costs of this concept, ORNL added costs for backup containment and for other features that would make the 3700-psi design more equivalent to the 1250-psi desirn. 
Estimated total costs of the 1250- and 2680-psi SCBR designs compare closely with the estimated costs of the PWR ( $\$ 131 / \mathrm{kw}$ versus $\$ 133 / \mathrm{kW})$. The estimate for the original 3700-psi design was about $\$ 17 / \mathrm{kw}(\mathrm{e})$ lower than for the other two SCBR designs but, a,s will be explained later, this cost difference was reduced to $\$ 9 / \mathrm{kw}(e)$ when features of the 3700-psi design were made more equivalent to those of the 1250-psi design.

Cost comparisons between the 1250-psi SCBR concept and the PWR are given in Table 6.5 .

Table 6.5. Comparison of Reference 1250-psi SCBR and PWR Unit Costs

\begin{tabular}{ccc} 
Account & \multicolumn{2}{c}{ Unit $\operatorname{Costs}[\$ / k w(e)]$} \\
\cline { 2 - 3 } $\begin{array}{c}\text { Reference } \\
\text { SCBR }\end{array}$ & PWR & Difference \\
$($ SCBR - PWR $)$
\end{tabular}

21 Structures and improvements

$\begin{array}{llrrr}212 \mathrm{D} & \text { Turbine building } & 6.2 & 3.2 & 3.0 \\ 212 \mathrm{G} & \text { Reactor auxiliary building } & 0.6 & 2.1 & -1.5 \\ 219 & \text { Reactor building } & 15.3 & 9.8 & 5.5 \\ \text { Other 2l } & 4.6 & 3.4 & 1.2\end{array}$

22 Reactor plant equipment

\subsection{Reactor vessel}

221.2 Control rods and drives

221.5 Auxiliary heating and cooling

222.1 Reactor coolant system

222.3 Steam generators

222.4 Reheater

222.5 Coolant treatment

223 Fuel handling

227 Feedwater supply and treatment

23 Turbine-generator plant

231 Turbine-generator

other accounts

Total

Variations

$\begin{array}{rrr}11.4 & 9.2 & 2.2 \\ 1.8 & 3.0 & -1.2 \\ 3.1 & 4.8 & -1.7 \\ 8.2 & 6.0 & 2.2 \\ & 12.9 & -12.9 \\ & 2.2 & -2.2 \\ 0.3 & 3.3 & -3.0 \\ 3.8 & 2.2 & 1.6 \\ 7.9 & 4.8 & 3.1\end{array}$

\begin{tabular}{|c|c|c|}
\hline 33.9 & 35.1 & $-1 \cdot 2$ \\
\hline 32.0 & 30.7 & 1.3 \\
\hline 129.1 & 132.7 & 3.6 \\
\hline & & $\begin{array}{l}+20.1 \\
-23.7\end{array}$ \\
\hline
\end{tabular}


It may be seen in Table 6.5 that the total unit costs of the two concepts differ by only about $\$ 4 / \mathrm{kw}(\mathrm{e})$; however, the variation is $+\$ 20.1 / \mathrm{kw}(\mathrm{e})$ and $-\$ 23.7 / \mathrm{kw}(\mathrm{e})$, which indicates an approximately equal range of higher and lower costs. The variations are discussed below.

Turbine building costs are $\$ 2.9 / \mathrm{kw}(\mathrm{e})$ higher for the SCBR directcycle plant, which requires shielding and larger areas for auxiliary systems than does the indirect cycle PWR. The reactor building has both high pressure and low pressure containment vessels which, in total, cost about $\$ 4$ million more than the PWR building.

The SCBR basic reactor vessel weighs about 100 tons less than the PWR vessel, but its internals, which include massive thermal shields and moisture separators, are more complicated and expensive than for the PWR. Thus, the complete SCBR vessel is estimated to cost $\$ 2.2 / \mathrm{kw}(\mathrm{e})$ more than the complete PWR vessel. There are a larger number of individual control rods in the 1250-psi SCBR than there are control rod clusters in the PWR, but the unit cost for the individual rod is about 20 to $25 \%$ of the cost of the cluster, with a resulting saving of $\$ 1.2 / \mathrm{kw}(e)$.

The auxiliary heating and cooling system for the reference SCBR consists of a core spray and emergency condenser system, but has no provisions for subsequent flooding of the reactor, as does the PWR. This results in a comparative saving for the SCBR of $\$ 1.7 / \mathrm{kw}(\mathrm{e})$.

The 1250-psi SCBR requires four 42,500-hp turbine-driven steam circulators that are located inside the reactor vessel in contrast to the four 6,000-hp motor-driven pumps required for the PWR. The much higher cost of the SCBR circulators ( $\$ 8.3 \mathrm{kw}$ versus about $\$ 2.7 \mathrm{kw}$ ) more than offsets the cost of the high pressure piping and pressurizer required in the external coolant circuit of the PWR.

The SCBR is a direct cycle plant and therefore does not require steam generators; this results in a saving of $\$ 12.9 / \mathrm{kw}(\mathrm{e})$. Also no reheater is provided in the 1250-psi design, although reheaters are included in the 2680- and 3700-psi designs.

The PWR has expensive coolant treatment facilities (account 222.5) compared with the SCBR, which depends primarily on full flow demineralization of the feedwater (part of account 227 costs) for coolant purity control. This results in a $\$ 3.0 / \mathrm{kw}(\mathrm{e})$ saving for the SCBR. 
The fuel handling machine for the 1250-psi SCBR concept is inserted into the reactor vessel and is operated semiremotely under pressure; this equipment is estimated to cost $\$ 1.6 / \mathrm{kw}(e)$ more than the direct access refueling equipment of the PWR. This account for the SCBR also includes about $\$ 0.8 / \mathrm{kW}(e)$ for special facilities for canning fast reactor fuel for shipments, which is a feature not required for the PWR.

Feedwater supply and treatment facilities for the direct cycle SCBR plant require more expensive materials of construction than the facilities for the indirent cycle PWR. Moreover a full flow filtration and deminerali. zation system is required in the SCBR plant. These features add $\$ 3.1$ million to SCBR costs.

As shown in Table 6.6 there are appreciable cost differences among the components of the three SCBR plants. It may be seen that the differences in unit costs are appreciable despite the fact that these are all

Table 6.6. Comparison of SCBR Plant Unit Cost Differences

\begin{tabular}{|c|c|c|c|}
\hline \multirow[b]{2}{*}{ Account } & \multicolumn{2}{|c|}{ Unit Costs $[\$ / k w(e)]$} & \multirow[b]{2}{*}{$\begin{array}{c}\text { Differential } \\
\text { Cost for } \\
3700-p s i \\
\text { Concept }\end{array}$} \\
\hline & $\begin{array}{l}\text { Base Cost } \\
\text { for } \\
\text { 1250-psi } \\
\text { Concept }\end{array}$ & $\begin{array}{c}\text { Differential } \\
\text { Cost for } \\
\text { 2680-psi } \\
\text { Concept }\end{array}$ & \\
\hline 21 structures and improvements & 26.6 & -5.1 & -4.6 \\
\hline \multicolumn{4}{|l|}{22 Reactor plant equipment } \\
\hline 221.1 Reactor vessel & 11.4 & 3.1 & 2.1 \\
\hline 222.1 Reactor coolant system & 8.2 & 10.2 & -3.0 \\
\hline 222.4 Reheater & & 5.0 & 5.4 \\
\hline $\begin{array}{l}226 \text { Instrumentation and con- } \\
\text { trols }\end{array}$ & 4.7 & 1.1 & 0 \\
\hline $\begin{array}{l}\text { 227, Feedwater, steam, and } \\
228 \text { condensate systems }\end{array}$ & 15.1 & 0.9 & 2.8 \\
\hline 23 Turbine-generator plant & 43.4 & -10.2 & $-10 \cdot 3$ \\
\hline \multirow[t]{3}{*}{ Other accounts } & 19.7 & -2.5 & 0.2 \\
\hline & 129.1 & 2.2 & -7.4 \\
\hline & & $\begin{array}{l}+20.0 \\
-17.8\end{array}$ & $\begin{array}{l}+10.5 \\
-17.9\end{array}$ \\
\hline
\end{tabular}


steam-cooled fast breeder reactors. Building costs for the 1250-psi SCBR design are higher than for the other two concepts because of the large high-pressure containment structure, larger areas in the controlledleakage reactor building, and a larger turbine building.

The 2680-psi SCBR reactor vessel has thicker walls and weighs more than the 1250-psi vessel. It has simpler internal structures, since the Loeffler boilers and circulators are in an external loop rather than being integral within the vessel as they are in the 1250-psi design. However, the lower cost of internal structures of the 2680-psi design is more than offset by the higher cost of more massive stainless steel thermal shields, which limit the neutron exposure of the walls of the 2680-psi vessel to a lower value than in the 1250-psi design. This results in a $\$ 3.1 / \mathrm{kw}(\mathrm{e})$ higher cost than for the low pressure design.

Although the overall dimensions of the 3700-psi vessel are less than the dimensions of the 1250-psi vessel, because of its higher design pressure, the basic vessel is heavier ( 800 tons versus 500 tons) and $\$ 2.1 / \mathrm{kw}(\mathrm{e}$ ) more expensive than for the 1200-psi concept.

As shown in Table 6.6, there are considerable differences in reactor coolant system costs. The 2680-psi concept has lower power and less expensive circulators than the 1250-psi concept, but the $\$ 10.2 / \mathrm{kw}(\mathrm{e})$ higher cost for the 2680-psi system reflects the much higher cost of Loeffler boilers in an external circuit, plus the cost of a secondary heat transfer system that is on line to generate steam for the turbine drives and to serve as an emergency cooling system. The modified reference 3700-psi coolant system design closely resembles the 1250-psi system, and costs $\$ 3.0 / \mathrm{kw}(\mathrm{e})$ less because of the much smaller steam circulator requirements.

Both the 2680- and 3700-psi designs have reheaters to improve the thermal efficiency; there is no reheater specified for the 1250-psi design. The cost of reheaters adds $\$ 5.0 / \mathrm{kw}(e)$ and $\$ 5.4 / \mathrm{kw}(\mathrm{e})$ to the estimates for the 2680- and 3700-psi concepts, respectively.

Instrumentation and control requirements are about the same for the three concepts; however, the 2680-psi design includes a burst slug detector that is not included in the other two designs, and which accounts for the $\$ 1.2 / \mathrm{kw}(\mathrm{e})$ higher cost for the 2680-psi instrumentation and control system. 
Steam, condensate, and feedwater system costs are nearly the same for the 1250- and 2680-psi systems, since costs associated with the higher pressure requirement for the 2680-psi system tend to offset costs for the higher flow requirement of the 1250-psi system. The highest pressure (3700-psi) system costs over $\$ 2 / \mathrm{kw}(\mathrm{e})$ more than the other two.

The difference of about $\$ 10 / \mathrm{kw}(e)$ in turbine-generator plant costs is one of the major cost differences between the 1250-psi concept and the two higher pressure concepts. A spread this large is not truly indicative of turbine-generator equipment cost differences, since the two higher pressure designs bear the cost of reheaters to obtain higher thermal efficiencies. If the cost of reheaters were included with account 23 instead of account 22 costs, as is often done, the overall account 23 cost difference would be reduced to about $\$ 5 \mathrm{kw}(\mathrm{e})$.

At the suggestion of B\&W, ORNL revised the original 3700-psi design and estimated the incremental costs of added safety features to make the 3700-psi design equivalent to the 1250-psi concept. The incremental costs for these changes were as follows:

$\begin{gathered}\text { Cost } \\ \text { (milizions of dollars) }\end{gathered}$
+2.5
+0.6
+2.0
+2.5
+0.8
4.4
$\frac{1.8}{6.2}$
$\sim 1.5$
$\sim 7.7$


Thus the unit cost of the 3700-psi concept with these added features was increased from about $\$ 114 / \mathrm{kw}(\mathrm{e})$ to the present value of $\$ 121.7 / \mathrm{kw}(\mathrm{e})$.

6.1.4.3 GCFR. Since the general features of the gas-cooled fast reactor plant are similar to those of the HTGR plants, the latter concept was used as a basis for comparison. The reactor and other primary heat transfer components are housed in a PCRV, and primary steam is generated at 2400 psi and $1000^{\circ} \mathrm{F}$ in the reference GCFR design as in the HTGR backup design. The derated GCFR design operates with a coolant temperature $100^{\circ} \mathrm{F}$ lower than in the reference design, and generates steam at $1800 \mathrm{psi}$ and $900^{\circ} \mathrm{F}$; however, the designs of reactor plant components are only slightly changed, if at all, because of the lower temperature operation.

There are several significant differences, however, between the GCFR and HTGR backup designs that affect costs, as shown in Table 6.7. The fast reactor core of the GCFR is much more compact than the graphite-moderated core of the HTGR. This feature makes it possible to use a more compact PCRV, which is in the form of a horizontal rectangular prism, with the reactor in a center compartment and the helium circulators and heat exchangers in two end compartments. This arrangement is in contrast to that of the PCRV for the HTGR which, for the backup design, is a vertical hexagonal prism with heat transfer system components located below the reactor. Cost estimates for the PCRV for the GCFR were based on unit costs consistent with those for the PCRV for the HTGR. Since it is much more compact, estimated costs are about $\$ 3.1 / \mathrm{kW}(\mathrm{e})$ lower than for the HrGR backup design. The cost of the graphite reflector in the HTGR design and a more expensive control rod system increases the total reactor equipment cost difference between HTGR and GCFR account 221 costs to about $\$ 8 / \mathrm{kW}$ (e) higher for the HTGR backup design and $\$ 3 / \mathrm{kw}(\mathrm{e})$ higher for the HTGR reference design.

The compact core and temperature restrictions in the GCFR result in about $20 \%$ more total helium flow and about five times higher pressure drop than in the HTGR design. As a result the GCFR circulators and drives are estimated to cost about $\$ 6.4 / \mathrm{kw}(\mathrm{e})$ more than the HTGR circulators and drives. The lower helium temperatures of the GCFR require steam generators about twice the size of the HTGR backup design but use stainless steel instead of Inconel tubes. Because of this feature and because the design of 
Table 6.7. Comparison of GCFR (Reference Design) and HTGR (Backup Design) Unit Costs

\begin{tabular}{|c|c|c|c|}
\hline \multirow{2}{*}{ Account } & \multicolumn{3}{|c|}{ Unit Costs $[\$ / k w(e)]$} \\
\hline & GCFR & HTGR & $\begin{array}{l}\text { Difference } \\
(\mathrm{GCFR}-\mathrm{HTGR})\end{array}$ \\
\hline $\begin{array}{l}21 \text { Structures and improvements } \\
22 \text { Reactor plant equipment }\end{array}$ & $15.0^{\mathrm{a}}$ & 11.5 & 3.5 \\
\hline $\begin{array}{l}221.1 \text { Reactor vessel } \\
221.2 \text { Control rods and drives } \\
221.4 \text { Reflector } \\
222.1 \text { Reactor coolant sysiem } \\
222.3 \text { steam generators } \\
222.5 \text { Coolant treatment }\end{array}$ & $\begin{array}{r}14.5 \\
2.6 \\
10.3 \\
16.4 \\
2.8\end{array}$ & $\begin{array}{r}17.6 \\
4.4 \\
3.6 \\
3.9 \\
13.4 \\
1.6\end{array}$ & $\begin{array}{r}-3.1 \\
-1.8 \\
-3.6 \\
6.4 \\
3.0 \\
1.2\end{array}$ \\
\hline Other accounts & 68.4 & $67 \cdot 3$ & 1.1 \\
\hline Total & 130.0 & 123.3 & 6.7 \\
\hline Variations & & & $\begin{array}{r}+15.2 \\
-8.5\end{array}$ \\
\hline
\end{tabular}

In the evaluation studies, ORNI recommended that the PCRV for the GCFR be enclosed in a secondary pressure containment vessel, whereas the requirement of secondary containment for the HTGR was not clearly indicated. Thus, the $\$ 3.5 / \mathrm{kw}(\mathrm{e})$ higher structure costs for the GCFR's are largely due to the cost of secondary containment.

the steam generator for the GCFR is considered to be less complex than for the HTGR, unit costs $\left(\$ / f t^{2}\right)$ for the former are estimated to be lower. As a net result the GCFR steam generators are estimated to cost about $\$ 3.0 / \mathrm{kW}(\mathrm{e})$ more than those of the HTGR backup design. Because of still lower unit costs, the steam generators for the GCFR derated design are estimated to cost about $\$ 2.1 / \mathrm{kW}(\mathrm{e})$ less than the GCFR reference design units, even though surface area requiments are essentially the same in the two designs.

The GCFR helium purification system is required to have a greater capacity than the HTGR system. This requirement explains the higher GCFR cost in account 222.5 . 
Turbine-generator plant costs are essentially the same for the $2403-p s i g / 1000^{\circ} \mathrm{F} / 1000^{\circ} \mathrm{F}$ steam cycles of the reference GCFR and backup HTGR designs. The HTGR account 23 costs are slightly higher, about $\$ 0.8 / \mathrm{kw}(\mathrm{e})$, because the circulator turbines are series fed by reheat steam, whereas the GCFR turbine drives have parallel feed discharging to separate condensers, which are priced with the turbine package. The turbinegenerator plant for the $1800-\mathrm{psig} / 900^{\circ} \mathrm{F} / 900^{\circ} \mathrm{F}$ cycle of the derated GCFR design costs about $\$ 2.0 / \mathrm{kw}(\mathrm{e})$ more because of the lower thermal efficiency.

Compensating cost differences discussed above result in an estimated total unit cost difference of $\$ 6.7 / \mathrm{kw}(\mathrm{e})$ between the reference GCFR and backup HTGR plants, or $\$ 8.3 / \mathrm{kw}(e)$ difference between the GCFR and HTGR reference designs, with the GCFR costs being the higher.

From the engineering review of the GCFR, it was concluded that significant capital cost uncertainties exist in the following areas:

1. Construction labor costs for the PCRV are not firm because of uncertainties in construction labor requirements. As a result of a number of complicating factors, construction time might be doubled from the present estimate. This could add approximately $\$ 5$ million to the total unit costs estimated for this concept.

2. Present uncertainties in heat transfer surface area requirements could affect the size of the steam generator units by $20 \%$ or more and add about $\$ 3 / \mathrm{kw}(\mathrm{e})$ to the cost of the plant.

3. Until more detailed safety analyses and some prototype experience are available, it is uncertain whether a secondary containment vessel around the PCRV of the GCFR plant will be required. In the ORNL estimate, the incremental cost of containment added about $\$ 4 / \mathrm{kw}(\mathrm{e})$ to the total unit cost. However, some modifications, such as redesign of PCRV penetrations, may reduce the cost penalty somewhat below this value.

\subsubsection{Influence of Capital Costs on Energy Costs}

Capital investment costs are converted into energy costs by using an annual fixed charge rate of $13.7 \%$ and an average effective lifetime plant factor of 0.8 . The results are summarized in Table 6.8. It may be seen that the corresponding energy costs for the altemate coolant breeders 
Table 6.8. Normalized Capital and Power Costs of Alternate Coolant Fast Breeders

\begin{tabular}{lcccc}
\hline Concept & $\begin{array}{c}\text { Net Electric } \\
\text { Power Level } \\
(\mathrm{Mw})\end{array}$ & $\begin{array}{c}\text { Total Cost } \\
(\$ \text { millions })\end{array}$ & $\begin{array}{c}\text { Unit Costa } \\
{[\$ / \mathrm{kw}(\mathrm{e})]}\end{array}$ & $\begin{array}{c}\text { Associated } \\
\text { Power } \\
\text { Costs }^{\text {b }} \\
\text { (mills } / \mathrm{kwhr})\end{array}$ \\
\hline SCBR & & & & \\
1250-psi system & 1012 & 130.26 & 129.1 & 2.53 \\
2680-psi system & 1000 & 131.40 & 131.4 & 2.57 \\
3700-psi system & 970 & 118.86 & 121.7 & 2.38 \\
GCFR & & & & \\
Derated plant & 1000 & 129.34 & 129.3 & 2.53 \\
Reference plant & 1000 & 130.03 & 130.0 & 2.54 \\
\hline
\end{tabular}

adjusted to $1000 \mathrm{Mw}(\mathrm{e})$ (net); see Section 3.3.

$\mathrm{b}_{\text {Based on }} 13.7 \%$ annual fixed charge rate and a plant factor of 0.8 .

range from a low of $2.38 \mathrm{mills} / \mathrm{kwhr}$ for the high-pressure SCBR to about 2.53 to $2.57 \mathrm{mills} / \mathrm{kwhr}$ for all the others.

\subsection{Fuel Cycle Costs}

Fuel treatment costs for the alternate coolant fast breeder reactors were divided into four categories: namely (1) preparation, (2) fabrication, (3) reprocessing, and (4) shipping. These costs are discussed in the following paragraphs.

\subsubsection{Fuel-Preparation Costs}

Fuel preparation includes those operations necessary to convert makeup and recycle fuel material to the proper chemical and physical form for feed to the fabrication process. In this case, the assumed fuel preparation steps are the following:

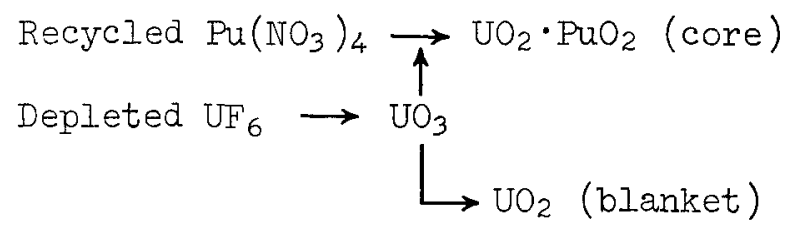


The fuel preparation plant is assumed to be an integral part of either the fuel fabrication plant or the spent fuel reprocessing plant, or both, in that no site costs are included and sharing of supporting services and service personnel is assumed. The costs would be approximately 10\% higher, and there would be one or two additional shipping charges if the preparation plant were independent.

Fuel preparation costs as a function of plant capacity are plotted in Fig. 6.1. Costs are based on 260 production days per year and a $22 \%$ annual charge on plant investment. Specific costs for 15,000- and 30,000-Mw(e) industries are summarized in Table 6.9 .

\subsubsection{Fabrication Costs}

Fabrication costs for the altemate coolant fast breeder reactors for exposures of 100,000 and 50,000 Mwd/MT are given in Tables 6.10 and 6.11, respectively. The data are summarized in Tables 6.12 and 6.13.

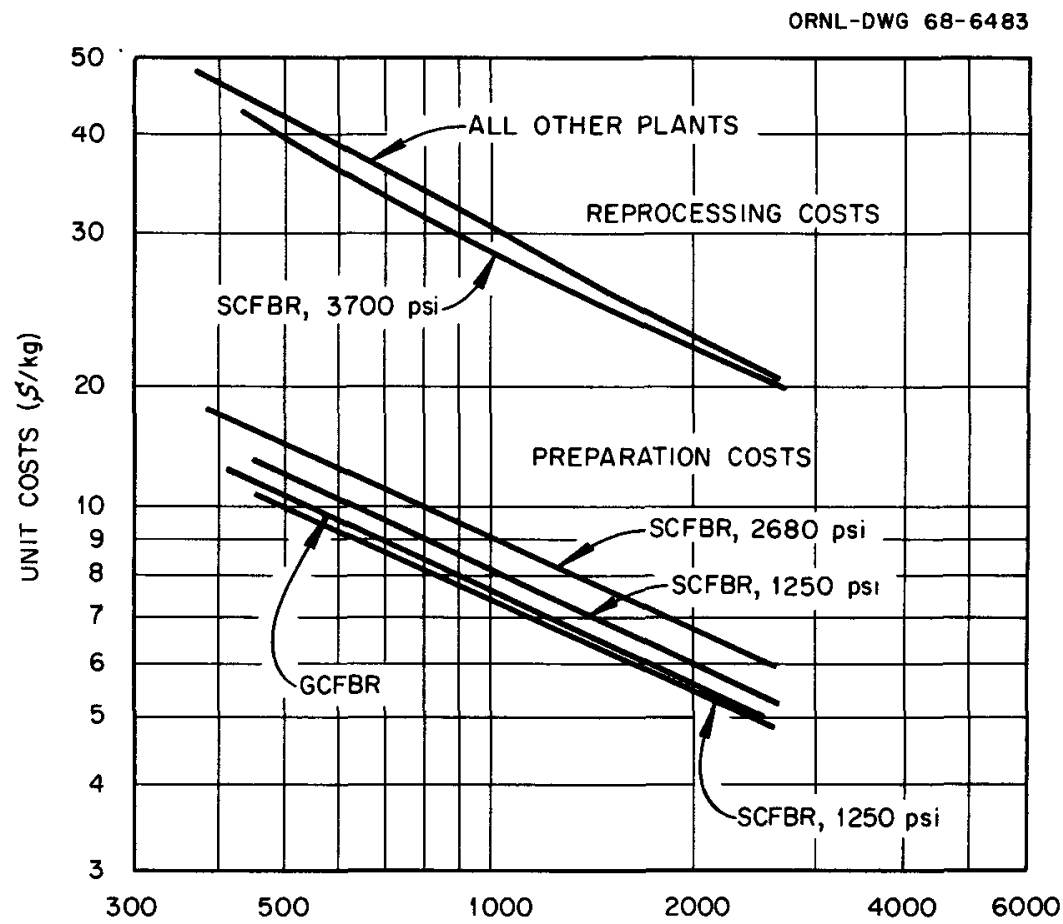

Fig. 6.1. Spent Fuel Reprocessing Costs and Fuel Preparation Costs for Steam- and Gas-Cooled Fast Breeder Reactors. 
Table 6.9. Fuel-Preparation (Conversion) Costs for Alternate-Coolant Fast

Breeder Reactors with 15,000- and 30,000-Mw(e) Economies

Basis: 1. Cost of preparation of $\mathrm{UO}_{2}$ and $\mathrm{UO}_{2}-\mathrm{PuO}_{2}$ for fabrication, starting from depleted $\mathrm{UF}_{6}$ and $\mathrm{Pu}\left(\mathrm{NO}_{3}\right)_{4}$

2. Preparation plant size assumed to match the amount and

type of reactor indicated

3. 260 production days per year

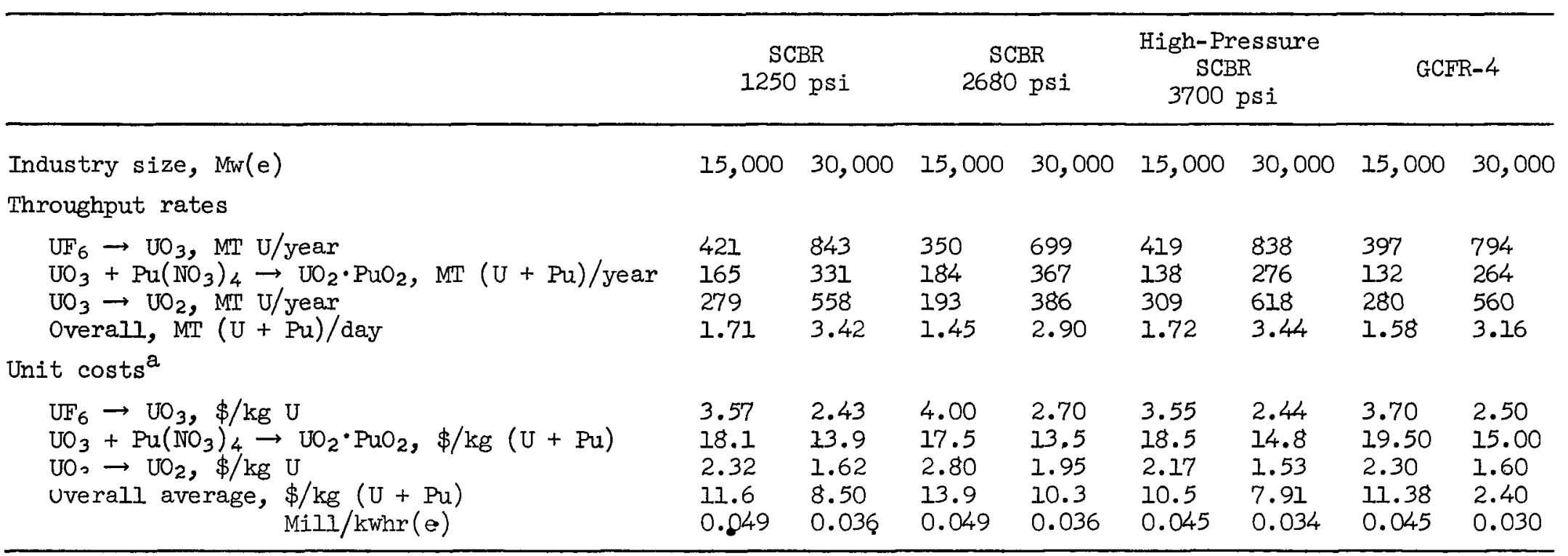

a Based on 22\%/year fixed charge rate on capital investment. 
Table 6.10. Fuel-Fabrication Costs ${ }^{a}$ for Alternate-Coolant Breeder Reactors with Core Fuel Exposures of 100,000 Mwd/MT

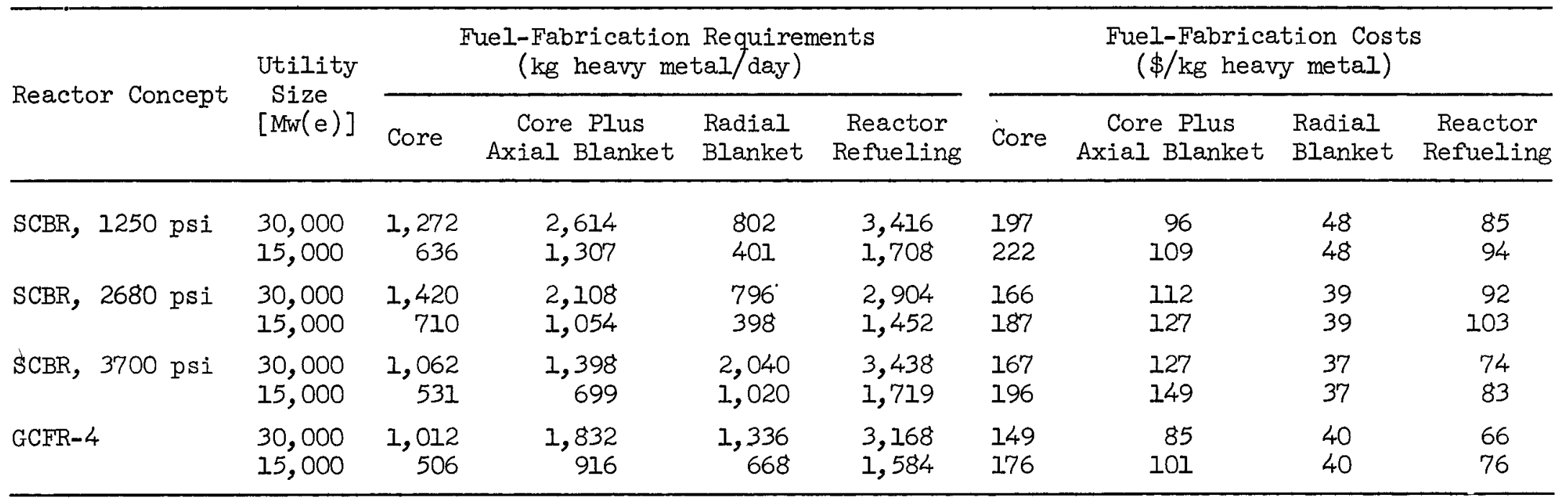

${ }^{a}$ Core fuel exposure cost based on $22 \% /$ year capital charge rate. 
Table 6.11. Fuel-Fabrication Costsa for Alternate-Coolant Breeder Reactors with Core Fuel Exposures of 50,000 Mwd/MT

\begin{tabular}{|c|c|c|c|c|c|c|c|c|c|}
\hline \multirow{2}{*}{ Reactor Concept } & \multirow{2}{*}{$\begin{array}{l}\text { Utility } \\
\text { Size } \\
{[\operatorname{Mw}(e)]}\end{array}$} & \multicolumn{4}{|c|}{$\begin{array}{l}\text { Fuel-Fabrication Requirements } \\
\text { (kg heavy metal/day) }\end{array}$} & \multicolumn{4}{|c|}{$\begin{array}{l}\text { Fuel-Fabrication Costs } \\
(\$ / \mathrm{kg} \text { heavy metal) }\end{array}$} \\
\hline & & Core & $\begin{array}{c}\text { Core Plus } \\
\text { Axial Blanket }\end{array}$ & $\begin{array}{l}\text { Radial } \\
\text { Blanket }\end{array}$ & $\begin{array}{l}\text { Reactor } \\
\text { Refueling }\end{array}$ & Core & $\begin{array}{c}\text { Core Plus } \\
\text { Axial Blanket }\end{array}$ & $\begin{array}{l}\text { Radial } \\
\text { Blanket }\end{array}$ & $\begin{array}{l}\text { Reactor } \\
\text { Refueling }\end{array}$ \\
\hline SCBR, $1250 \mathrm{psi}$ & $\begin{array}{l}30,000 \\
15,000\end{array}$ & $\begin{array}{l}2,544 \\
1,272\end{array}$ & $\begin{array}{l}5,228 \\
2,614\end{array}$ & $\begin{array}{l}80 \% \\
401\end{array}$ & $\begin{array}{l}6,030 \\
3,015\end{array}$ & $\begin{array}{l}180 \\
197\end{array}$ & $\begin{array}{l}88 \\
97\end{array}$ & $\begin{array}{l}48 \\
48\end{array}$ & $\begin{array}{l}79 \\
85\end{array}$ \\
\hline SCBR, 3700 psi & $\begin{array}{l}30,000 \\
15,000\end{array}$ & $\begin{array}{l}2,124 \\
1,062\end{array}$ & $\begin{array}{l}2,796 \\
1,398\end{array}$ & $\begin{array}{l}2,040 \\
1,020\end{array}$ & $\begin{array}{l}4,836 \\
2,418\end{array}$ & $\begin{array}{l}146 \\
167\end{array}$ & $\frac{111}{127}$ & $\begin{array}{l}37 \\
37\end{array}$ & $\begin{array}{l}67 \\
74\end{array}$ \\
\hline GCFR-4 & $\begin{array}{l}30,000 \\
15,000\end{array}$ & $\begin{array}{l}2,024 \\
1,012\end{array}$ & $\begin{array}{l}3,664 \\
1,832\end{array}$ & $\begin{array}{r}1,336 \\
668\end{array}$ & $\begin{array}{l}5,000 \\
2,500\end{array}$ & $\begin{array}{l}130 \\
149\end{array}$ & $\begin{array}{l}74 \\
85\end{array}$ & $\begin{array}{l}40 \\
40\end{array}$ & $\begin{array}{l}60 \\
67\end{array}$ \\
\hline
\end{tabular}

${ }^{a}$ Core fuel exposure cost based on $22 \% /$ year capital charge rate. 
Table 6.12. Fuel Fabrication Costs as a Function of Utility Size and Fuel Exposure*

\begin{tabular}{|c|c|c|c|c|c|}
\hline \multirow{2}{*}{$\begin{array}{c}\text { Utility } \\
\text { Size } \\
{[\operatorname{Mw}(e)]}\end{array}$} & \multirow{2}{*}{$\begin{array}{l}\text { Core Fuel } \\
\text { Exposure } \\
\text { (Mwd/MT) }\end{array}$} & \multicolumn{4}{|c|}{ Fuel-Fabrication Cost $[\mathrm{mi}] \mathrm{l} / \mathrm{kwhr}(\mathrm{e})]$} \\
\hline & & $\begin{array}{c}\text { SCF'B } \\
1250 \mathrm{psi}\end{array}$ & $\begin{array}{c}\text { SCBR } \\
2680 \text { psi }\end{array}$ & $\begin{array}{c}\text { SCBR } \\
3700 \text { psi }\end{array}$ & GCFR-4 \\
\hline 30,000 & 100,000 & 0.36 & 0.33 & 0.31 & 0.23 \\
\hline 15,000 & 100,000 & 0.40 & 0.37 & 0.35 & 0.26 \\
\hline 30,000 & 50,000 & 0.59 & 0.53 & 0.40 & 0.37 \\
\hline 15,000 & 50,000 & 0.63 & 0.58 & 0.44 & 0.41 \\
\hline
\end{tabular}

Table 6.13. Fuel Fabrication Costs as a Function of Utility Size and Fuel Exposure*

\begin{tabular}{cccccc}
\hline $\begin{array}{l}\text { Utility } \\
\text { Size } \\
{[\text { Mw(e) }}\end{array}$ & $\begin{array}{c}\text { Core Fuel } \\
\text { Exposure } \\
(\text { Mwd/MT })\end{array}$ & \multicolumn{4}{c}{ Fuel Fabrication Cost $(\$ /$ kg heavy metal) } \\
\cline { 3 - 6 } & $\begin{array}{c}\text { SCBR } \\
1250 \text { psi }\end{array}$ & $\begin{array}{c}\text { SCBR } \\
2680 \text { psi }\end{array}$ & $\begin{array}{c}\text { SCBR } \\
3700 \text { psi }\end{array}$ & GCFR-4 \\
\hline 30,000 & 100,000 & 85 & 92 & 74 & 66 \\
15,000 & 100,000 & 94 & 103 & 83 & 76 \\
30,000 & 50,000 & 79 & 85 & 67 & 60 \\
15,000 & 50,000 & 85 & 93 & 74 & 67 \\
\hline \multicolumn{5}{c}{$*$ Costs based on 22\%/year capital charge rate. }
\end{tabular}

Since the GCFR sponsor proposed the use of a fission gas pressure equalizing system in lieu of a gas plenum at the top of each pin, calculations were performed to compare fabrication costs for these two approaches. The results are summarized in Table 6.14.

It may be seen that at low throughputs (below $1000 \mathrm{~kg} /$ day), the sealed pin concept is probably cheaper; however, the manifolded concept may be cheaper at higher throughputs. The additional costs entailed by fabricating the fission gas collection and pressure equalizing system and 
Table 6.14. Comparison of Fabrication Costs of Nonvented and Pressure Equalizing Fuel Pins

\begin{tabular}{rccccc}
\hline $\begin{array}{l}\text { Plant } \\
\text { Capacity } \\
\text { (kg/day) }\end{array}$ & Nonvented Fuel Pins & & \multicolumn{2}{c}{ Pressure Equalizing Fuel Pins } \\
\cline { 6 - 7 } \cline { 6 - 7 } & $\$ / \mathrm{kg}$ & $\$ /$ Element & & $\$ / \mathrm{kg}$ & \$/Element \\
\hline 250 & 217.58 & 4,460 & & $218.09-234.05$ & $5,899-7,865$ \\
500 & 176.37 & 3,525 & & $174.28-186.89$ & $4,663-6,217$ \\
750 & 158.97 & 3,072 & & $155.60-166.60$ & $4,064-5,418$ \\
1,000 & 149.16 & 2,786 & & $144.99-154.96$ & $3,686-4,914$ \\
1,500 & 137.56 & 2,428 & & $132.37-141.06$ & $3,212-4,283$ \\
2,000 & 130.46 & 2,202 & & $124.63-132.51$ & $2,913-3,885$ \\
3,000 & 121.79 & 1,920 & & $115.15-122.03$ & $2,539-3,385$ \\
4,000 & 116.47 & 1,741 & & $109.31-115.54$ & $2,303-3,071$ \\
6,000 & 110.25 & 1,517 & & $102.45-107.88$ & $2,007-2,676$ \\
10,000 & 103.61 & 1,276 & & $95.10-99.67$ & $1,687-2,250$ \\
\hline
\end{tabular}

its assembly as part of the fuel bundle were based on costs of materials, machining, brazing, and assembly. These costs were partially compensated by the lack of a fission gas plenum in the pressure equalized pins.

\subsubsection{Shipping Costs}

The costs of shipping irradiated fuel elements were computed with a special computer code, MYRA. ${ }^{38}$ Cooling times of 30 days for core elements and 90 days for blanket elements were selected as compromises between shorter cooling times that would be more economical and longer times that would reduce the heat and activity of the elements. Costs include: (1) loading, unloading, rigging, testing, and decontamination, (2) insurance, (3) railroad freight charges, and (4) annual fixed charges on cask costs. Other assumptions and cost bases were: (1) 1000-mile shipment each way, (2) compliance with AEC dose limits of $10 \mathrm{mr} / \mathrm{hr}$ at $6 \mathrm{ft}$ from outside the vehicle, (3) maximum weight of cask of 120 short tons, (4) cask cost of $\$ 1.25$ per pound of cask weight, and (5) casks shared sufficiently among plants to reach a maximum utilization of $80 \%$.

Costs were also estimated for shipping recycled fresh fuel of moderate ramma activity and virgin fuel of zero gamma activity, where applicable. 
These shipping costs are summarized in Table 6.15. The unit shipping costs were combined with the mass balances throughout the lifetime of the reactors to obtain levelized values for the effect of shipping costs on the unit fuel cycle costs.

Table 6.15. Fuel Shipping Costs

\begin{tabular}{|c|c|c|c|c|c|c|}
\hline \multirow{2}{*}{ Reactor } & \multirow{2}{*}{$\begin{array}{c}\text { Fuel } \\
\text { Assembly } \\
\text { Type }\end{array}$} & \multirow{2}{*}{$\begin{array}{l}\text { Year } \\
\text { Shipped }\end{array}$} & \multirow{2}{*}{$\begin{array}{l}\text { Cooling } \\
\text { Time } \\
\text { (days) }\end{array}$} & \multicolumn{3}{|c|}{$\begin{array}{c}\text { Shipping Costs } \\
(\$ / \mathrm{kg} \text { heavy metal) }\end{array}$} \\
\hline & & & & $\begin{array}{l}\text { Spent } \\
\text { Fuel }\end{array}$ & $\begin{array}{l}\text { Fresh } \\
\text { Fuel }\end{array}$ & $\begin{array}{l}\text { Recycled } \\
\text { Fuel }\end{array}$ \\
\hline \multirow[t]{2}{*}{ SCBR, 1250 psi } & $\begin{array}{l}\text { Core and axial } \\
\text { blanket }\end{array}$ & $\begin{array}{l}1980 \\
1990\end{array}$ & $\begin{array}{l}30 \\
30\end{array}$ & $\begin{array}{l}12.00 \\
11.00\end{array}$ & $\begin{array}{l}1.70 \\
1.50\end{array}$ & $\begin{array}{l}2.40 \\
2.10\end{array}$ \\
\hline & Radial blanket & $\begin{array}{l}1980 \\
1990\end{array}$ & $\begin{array}{l}90 \\
90\end{array}$ & $\begin{array}{l}2.50 \\
2.10\end{array}$ & $\begin{array}{l}0.55 \\
0.45\end{array}$ & \\
\hline \multirow[t]{2}{*}{ SCBR, $2680 \mathrm{psi}$} & $\begin{array}{l}\text { Core and axial } \\
\text { blanket }\end{array}$ & $\begin{array}{l}1980 \\
1990\end{array}$ & $\begin{array}{l}30 \\
30\end{array}$ & $\begin{array}{r}10.00 \\
9.00\end{array}$ & $\begin{array}{l}1.20 \\
1.00\end{array}$ & $\begin{array}{l}2.00 \\
1.80\end{array}$ \\
\hline & Radial blanket & $\begin{array}{l}1980 \\
1990\end{array}$ & $\begin{array}{l}90 \\
90\end{array}$ & $\begin{array}{l}2.20 \\
1.80\end{array}$ & $\begin{array}{l}0.50 \\
0.40\end{array}$ & \\
\hline \multirow[t]{2}{*}{ SCBR, $3700 \mathrm{psi}$} & $\begin{array}{l}\text { Core and axiar } \\
\text { blanket }\end{array}$ & $\begin{array}{l}1980 \\
1990\end{array}$ & $\begin{array}{l}30 \\
30\end{array}$ & $\begin{array}{l}18.00 \\
16.00\end{array}$ & $\begin{array}{l}2.00 \\
1.70\end{array}$ & $\begin{array}{l}2.70 \\
2.40\end{array}$ \\
\hline & Radial blanket & $\begin{array}{l}1980 \\
1990\end{array}$ & $\begin{array}{l}90 \\
90\end{array}$ & $\begin{array}{l}3.00 \\
2.50\end{array}$ & $\begin{array}{l}0.60 \\
0.50\end{array}$ & \\
\hline \multirow[t]{2}{*}{$\mathrm{GCFR}$} & $\begin{array}{l}\text { Core and axial } \\
\text { blanket }\end{array}$ & $\begin{array}{l}1980 \\
1990\end{array}$ & $\begin{array}{l}30 \\
30\end{array}$ & $\begin{array}{l}14.00 \\
13.00\end{array}$ & $\begin{array}{l}2.00 \\
1.70\end{array}$ & $\begin{array}{l}2.60 \\
2.30\end{array}$ \\
\hline & Radial blanket & $\begin{array}{l}1980 \\
1990\end{array}$ & $\begin{array}{l}90 \\
90\end{array}$ & $\begin{array}{l}2.80 \\
2.40\end{array}$ & $\begin{array}{l}0.60 \\
0.50\end{array}$ & \\
\hline
\end{tabular}

\subsubsection{Reprocessing Costs}

Spent fuel reprocessing cost estimates were based on published costs of reprocessing plants. ${ }^{39,40}$ These costs were revised by ORNL to include the effect of escalation, competitive conditions, head-end treatment, throughput rates, land, startup costs, working capital, and ultimate waste 
isposal. Reference capital costs were $\$ 29$ million based on Nuclear Fuel Service's 1-MT/day light water reactor fuel processing plant (260 MT/year) and $\$ 62$ million for a du Pont designed 9-MT/day plant (2350 MT/year), but costs for the breeder fuel reprocessing plants are higher because of higher burnups, shorter cooling times, and the presence of plutonium. Operating costs include interim and ultimate waste disposal charges, and storage charges for depleted uranium were estimated so that the estimators could plan on recycle of depleted uranium or not, depending on the economics of the particular case. Since the plants were assumed to handle a single type of fuel, no "turnaround" penalty was applied per se; however, the number of operating days per year was taken as 260 to allow for periodic cleanup and SF accountability.

Processing costs for the alternate coolant fast breeder reactor concepts are shown in Table 6.16 for industry sizes of 15,000 and 30,000 Mw(e) and are shown in Fig. 6.1 as a function of throughput. The reference cases for 15,000-Mw(e) capacity are located at the higher cost end of these curves.

\subsubsection{Summary of Fuel Cycle Costs}

Fuel cycle costs were obtained for each concept by using the present value discounting technique to obtain 30-year lifetime costs. The average fuel cost was determined by computing the present value (discounted to reactor startup) of all future costs and dividing it by the discounted amount of energy sold during the life of the plant. This levelized cost represents the fixed price that must be received per unit of electricity in order to pay all costs associated with the fuel cycle. It was assumed that neither the reactor load factor nor the unit cost of purchased materials or services varied during plant life.

For the computation of interest costs, it was assumed that fuel purchase would be subject to a $13.2 \%$ annual charge, working capital funds would bear a 12.8\% annual charge, and spent fuel shipping and reprocessing would be treated as nontaxable operating costs at $7.2 \%$ per annum. The resulting fuel cycle costs are summarized in Table 6.17. 
Table 6.16. Spent Fuel Reprocessing Costs for Alternate Coolant Fast Breeder Reactors with 15,000- and 30,000-Mw(e) Economies

Basis: 1. Single purpose, central, aqueous processing plants sized to match the assumed amount and type of reactor indicated

2. 260 production days per year

\begin{tabular}{|c|c|c|c|c|c|c|c|c|}
\hline & \multicolumn{2}{|c|}{$\begin{array}{l}\text { SCBR } \\
1250 \mathrm{psi}\end{array}$} & \multicolumn{2}{|c|}{$\begin{array}{c}\text { SCBR } \\
2680 \text { psi }\end{array}$} & \multicolumn{2}{|c|}{$\begin{array}{l}\text { SCBR } \\
3700 \text { psi }\end{array}$} & \multicolumn{2}{|c|}{ GCFR-4 } \\
\hline Industry size, $M w(e)$ & 15,000 & 30,000 & 15,000 & 30,000 & 15,000 & 30,000 & 15,000 & 30,000 \\
\hline \multicolumn{9}{|l|}{ Throughput rate, $U+P u+F P$} \\
\hline $\begin{array}{l}\mathrm{MT} / \text { year } \\
\mathrm{MT} / \text { day }\end{array}$ & $\begin{array}{l}444 \\
1.71\end{array}$ & $\begin{array}{l}888 \\
3.42\end{array}$ & $\begin{array}{l}377 \\
1.45\end{array}$ & $\begin{array}{l}754 \\
2.90\end{array}$ & $\begin{array}{l}447 \\
1.72\end{array}$ & $\begin{array}{l}894 \\
3.44\end{array}$ & $\begin{array}{l}411 \\
1.58\end{array}$ & $\begin{array}{l}823 \\
3.16\end{array}$ \\
\hline Capital investment, \$ million & 47.6 & 60.7 & 45.0 & 57.4 & 47.8 & 60.8 & 46.4 & 58.7 \\
\hline Annual operating cost, $\$$ million & 4.45 & 5.99 & 4.16 & 5.57 & 4.46 & 6.01 & 4.31 & 5.75 \\
\hline Annual waste charge, $\$$ million & 1.78 & 3.20 & 1.58 & 2.84 & 1.48 & 2.65 & 1.74 & 2.85 \\
\hline $\begin{array}{l}\text { Annual charge for depleted-uranium } \\
\text { storage, \$ million }\end{array}$ & 0.74 & 1.28 & 0.63 & 1.13 & 0.73 & 1.32 & 0.69 & 1.24 \\
\hline \multicolumn{9}{|l|}{ Unit total cost* } \\
\hline $\begin{array}{l}\$ / \mathrm{kg} \\
\mathrm{Mill} / \mathrm{kwhr}(\mathrm{e})\end{array}$ & $\begin{array}{l}39.3 \\
0.166\end{array}$ & $\begin{array}{l}26.8 \\
0.113\end{array}$ & $\begin{array}{l}43.1 \\
0.155\end{array}$ & $\begin{array}{l}29.4 \\
0.105\end{array}$ & $\begin{array}{l}36.8 \\
0.163\end{array}$ & $\begin{array}{l}24.7 \\
0.111\end{array}$ & $\begin{array}{l}41.2 \\
0.161\end{array}$ & $\begin{array}{l}27.6 \\
0.108\end{array}$ \\
\hline
\end{tabular}

* Based on $22 \% /$ year fixed charge rate on capital investment. 
Table 6.17. 30-Year Levelized Fuel-Cycle Costs for Alternate Coolant Breeder Reactorsa

\begin{tabular}{|c|c|c|c|c|c|}
\hline & \multicolumn{5}{|c|}{ Costs (mills/kwhr) } \\
\hline & \multirow{2}{*}{$\begin{array}{c}\text { SCBR } \\
1250 \mathrm{psi}\end{array}$} & \multirow{2}{*}{$\begin{array}{c}\text { SCBR } \\
2680 \text { psi }\end{array}$} & \multirow{2}{*}{$\begin{array}{c}\text { SCBR } \\
3700 \text { psi }\end{array}$} & \multicolumn{2}{|c|}{ GCFR } \\
\hline & & & & Reference & Derated \\
\hline Burnup, $U+P u$ & -0.39 & -0.11 & -0.05 & -0.45 & -0.45 \\
\hline Preparation and fabrication & 0.50 & 0.43 & 0.41 & 0.38 & 0.40 \\
\hline Processing and shipping & 0.21 & 0.17 & 0.18 & 0.20 & 0.21 \\
\hline Inventory, $\mathrm{U}+\mathrm{Pu}$ & 0.87 & 0.89 & 0.68 & 0.76 & 0.82 \\
\hline Working capital interest & 0.17 & 0.14 & 0.04 & 0.07 & 0.07 \\
\hline Total & 1.36 & 1.52 & 1.26 & 0.96 & 1.05 \\
\hline
\end{tabular}

a Based on 15,000-Mw(e) industry.

\subsection{Operating and Maintenance Costs}

Operating and maintenance costs include payroll costs, repair and maintenance labor and materials, contract services, and insurance. These costs are based on data and ground rules given in the latest draft of "Guide for Economic Evaluations of Nuclear Reactor Plant Designs" prepared for the U.S. Atomic Energy Commission by the NUS Corporation and dated November 1967. A breakdown of these costs for the reactors considered in this evaluation is given in Table 6.18.

\subsection{Power Costs}

Data on costs given previously for fuel preparation, reprocessing, shipping, capital, and operating and maintenance are combined and summarized in Table 6.19 to provide a basis for comparing total power costs in the various concepts. Capital and operation and maintenance costs could be transposed directly from the individual sections into the summary, but the component parts of fuel cycle costs vary throughout the operating life of the individual reactor system. Consequently, it was necessary to feed 
Table 6.18. Operating and Maintenance Costs

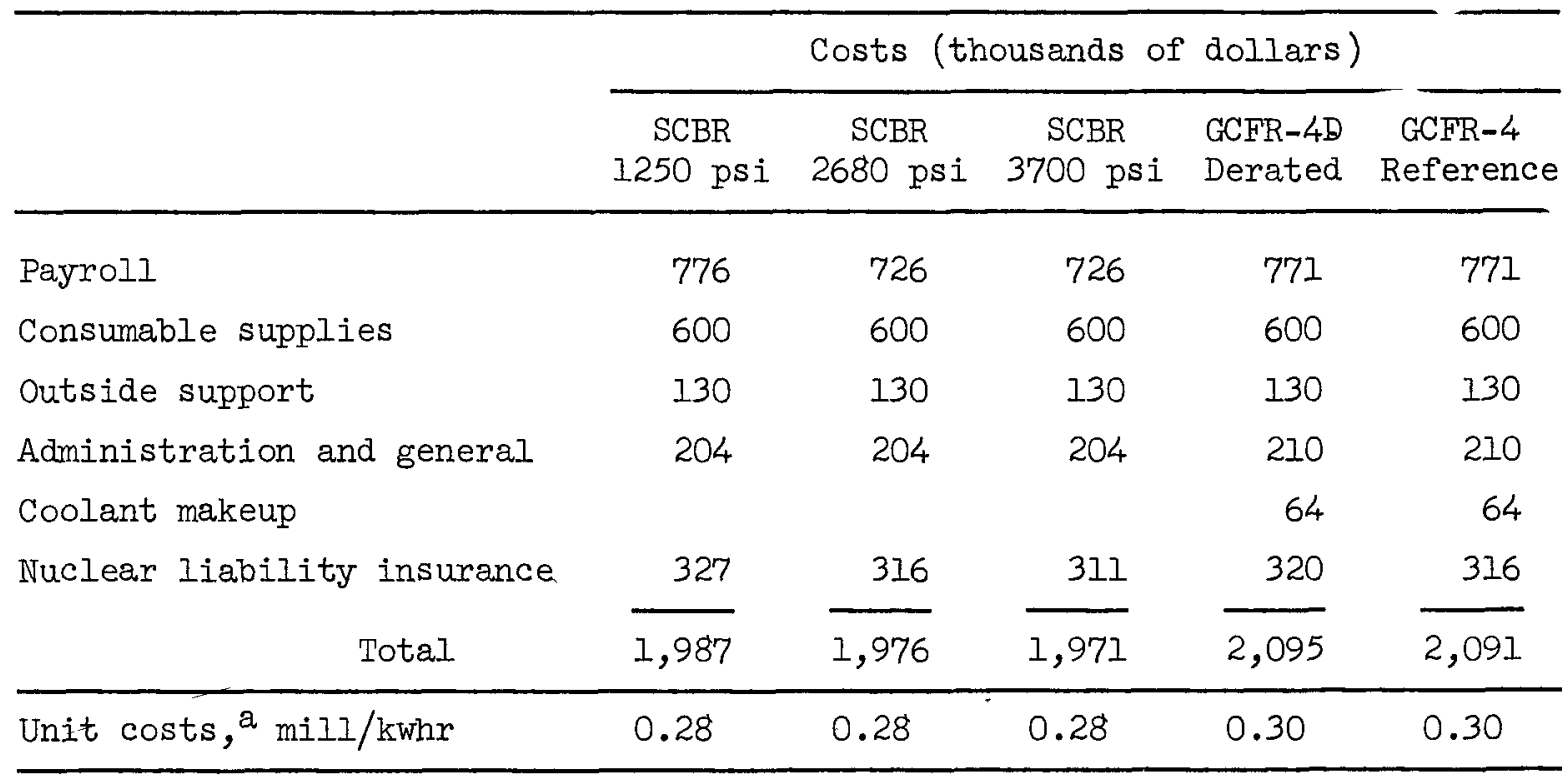

at a power factor of 0.8 .

Table 6.19. Power Costs for Investor Owned Alternate Coolant Breeder Reactors

\begin{tabular}{lllll}
\hline & \multicolumn{3}{c}{ Costs (mills/kwhr) } \\
\cline { 2 - 5 } Concept & Capital & $\begin{array}{c}\text { Fuel } \\
\text { Cycle }\end{array}$ & $\begin{array}{c}\text { Operation } \\
\text { and } \\
\text { Maintenance }\end{array}$ & Total \\
& & & & \\
SCBR & & & 0.28 & 4.17 \\
1250-psi system & 2.52 & 1.36 & 0.28 & 4.37 \\
2680-psi system & 2.57 & 1.52 & 0.28 & 3.92 \\
3700-psi system & 2.38 & 1.26 & & \\
GCFR & & & 0.30 & 3.88 \\
Backup plant & 2.53 & 1.05 & 0.30 & 3.80 \\
Reference plant & 2.54 & 0.96 & 0.96 \\
\hline
\end{tabular}


the mass balances over the reactor lifetime and the components of fuel cycle costs into the computer program to arrive at 30-year levelized fuel cycle costs.

Power costs for the GCFR's and the 3700-psi SCBR are in the range of 3.8 to $3.9 \mathrm{mills} / \mathrm{kwhr}$, while costs for the other two SCBR's range from 4.2 to $4.3 \mathrm{mills} / \mathrm{kwhr}$.

Although the carbide fueled GCFR design was not evaluated by ORNL, power costs were estimated to indicate the cost potential of this more advanced GCFR design. GGA estimates indicated that the capital cost for the carbide fueled GCFR would be slightly lower than for the reference oxide fueled GCFR. However, the plant designs on which the costs were based are at such a preliminary stage that it seems reasonable that no credit be taken for the apparent cost decrease. Therefore, it was assumed that the capital costs for the carbide and reference oxide fueled plants would be the same; that is, $\$ 130 / \mathrm{kw}(\mathrm{e})$ at $13.7 \%$ fixed charge rate and a 0.8 power factor. Operating and maintenance costs were also assumed to be the same for the two plants. Fuel cycle costs were based on GGA physics results for the equilibrium cycle and unit cost estimates prepared by ORNL. The resulting power costs are presented below:

\begin{tabular}{lc} 
& $\begin{array}{c}\text { Cost } \\
\text { Capilis } / \mathrm{kwh})\end{array}$ \\
\cline { 2 - 2 } Fuel cycle cost & 2.54 \\
Operating and \\
maintenance cost & 0.55 \\
Total & 0.30 \\
\hline
\end{tabular}




\section{RESEARCH AND DEVELOPMENT PROGRAMS}

The following research and development estimates and proposed schedules are based primarily on estimates provided by the proponents. The AEC considers these estimates to be optimistic and concludes, based on experience with other difficult development projects, that the costs would be several times the projected levels and the time requirements would be correspondingly extended.

\subsection{Steam-Cooled Breeder Reactors}

\subsubsection{Annual and Total Costs}

The research and development programs for steam-cooled fast breeder reactors include design, construction, and operation of a 50-Mw(e) experiment, a 500-Mw(e) power prototype plant, and cost assistance for the first-of-a-kind commercial demonstration plant of 1000-Mw(e) capacity. ${ }^{41}$ In adition to the reactor construction and testing program, parallel efforts are to include development of materials and components and research and development on the safety and thermal-hydraulic and physics characteristics of the reactors. It is assumed that fuel materials for fast breeder reactors will be developed as a part of the liquid metal-cooled fast breeder reactor program, but some development work will be necessary for determination of the best cladding material for compatibility with the steam coolant. Separate programs have been developed for the 1250- and the 3700-psi reactors, as well as a combined program for the two. In each of the separate programs, the reactor experiment, the prototype power plant, the 1000-Mw (e) demonstration plant, and the research and development programs have been included, and in the combined program all six of the reactors have been included with combined research and development programs. Table 7.1 gives the cost breakdown by years for the 1250-psi program; Table 7.2 gives the breakdown by years for the 3700-psi program; and Table 7.3 gives the breakdown by years for the combined program. It can be seen that the supporting research and development programs constitute a relatively small fraction of the total development costs, with the major costs being attributable to the reactor experiments and the demonstration 
Table 7.1. 1250-psi SCBR Research and Development Costs

\begin{tabular}{|c|c|c|c|c|c|}
\hline \multirow[b]{2}{*}{$\begin{array}{l}\text { Fiscal } \\
\text { Year }\end{array}$} & \multicolumn{5}{|c|}{ Costs (thousands of dollars) } \\
\hline & $\begin{array}{l}\text { 50-Mv }(e) \\
\text { Reactor } \\
\text { Experiment }\end{array}$ & $\begin{array}{l}500-M w(e) \\
\text { Prototype } \\
\text { Plant }\end{array}$ & $\begin{array}{c}1000-M_{W}(e) \\
\text { First } \\
\text { Commercial } \\
\text { Planta }\end{array}$ & $\begin{array}{l}\text { Support- } \\
\text { ing Work }\end{array}$ & Total \\
\hline $\begin{array}{l}1969 \\
1970 \\
1971 \\
1972 \\
1973 \\
1974 \\
1975 \\
1976 \\
1977 \\
1978 \\
1979 \\
1980 \\
1981\end{array}$ & $\begin{array}{l}1,250 \\
4,500 \\
6,700 \\
6,700 \\
3,000 \\
3,000 \\
3,000 \\
3,000\end{array}$ & $\begin{array}{r}200 \\
100 \\
100 \\
200 \\
3,900 \\
19,000 \\
26,400 \\
28,100 \\
23,200 \\
12,070 \\
11,270\end{array}$ & $\begin{array}{r}200 \\
100 \\
100 \\
100 \\
100 \\
100 \\
200 \\
900 \\
2,000 \\
3,200 \\
4,500 \\
4,500 \\
3,000\end{array}$ & $\begin{array}{r}6,272 \\
7,422 \\
7,118 \\
6,429 \\
5,036 \\
3,006 \\
2,080 \\
1,275 \\
900 \\
1,200 \\
900 \\
900\end{array}$ & $\begin{array}{r}7,922 \\
12,122 \\
14,018 \\
13,429 \\
15,736 \\
25,106 \\
31,680 \\
33,275 \\
29,100 \\
16,470 \\
16,670 \\
5,400 \\
3,000\end{array}$ \\
\hline & & & & Total & 223,928 \\
\hline
\end{tabular}

${ }^{a}$ Costs include only first-of-a-kind engineering and construction assistance.

Table 7.2. 3700-psi SCBR Research and Development Costs

\begin{tabular}{|c|c|c|c|c|c|}
\hline \multirow[b]{2}{*}{$\begin{array}{l}\text { Fiscal } \\
\text { Year }\end{array}$} & \multicolumn{5}{|c|}{ Costs (thousands of dollars) } \\
\hline & $\begin{array}{c}50-M w(e) \\
\text { Reactor } \\
\text { Experiment }\end{array}$ & $\begin{array}{l}500-M w(e) \\
\text { Prototype } \\
\text { Plant }\end{array}$ & $\begin{array}{c}1000-\mathrm{Mw}(\mathrm{e}) \\
\text { First } \\
\text { Commercial } \\
\text { Planta }\end{array}$ & $\begin{array}{l}\text { Support- } \\
\text { ing Work }\end{array}$ & Total \\
\hline 1969 & 1,250 & 200 & 200 & 7,282 & 8,932 \\
\hline 1970 & 4,500 & 100 & 100 & 8,022 & 12,722 \\
\hline 1971 & 6,700 & 100 & 100 & 7,348 & 14,248 \\
\hline 1972 & 6,700 & 200 & 100 & 6,659 & 13,659 \\
\hline 1973 & 3,000 & 3,900 & 100 & 5,196 & 15,896 \\
\hline 1974 & 3,000 & 18,000 & 100 & 3,006 & 24,106 \\
\hline 1975 & 3,000 & 22,600 & 200 & 2,080 & 27,880 \\
\hline 1976 & 3,000 & 28,100 & 900 & 1,275 & 33,725 \\
\hline 1977 & & 19,500 & 2,000 & 900 & 25,400 \\
\hline 1978 & & 8,562 & 3,000 & 1,200 & 12,762 \\
\hline 1979 & & 8,562 & 3,900 & 900 & 13,362 \\
\hline 1980 & & & 4,000 & 900 & 4,900 \\
\hline \multirow[t]{2}{*}{1981} & & & 3,000 & & 3,000 \\
\hline & & & & Total & 210,142 \\
\hline
\end{tabular}

${ }^{\mathrm{a}}$ Costs include only first-of-a-kind engineering and construction assistance. 
Table 7.3. Annual and Total Costs for Developing 1250- and 3700-psi Steam-Cooled Breeder Reactors Simultaneously

\begin{tabular}{|c|c|c|c|c|c|}
\hline \multirow[b]{2}{*}{$\begin{array}{l}\text { Fiscal } \\
\text { Year }\end{array}$} & \multicolumn{5}{|c|}{ Costs (thousands of dollars) } \\
\hline & $\begin{array}{l}\text { Two } 50-\mathrm{Mw}(\mathrm{e}) \\
\text { Experiments }\end{array}$ & $\begin{array}{c}\text { Two } 500-\mathrm{Mw}(\mathrm{e}) \\
\text { Prototype } \\
\text { Reactors }\end{array}$ & $\begin{array}{c}\text { Two } 1000-\mathrm{Mw}(e) \\
\text { Commercial } \\
\text { Plants }\end{array}$ & $\begin{array}{l}\text { Supporting } \\
\text { Work }\end{array}$ & Total \\
\hline 1969 & 2,500 & 400 & 400 & 11,759 & 15,059 \\
\hline 1970 & 9,000 & 200 & 200 & 13,782 & 23,182 \\
\hline 1971 & 13,400 & 200 & 200 & 12,585 & 26,385 \\
\hline 1972 & 13,400 & 400 & 200 & 11,538 & 25,538 \\
\hline 1973 & 13,400 & 7,800 & 200 & 8,824 & 30,224 \\
\hline 1974 & 6,000 & 37,000 & 200 & 5,044 & 48,244 \\
\hline 1975 & 6,000 & 49,000 & 400 & 3,843 & 59,243 \\
\hline 1976 & 6,000 & 56,200 & 1,800 & 2,363 & 66,363 \\
\hline 1977 & 6,000 & 42,700 & 4,000 & 1,800 & 54,500 \\
\hline 1978 & & 20,632 & 6,200 & 2,400 & 29,332 \\
\hline 1979 & & 19,832 & 8,400 & 1,800 & 30,032 \\
\hline 1980 & & & 8,500 & 1,800 & 10,300 \\
\hline \multirow[t]{2}{*}{1981} & & & 6,000 & & 6,000 \\
\hline & & & & TotaI & 424,302 \\
\hline
\end{tabular}

* Costs include only first-of-a-kind engineering and construction assistance.

reactors. It is roughly estimated that these supporting research and development programs benefit from LMFBR programs by a saving of approximately $\$ 7$ to $\$ 10$ million.

\subsubsection{Summary of Important Milestones}

Based on allowing five years for design and construction of each reactor and operating for four years to obtain data for construction of the core for the next reactor, a summary of important milestone dates is given in Table 7.4. The start of the research and development program, including conceptual design of all three sizes of each concept, is assumed to be in July 1968, and startup and preliminary testing of the 1000-Mw(e) reactor begins in January 1981. 
Table 7.4. Summary of Important Milestone Dates in Steam-Cooled Fast Breeder Reactor Development Programs*

Start of program

50-Mw(e) experiment design start

$7-1-68$

500-Mw (e) prototype reactor design start

$7-1-68$

50-Mw(e) experiment construction complete

$7-1-72$

Control-rod drive development complete

$7-1-73$

$7-1-79$

50-Mw (e) experiment test and operation start

$12-1-73$ to

$7-1-77$

Component development complete

$7-1-74$

Physics research and development complete

$7-1-79$

Coolant chemistry development complete

$7-1-74$

Fuel assembly development complete

$7-1-79$

Instrumentation and control development complete

$7-1-79$

Management research and development complete

$7-1-79$

1000-Mw(e) demonstration plant design start

$1-1-76$

Reactor safety research and development complete

$7-1-76$

$500-\mathrm{Mw}(\mathrm{e})$ prototype plant in operation

$12-1-77$

$500-\mathrm{Mw}(\mathrm{e})$ demonstration plant in precommercial operation

$12-1-77$ to

$7-1-79$

Contract let for four $1000-\mathrm{Mw}(e)$ plants

$1-1-79$

$1000-\mathrm{Mw}(\mathrm{e})$ demonstration plant begins commercial operation 1-1-81

Four commercial plants available

1982

* Same for all pressures or combined program involving two different pressures.

\subsubsection{Dates of Commercial Availability}

The schedule of important milestone dates given in Table 7.4 indicates the beginning of commercial operation of the large-scale reactor by January 1, 1981, based on a program starting July 1, 1968. It would be reasonable to assume that four $1000-\mathrm{Mw}(\mathrm{e})$ steam-cooled fast breeder reactors could be available for commercial operation by December 31, 1982.

\subsection{Gas-Cooled Fast Breeder Reactors}

The research and development program outlined by GGA for heliumcooled fast reactors insludes the design and construction of a 100-Mw(th) (with no electrical generation) gas-cooled reactor experiment (GCFRE) costing $\$ 33.6$ million. The annual operating cost for this experiment is estimated to be $\$ 3$ million, including charges on the fuel. An extensive 
fuel irradiation program is included that utilizes the FFTF and other facilities at a cost of $\$ 77.7$ million. Other aspects of the program, which include program planning and design studies, core materials development, core mechanical and thermal tests, and components development, add another $\$ 52.2$ million to bring the total cost of the GGA development plan for the GCFR to $\$ 187.5$ million through 1980 (including eight years of operating costs for the GCFRE).

These cost figures do not include costs for developing carbide fuels or any other research and development costs in the LMFBR and HTGR programs. These programs will contribute an estimated $\$ 200$ million worth of applicable research and development to the GCFR program.

Also not included in the above figures are the cost assistance required for an intermediate size prototype plant and the first 1000-Mw(e) demonstration plant. It was the opinion of the task force that a prototype plant with a power level of about 300 to $500 \mathrm{Mw}(\mathrm{e})$ should be included in the development program. This would require perhaps $\$ 40$ million in financial assistance, over and above power plant costs. The first 1000Mw(e) GCFR demonstration plant would require about $\$ 20$ million for engineering and construction cost assistance as a first-of-a-kind plant.

The total of the above development costs is $\$ 247.5$ million; and these expenditures would lead to operation of the first 1000-Mw(e) GCFR in 1980. A review of the schedule of important milestones, with the addition of the prototype, led ORNL to conclude that the first 1000-Mw(e) commercial derated GCFR plant probably could be in operation in December 1980 . This results in introduction of four commercial plants of this type in 1982 and four 1000-Mw(e) reference design plants two years later.

\subsubsection{Performance Characteristics of Preferred and Alternative Designs}

Three concepts were selected by General Atomic for consideration in the system analysis study. These are (1) the GCFR-4D first 1000-Mw(e) prototype plant, (2) the GCFR reference oxide fueled design, and (3) the reference carbide fueled GCFBR. The important performance characteristics of these three designs are summarized in Table 7.5. In cases where ORNL's 
Table 7.5. Performance Characteristics of 1000-Mw(e) GCFR Concepts

\begin{tabular}{|c|c|c|c|}
\hline & $\begin{array}{l}\text { GCFR-4D } \\
\text { Prototype }\end{array}$ & $\begin{array}{c}\text { GCFR-4 } \\
\text { Reference, } \\
\text { Oxide Fueled }\end{array}$ & $\begin{array}{l}\text { GCFR-C } \\
\text { Reference, } \\
\text { Carbide } \\
\text { Fueled }\end{array}$ \\
\hline Helium temperature, inlet/outlet, ${ }^{\circ} \mathrm{C}$ & $315 / 590$ & $340 / 635$ & $315 / 587$ \\
\hline Helium pressure, psi & 1250 & 1250 & 1750 \\
\hline Steam temperature, ${ }^{\circ} \mathrm{F}$ & $900 / 900$ & $1000 / 1000$ & $900 / 900$ \\
\hline Steam pressure, psi & 1800 & 2400 & 1800 \\
\hline Net plant efficiency, $\%$ & 37.3 & 39.5 & 37.3 \\
\hline Fuel material & $\begin{array}{l}\mathrm{UO}_{2}-\mathrm{PuO}_{2} \text { hollow } \\
\text { pellets }\end{array}$ & $\begin{array}{l}\mathrm{UO}_{2}-\mathrm{PuO}_{2} \text { hollow } \\
\text { pellets }\end{array}$ & $\begin{array}{l}\text { He-bonded } \\
\text { UC-PuC }\end{array}$ \\
\hline Maximum cladding temperature, ${ }^{a}{ }^{\circ} \mathrm{C}$ & 650 & 700 & 700 \\
\hline Maximum heat rating, $\mathrm{kw} / \mathrm{ft}$ & 16.5 & 18 & 30 \\
\hline Core burnup, Mwd/kg (max) & $50-100$ & 100 & 150 \\
\hline Fuel specific power, $\mathrm{kw} / \mathrm{kg}$ fissile $\mathrm{Pu}$ & 820 & 855 & 1500 \\
\hline Fissile inventory (total), $\mathrm{kg} / \mathrm{Mw}(\mathrm{e})$ & 5.2 & 4.8 & 2 \\
\hline Power density, kw/liter & 257 & 277 & 615 \\
\hline Breeding ratio & 1.5 & 1.5 & 1.60 \\
\hline Exponential doubling time, years & 11 & 10 & 5 \\
\hline Fuel-cycle cost, $\mathrm{b}$ mills $/ \mathrm{kwhr}$ & 1.05 & 0.96 & 0.55 \\
\hline Power cost, mills $/ k_{w h r} \mathrm{c}$ & 3.88 & 3.80 & 3.39 \\
\hline
\end{tabular}

$a_{\text {At }} 100 \%$ power, with no engineering factors included.

${ }^{b}$ Assumed 15,000-Mw(e) industry size.

Investor-owned utility.

calculated design conditions differ with those of GGA, the former are used as a basis for comparison.

It may be seen from Table 7.5 that the main differences of the three concepts are related to the type of fuel and its performance. The planned development program, while aimed primarily at achieving the performance of the GCFR-4D design, hopefully will also establish the feasibility of the GCFR-4 reference oxide fueled design. Since the performance gains achieved by this latter concept appear to be quite minimal (as indicated in the table), very little incremental development work can be justified if the higher rated fuel does not prove to be feasible. Development of the carbide fuel is expected to be achieved in the LMFBR program; therefore, no 
development work on this type of fuel is included in the GCFR program. If carbide fuels are developed and operate as expected, this would result in an appreciable performance gain for the GCFR at relatively little added development cost.

\subsubsection{Problems Associated with Each GCFR Design Alternative}

The three concepts being considered are enough alike so that solutions to the problems associated with the GCFR-4D prototype plant will be equally applicable to the reference oxide fueled and carbide fueled designs. These common problems include: (1) more accurate design information, (2) fuel element development, (3) core structure development and testing, (4) helium circulator development, (5) steam-generator development, (6) PCRV development, and (7) safety analyses. The only additional problem associated with the reference oxide fueled design over the derated design is related to the effect of increasing the linear heat rating from 16.5 to $18 \mathrm{kw} / \mathrm{ft}$, which might result in center melting of fuel. The only new problem for the reference carbide fueled design is the design and development of a PCRV capable of withstanding 1750 psi compared with 1250 psi for the oxide fueled design.

\section{2 .3 Costs of Program}

Annual and total costs of individual programs are summarized in Table 7.6. As may be seen, total costs range from $\$ 10$ million to $\$ 25$ million per year, and add up to $\$ 188$ million by 1980 . Not included are costs of the IMFBR and HTGR programs that contribute about $\$ 200$ million worth of applicable research and development effort to the GCFR program.

Also not included in the above figures are the cost assistance required for an intermediate size prototype plant and the first 1000-Mw(e) demonstration plant. It was the opinion of the task force that a prototype plant with a power level of about 300 to $500-\mathrm{Mw}(\mathrm{e})$ should be included in the development program. This would require perhaps $\$ 40$ million in financial assistance. The first 1000-Mw(e) GCFR demonstration plant would require about $\$ 20$ million for engineering and construction cost assistance as a first-of-a-kind plant. This would raise the total costs of the GCFR 
Table 7.6. Summary of GCFR Development Costs Proposed by Gulf General Atomic

\begin{tabular}{|c|c|c|c|c|c|c|c|c|c|c|c|c|c|c|}
\hline & \multicolumn{13}{|c|}{ Costs (thousands of dollars) } & \multirow{3}{*}{ Total } \\
\hline & \multicolumn{2}{|c|}{$C Y-68$} & $\mathrm{CY}-70$ & CY -71 & $\mathrm{CY}-72$ & $\mathrm{CY}-73$ & CY -74 & $\mathrm{CY}-75$ & $\mathrm{CY}-76$ & CY -77 & $C Y-78$ & \multicolumn{2}{|c|}{ CY -79} & \\
\hline & $F Y-68$ & $F Y-69$ & $F Y-70$ & $\mathrm{FY}-71$ & $F Y-72$ & $F Y-73$ & $F Y-74$ & $\mathrm{FY}-75$ & FY -76 & $F Y-77$ & $F Y-78$ & $\mathrm{FY}-79$ & $F Y-80$ & \\
\hline Program planning and design studies & 600 & 600 & 600 & 600 & 600 & 600 & 500 & 500 & 400 & 400 & 400 & 400 & 400 & 6,600 \\
\hline Physics development & 620 & 780 & 680 & 680 & 550 & 860 & 830 & 650 & 810 & 810 & 440 & 190 & 140 & 8,040 \\
\hline \multicolumn{15}{|l|}{ Core development } \\
\hline $\begin{array}{l}\text { Design and analysis } \\
\text { Materials and fabrication } \\
\text { Mechanical and thermal tests } \\
\text { Irradiation program }\end{array}$ & $\begin{array}{r}100 \\
200 \\
80 \\
170\end{array}$ & $\begin{array}{r}100 \\
475 \\
850 \\
2,850\end{array}$ & $\begin{array}{r}200 \\
800 \\
850 \\
4,050\end{array}$ & $\begin{array}{r}200 \\
800 \\
1,050 \\
4,550\end{array}$ & $\begin{array}{r}200 \\
425 \\
1,500 \\
3,350\end{array}$ & $\begin{array}{r}100 \\
400 \\
1,000 \\
4,250\end{array}$ & $\begin{array}{r}200 \\
150 \\
400 \\
6,000\end{array}$ & $\begin{array}{r}200 \\
50 \\
200 \\
8,040\end{array}$ & $\begin{array}{r}100 \\
50 \\
300 \\
8,180\end{array}$ & $\begin{array}{r}100 \\
150 \\
1,100 \\
5,650\end{array}$ & $\begin{array}{r}50 \\
150 \\
1,000 \\
5,000\end{array}$ & $\begin{array}{r}50 \\
100 \\
300 \\
5,000\end{array}$ & $\begin{array}{r}30 \\
50 \\
2,100\end{array}$ & $\begin{array}{r}1,630 \\
3,800 \\
8,630 \\
59,190\end{array}$ \\
\hline Plant components development & & & 600 & 800 & 600 & 300 & 300 & 400 & 850 & 2,850 & 300 & 200 & 100 & 7,300 \\
\hline Concrete reactor vessel (PCRV) & 70 & 70 & 80 & 130 & 250 & 480 & 1,070 & 720 & 500 & 240 & 10 & & & 3,620 \\
\hline Plant studies & 100 & 150 & 150 & 150 & 150 & 150 & 150 & 150 & 150 & 150 & 150 & 150 & 150 & 1,900 \\
\hline Subtotal & 1,940 & 5,875 & 8,010 & 8,960 & 7,625 & 8,140 & 9,600 & 10,910 & 11,340 & 11,450 & 7,500 & 6,390 & 2,970 & 100,710 \\
\hline \multicolumn{15}{|l|}{ GCFRE design and construction } \\
\hline $\begin{array}{l}\text { Physics development and design } \\
\text { Core and component development } \\
\text { Construction } \\
\text { Operation and fuel charge }\end{array}$ & $\begin{array}{l}350 \\
880\end{array}$ & $\begin{array}{r}460 \\
3,120 \\
1,000\end{array}$ & $\begin{array}{r}640 \\
2,760 \\
13,000\end{array}$ & $\begin{array}{r}490 \\
580 \\
11,250\end{array}$ & $\begin{array}{r}230 \\
150 \\
8,330\end{array}$ & $\begin{array}{r}340 \\
50 \\
3,000 \\
\end{array}$ & $\begin{array}{r}240 \\
3,000 \\
\end{array}$ & $\begin{array}{r}140 \\
3,000 \\
\end{array}$ & 3,000 & $\begin{array}{r}105 \\
3,000 \\
\end{array}$ & $\underline{3,000}$ & 3,000 & 3,000 & $\begin{array}{r}3,135 \\
7,540 \\
33,580 \\
24,000 \\
\end{array}$ \\
\hline Subtơtal GCFRE & 1,230 & 4,580 & 16,400 & 12,320 & 8,710 & 3,390 & 3,240 & 3,140 & 3,140 & 3,105 & 3,000 & 3,000 & 3,000 & 68,255 \\
\hline \multicolumn{15}{|l|}{ FFTF loop rental } \\
\hline $\begin{array}{l}\text { Multirod loop } \\
\text { Components loop }\end{array}$ & & & & & & & & $\begin{array}{r}2,450 \\
640 \\
\end{array}$ & $\begin{array}{r}2,450 \\
640 \\
\end{array}$ & $\begin{array}{r}2,450 \\
640 \\
\end{array}$ & $\begin{array}{r}2,450 \\
640 \\
\end{array}$ & $\begin{array}{r}2,450 \\
640 \\
\end{array}$ & $\begin{array}{r}2,450 \\
640 \\
\end{array}$ & $\begin{array}{r}14,700 \\
3,840 \\
\end{array}$ \\
\hline Subtotal FFTF rental and loops & & & & & & & & 3,090 & 3,090 & 3,090 & 3,090 & 3,090 & 3,090 & 18,540 \\
\hline Total development cost & 3,170 & 10,455 & 24,390 & 21,280 & 16,335 & 11,530 & 12,840 & 17,140 & 17,570 & 17,645 & 13,590 & 12,480 & 9,060 & 187,505 \\
\hline
\end{tabular}


development program to $\$ 248$ million. It appears that this level of support would be adequate to achieve the development required for a 1000-Mw(e) commercial plant.

\subsubsection{Important Milestones}

The most important of the GCFR milestones are the dates of availability of various experimental facilities. The first of these is the GCFRE, for which construction is expected to start in January 1970. Irradiation of test fuel element bundles is to start by April 1973. The given schedule for the construction and operation of the GCFRE as a fuel test facility does not appear unreasonable; however, it makes no allowance for any possible setbacks that might occur.

The 300-Mw(e) prototype plant depends on the GCFRE to prove the fuel element design. Thus, the prototype plant could not go into operation before adequate irradiation data were obtained from the GCFRE. The 1000Mw(e) commercial plant should lag the prototype plant by two or three years. The important milestones in the development schedule proposed by ORNL are listed below.

1. Start design of GCFRE in July 1968; in operation by December 1973.

2. Start design of 300-Mw(e) prototype plant by December 1971; in operation December 1977.

3. Commit first 1000-Mw(e) demonstration plant (GCFR-4D) by December 1975; in operation December 1980.

4. Commit four 1000-Mw(e) commercial plants (GCFR-4D) by December 1978; date of introduction is 1982 .

5. Reference oxide fueled GCFR could be introduced two years later.

6. The reference carbide fueled GCFR depends on the LMFBR carbide fuel development program, with the date of introduction being 1986 .

\subsubsection{Applicability of Other Research and Development Work to the GCFR Program}

Analyses were made of the IMF'BR and HTGR programs to determine what parts would be applicable to GCFR development. ${ }^{15}$ In the case of the LMFBR program, the analysis emphasized core design, fuel recycle, physics, and fuel irradiation work. In the case of the HTGR, work on circulators, 
steam generators, and the PCRV was found to be applicable. Table 7.7 lists total costs of programs in the given areas and the amounts applicable to GCFR development.

Table 7.7. Applicability of Other Research and Development Programs to GCFR

\begin{tabular}{lcc}
\hline & $\begin{array}{c}\text { Total Cost } \\
(\$ \text { millions) }\end{array}$ & $\begin{array}{c}\text { Cost of Work } \\
\text { Applicable } \\
\text { to GCFR } \\
(\$ \text { millions })\end{array}$ \\
\hline IMFBR program & & \\
Core design & 40.6 & 6.7 \\
Fuel recycle & 145.5 & 85.9 \\
Physics & 108.4 & 9.3 \\
Fuel irradiations & $\sim 300$ & 100 \\
HTGR program & & \\
Circulators & 1.8 & 1.0 \\
Steam generators & 1.9 & 1.0 \\
PCRV & 5.2 & 5.0 \\
Other & 42.7 & 0 \\
\hline
\end{tabular}




\section{CONCLUSIONS}

This report presents evaluations of the technical feasibility, physics performance, and economics of steam- and gas-cooled fast breeder reactors. In attempting to draw meaningful and significant conclusions from this study, the committee was acutely aware of the limitations imposed by the nature of the information provided. In particular, the widely different stages of prior design refinement represented in the reference designs provided, and the differing degrees of conservatism reflected in these, rendered the drawing of comparisons extremely difficult. Additionally, the committee recognized that meaningful assessment of widely differing reactor types involved far more than the substantiation of performance and its numerical comparison. Qualitative judgments of reliability, maintainability, and of the degree of departure from present experience involved, as well as the extent of future developmental potential, for example, are at least equally important. Nevertheless, the following important conclusions have emerged in the course of this study:

1. Fast breeder reactors cooled by gas or steam are technically feasible in that no research and development breakthroughs are required.

2. Both steam - and gas-cooled reactors are capable of operating with breeding ratios of interest. The gas-cooled breeder reactor, due to its harder neutron spectrum, can achieve the highest breeding ratio. Breeding ratios of low pressure steam-cooled reactors can be attractive, if somewhat lower. The conversion ratios attainable in supercritical pressure steam-cooled reactors, on the other hand, can be compared with those achieved in the advanced converter reactors.

3. The loss-of-coolant accident or the loss-of-flow accident (more properly, depressurization) is a major consideration in the safety analysis of reactors operating with pressurized coolant in that forced circulation of coolant must be guaranteed. Nevertheless, it appears that engineered safeguards could cope with realistic depressurization rates in the gasand steam-cooled reactors.

4. On the basis of the designs evaluated and the combined criteria of low power costs and good breeding capability, GCFR's have the most 
potential of the concepts considered. Steam-cooled reactors, on the other hand, suffer either from higher power costs (1250- and 2680-psi SCBR's) or low breeding ratio (3700-psi SCBR). 


\section{COMMENTS OF REVIEWERS}

1. There are instances where a deficiency of technology has been attributed solely to the GCFR or SCBR rather than being described as a problem common to all types of fast breeder reactors. Since the commonality of many problems may not be well known to the reader, this would help to insure that the reports would not be misconstrued.

2. The quoted temperature rise rates following loss of flow or loss of coolant in a GCFR are entirely misleading because they ignore the very important effect of the Doppler coefficient, and because they relate only to the incredible situation of instantaneous loss of coolant. As properly mentioned in the earlier text, but significantly deleted in the revision, this hypothetical situation is, in any case, far worse for typical LMFBR's.

3. All American designs evaluated for both GCFR's and SCBR's are said to violate the criterion of no central melting. The linear heat rating in kilowatts per foot of fuel rod is not a particularly sensitive variable with respect to pnformance or fuel-cycle cost, as pointed out elsewhere in these reports. Since the GCFR's use the same fuel materials as the LMFBR for purposes of this study, linear heat ratings assumed to be typical of LMFBR's were selected.

4. The report provides an excellent identification of problem areas to be studied in order to develop an evaluation of the various alternate coolant concepts. It does an adequate job in presenting factual information and data in selected areas. It does not provide effective normalizations of concepts and criteria relative to the various steam-cooled reactors and the gas-cooled reactors It is unfortunate that $\mathrm{ORNL}$ and the contractors did not make a deeper study into the relative technological and economic aspects of the various reactor concepts. This evaluation could have been made much more useful and authoritative if the length of time required to make the evaluation had been realized at the time the evaluation was initiated.

5. In many aspects the designs of this report have severe deficiencies. The steam-cooled reactors lack adequate operational and safety information, and do not have defined systems for cooling the debris of 
the plant after a destructive incident. The gas-cooled reactors presented have several possible deficiencies, including a fuel element and subassembly that may not be operable under the existing operating conditions, a single concrete containment barrier of questionable integrity surrounding the reactor, and no convincing method of avoiding core damage in case of a rapid loss of coolant. Even though the features typified by these examples can be designed into both the steam- and gas-cooled reactors, they could result in significant impact on the normalized evaluation and lead to substantial economic penalties. Surely, questions of this type cannot be answered at this time due to the limited engineering and development of these concepts. Many of these same questions have not been answered for the IMFBR.

6. A discussion is presented on the effects of the possible higher capture-to-fission ratio for ${ }^{239} \mathrm{Pu}$. It is indicated that the greatest effect would be the lengthening of the doubling time, particularly in those systems with low breeding ratios. This is true; however, the economic impact is about equivalent for systems with high or low breeding ratios. The most severe and probably significant effect would occur in those reactors designed for near minimum leakage geometry with an in-core breeding ratio near unity and small control rod requirements. In this type of system major, design changes would be required from a resultant lower breeding ratio, which could result in substantial economic effect.

7. Although the maximum peak-to-average power ratio for the steamcooled breeder reactors is higher than that for the gas-cooled breeder reactors, further optimization of the SCBR designs should result in equally low power peaking factors.

8. It is unfortunate that the carbide fueled GCFR design did not receive as thorough a review by the task force and its working group as did the other reactors evaluated. In particular, the basis for the capital costs and fuel cycle costs for this design is not adequately justified. Furthermore, an estimate is needed for the additional research and development program required to develop the radically different pressure vessel and component designs and for the carbide fuel development. Admittedly, this design was developed at a later date than the others and 
there was less time available for evaluation. However, since in systems analysis calculations all reactors have "equal standing" and the carbide fueled GCFR performs favorably, the assumptions for its performance and estimated costs appear to demand more thorough study and presentation in these reports.

9. While the reports conclude that the GCFR is technically feasible and requires no "research and development breakthrough," it is important te note that its performance is strongly dependent on the behavior of the fuel cladding. Since a reliable assessment of the GCFR depends strongly on demonstration of satisfactory operation of some type of pressure-equalized cladding, a program to attempt such a demonstration should precede any more comprehensive effort to develop the GCFR. 
REFERENCES

1. D. Okrent et al., Proceedings of the Conference on Breeding, Economics and Safety in Iarge Fast Power Reactors, USAEC Report ANL6792, Argonne National Laboratory, December 1963.

2. M. Bender et al., Gas-Cooled Fast Reactor Concepts, USAEC Report ORNL-3642, Oak Ridge National Laboratory, September 1964.

3. Babcock \& Wilcox Company, 3600 psi Steam Cooled Breeder Reactor, Condensed Description, USAEC Report BAW-1309, January 1967; see also Babcock \& Wilcox Company and American Electric Power Service Corporation, 1963 Progress Reports, Steam Cooled Breeder Reactor Study, Reports AEPSCO-864, BAW-240, August 1964 and AEPSCO-1165, BAW-273, September 1965.

4. D. Okrent et al., Proceedings of the Conference on Safety, Fuels, and Core Design in Large Fast Power Reactors, USAEC Report ANL-7120, Argonne National Laboratory, October 1965.

5. Babcock \& Wilcox Company, Condensed Description - 1,000 MwE - 1250 psi Steam-Cooled Breeder Reactor Design, USAEC Report BAW-1319, June 1967.

6. Babcock \& Wilcox, 1,000 MwE - 1250 psi Steam-Cooled Breeder-Reactor Design, USAEC Report BAW-1318, SL-2397, September 1967.

7. A. Mueller et al., Reference Study for the 1,000 MwE Steam-Cooled Fast Breeder Reactor (DI), Karlsruhe Nuclear Research Center Institute of Reactor Development, German Report KFK-392, August 1966; for English translation see ORNL-TR-1541.

8. J. C. Fox et al., Steam-Cooled Fast Breeder Power Reactors, Parametric Design Study, USAEC Report BNWL-713, Pacific Northwest Laboratories, April 1968.

9. P. Fortescue, A Study of Gas-Cooled Reactors - Initial Study - Core Design Analysis and System Development Program, USAEC Report GA-5537, General Atomic, 1964.

10. Staff Report, Annual Progress Report for Period Ending JuIy 31, 1965, Gas-Cooled Fast Breeder, USAEC Report GA-6667, General Atomic, Oct. 1, 1965; see also interim report GA-6666, Dec. 17, 1965.

11. Staff Report, Design Study of a 1000 MwE Gas-Cooled Fast Reactor Plant, USAEC Report GA-7240 (AEPSC-6608N), Vols. I and II, General Atomic, December 1966.

12. Staff Report, A 1000 MwE Gas-Cooled Fast Reactor Study for the Alternate Coolant Task Force, USAEC Report GA-7804, General Atomic, July 21, 1967. 
13. M. Dalle Donne, Comparison of $\mathrm{He}, \mathrm{CO}_{2}$, and Steam as Coolants of a 1000 MwE Fast Reactor, German Report KFK-447, July 1966.

14. M. Dalle Donne et al., Some Considerations on Gas Cooling for Fast Breeders, German Report KFK-595, June 1967.

15. General Atomic, Addendum to a $1000 \mathrm{MwE}$ Gas-Cooled Fast Reactor Study for the Alternate Coolant Task Force, USAEC Report GA-7804 (Add.), Sept. 28, 1967.

16. General Atomic, Addendum 2 to a 1000 MwE Gas-Cooled Fast Reactor Study for the Alternate Coolant Task Force, USAEC Report GA-7804 (Add. 2), Nov. 13, 1967.

17. General Atomic, Preliminary Development Plan for the Gas-Cooled Fast Reactor (GCF'R), USAEC Report GA-8257, Oct. 11, 1967.

18. General Atomic, Design Study of a 1000 MwE Gas-Cooled Fast Reactor Plant, USAEC Report GA-7240, Vols. I and 2, Dec. 5, 1966.

19. P. Fortescue, Vented Fuel Elements for the Gas-Cooled Fast Reactor, USAEC Report GAMD-7697, General Atomic, Mar. 15, 1967.

20. U.S. Atomic Energy Commission, An Evaluation of Steam-Cooled Fast Reactors, USAEC Report WASH-1088 (to be published).

21. U.S. Atomic Energy Commission, An Evaluation of Gas-Cooled Fast Reactors, USAEC Report WASH-1089 (to be published).

22. U.S. Atomic Energy Commission, Guide to Nuclear Power Cost Evaluation, USAEC Report TID-7025, Vol. 1, Mar. 15, 1962.

23. J. P. Heineman, An Experimental Investigation of Heat Transfer to Superheated Steam in Round and Rectangular Channels, USAEC Report ANL-6216, Argonne National Laboratory, 1960.

24. Staff Report, High Temperature Supercritical Pressure Water Loop, Part IV, USAEC Report WCAP-2056, Westinghouse Electric Corporation, 1964.

25. A. Stathopolos, Capability of Pressure Vessel to Safely Contain Explosion Energy, Nuclear Technology Corporation Memo 1008-106, June 1967.

26. D. R. Vondy, T. B. Fowler, and M. I. Tobias, Reactor Depletion Code ASSAULT (Two Dimensional, Multi-Neutron-Group, Diffusion), USAEC Report ORNL-TM-1302, Oak Ridge National Laboratory, March 1966.

27. T. Lauitzen and F. A. Comprelli, The Out of Pile Compatibility of Austenitic Stainless Steel with Mixed-Oxide Fuel, Trans. Amer. Nucl. Soc., 10(2): 459 (November 1967). 
28. J. F. W. Bishop et al., Design and Development of Fuel and Fuel Elements for Prototype Fast Reactor, Paper $4 \mathrm{~B} / \mathrm{I}$ presented at London Conference on Fast Breeder Reactors, British Nuclear Energy Society, May 1966.

29. F. Anselin and W. E. Baily, The Role of Fission Products in the Swelling of Irradiated $\mathrm{UO}_{2}$ and (U,Pu) $\mathrm{O}_{2}$ Fuels, Trans. Amer. Nucl. Soc., 10(1) : 103 (June 1967).

30. E. L. Zebroski, H. Kittel, and D. Moss, Review of Status of Technology of Fast Reactor Fuels, paper presented at Fast Reactors National Topical Meeting, April 1967, pp. 2-63 in American Nuclear Society publication ANS-101.

31. R. E. Shavdahl, C. N. Spalaris, and E. L. Zebroski, Fast Reactor Fuels, paper presented at the Nuclear Metallurgy Symposium of AIME at Phoenix, Arizona, October 1967.

32. J. R. Weir, Oak Ridge National Laboratory, personal communication to R. E. Adams, Oak Ridge National Laboratory.

33. H. Lawton et al., The Irradiation Behavior of Plutonium-Bearing Ceramic Fuel Pins, Paper 4B/4 presented at London Conference on Fast Breeder Reactors, British Nuclear Energy Society, May 1966.

34. Chen Pang Tan, Prestressed Concrete in Nuclear Pressure Vessels, A Critical Review of Current Literature, USAEC Report ORNL-4227, Oak Ridge National Laboratory, May 1968.

35. U.S. Atomic Energy Commission, Civilian Nuclear Power - Current Status and Future Technology and Economic Potential of Light Water Reactors, USAEC Report WASH-1082, January 1968; see also letter M. J. Whitman, USAEC, to J.A. Lane, Oak Ridge National Laboratory dated May 16, 1967.

36. Letter K. A. Hub, Argonne National Laboratory, to J. A. Lane, Oak Ridge National Laboratory, dated Nov. 6, 1967.

37. Letter D. T. Farney to E. T. Henson, Oak Ridge National Laboratory, dated May 24, 1967.

38. R. Salmon, A Computer Code for Calculating the Cost of Shipping, USAEC Report ORNL-3648, Oak Ridge National Laboratory, August 1964.

39. R. J. Cristl et al., Radiochemical Separations Plant Study, USAEC Report DP-730, Savannah River Laboratory, September 1964.

40. J. Davidson, Details Processing Plant at Nuclear Congress, Nucleonics, p. 20, July 1962. 
41. D. C. Schluderberg, Preliminary Development Plans for Low Pressure and High Pressure Steam-Cooled Fast Breeäers, USAEC Report BAW-1323, Babcock \& Wilcox Company, February' 1968. 